VALMIR JOSÉ CAMOLESI

CARACTERIZAÇÃO DO QUEROSENE ATRAVÉS DA ESPECTROSCOPIA DE INFRAVERMELHO PRÓXIMO

São Paulo 2009 
VALMIR JOSÉ CAMOLESI

\section{CARACTERIZAÇÃO DO QUEROSENE ATRAVÉS DA ESPECTROSCOPIA DE INFRAVERMELHO PRÓXIMO}

Dissertação apresentada à Escola Politécnica da Universidade de São Paulo para obtenção do título de Mestre em Engenharia.

São Paulo 
VALMIR JOSÉ CAMOLESI

\section{CARACTERIZAÇÃO DO QUEROSENE ATRAVÉS DA ESPECTROSCOPIA DE INFRAVERMELHO PRÓXIMO}

Dissertação apresentada à Escola Politécnica da Universidade de São Paulo para obtenção do título de Mestre em Engenharia.

Área de Concentração:

Engenharia Química

Orientador:

Prof. Dr. Cláudio A. Oller do

Nascimento

São Paulo 
Este exemplar foi revisado e alterado em relação à versão original, sob responsabilidade única do autor e com a anuência de seu orientador.

São Paulo, 20 de maio de 2009.

Assinatura do autor

Assinatura do orientador

FICHA CATALOGRÁFICA

Camolesi, Valmir José

Caracterização do querosene através da espectroscopia de infravermelho próximo / V.J. Camolesi. -- ed.rev. -- São Paulo, 2009.

$100 \mathrm{p}$.

Dissertação (Mestrado) - Escola Politécnica da Universidade de São Paulo. Departamento de Engenharia Química.

1. Espectroscopia infravermelha 2. Querosene 3. Redes neurais I. Universidade de São Paulo.Escola Politécnica. Departa mento de Engenharia Química II. t. 


\section{DEDICATÓRIA}

Dedico este trabalho a meus pais, Laurélio e Ida, que são a base de minha vida e me conduziram pelos caminhos dos estudos. 


\section{AGRADECIMENTOS}

Ao Professor Cláudio Augusto Oller do Nascimento, pela presteza e atenção durante o período de orientação do mestrado.

À Petrobras, que estimulou minha participação na obtenção do Mestrado e disponibilizou os recursos necessários.

Aos Técnicos de Operação e de Laboratório da Refinaria Henrique Lage (REVAP) que trabalharam para a obtenção das informações técnicas das amostras utilizadas.

Aos professores do LSCP que me permitiram adquirir os conhecimentos necessários durante o Mestrado.

À Patrícia Araújo Pantoja , ao Francisco Falla Sotelo, ao Aerenton Ferreira Bueno e ao Rubens Villalba Medeiros que me auxiliaram durante a fase do Mestrado.

Às pessoas que colaboraram com meu crescimento ao longo de minha vida. 


\section{RESUMO}

Ensejou-se obter a caracterização do Querosene via espectroscopia de infravermelho próximo com o objetivo de se instalar um analisador NIR (Near InfraRed) na unidade de processo de destilação industrial, permitindo a otimização do processo de produção.

Foi construído um banco de dados espectrais (NIR) e das propriedades: densidade $\mathrm{D} 20 / 4^{\circ} \mathrm{C}$, destilação (PIE, 5\%, 10\%, 20\%, 30\%, 40\%, 50\%, 60\%, $70 \%, 80 \%, 90 \%$ e PFE), enxofre total, ponto de fulgor, ponto de congelamento e viscosidade a $-20^{\circ} \mathrm{C}$ e a $40^{\circ} \mathrm{C}$ durante um período de 8 meses.

A partir dos dados experimentais foram construídos modelos de inferência para as propriedades do querosene através dos métodos PLS (Partial Least Squares) e redes neurais.

Inferências a partir de dados operacionais foram também elaboradas para comparação.

As inferências construídas com os dados espectrais apresentaram resultados melhores que as obtidas com as variáveis operacionais. 
ABSTRACT

This work aimed to obtain the characterization of Kerosene by Near Infrared Spectroscopy (NIR) with the intention to install a NIR analyzer at an industrial process of distillation, allowing optimization of the production process.

A database of spectral data (NIR) was built and another with the properties: density $\mathrm{D} 20 / 4^{\circ} \mathrm{C}$, distillation (IBP, $5 \%, 10 \%, 20 \%, 30 \%, 40 \%, 50 \%, 60 \%, 70 \%$, $80 \%, 90 \%$ and FBP), total sulfur, flash point, freezing point and viscosity at $-20^{\circ} \mathrm{C}$ and $40^{\circ} \mathrm{C}$ for a period of 8 months.

Models of inference to kerosene properties by the PLS (Partial Least Squares) and neural networks methods were built up from experimental data.

Inferences from operational data were also compiled for comparison.

As a conclusion of this work, inferences from spectroscopy data were better than those from operational data. 


\section{LISTA DE FIGURAS}

Figura 1.1 - Espectro da radiação eletromagnética 21

Figura 1.2 - Grupos funcionais e seus respectivos comprimentos de ondas de absorção. 23

Figura 3.1 - Fluxograma simplificado de uma unidade de Destilação de Petróleo

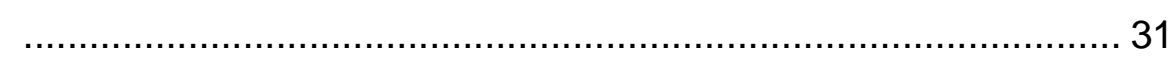

Figura 4.1 -Sinal de ruído de uma banda de absorção ................................... 33

Figura 4.2 - Aumento da resolução pelo uso das derivadas ............................. 34

Figura 4.3 - Gráfico de um conjunto de dados bidimensionais mostrando os eixos dos Componentes Principais PC1 e PC2 …………......... 36

Figura 4.4 - Número ótimo de componentes em função do erro de predição .. 38

Figura 4.5 - Pontos discrepantes com diferentes leverages (Bueno, 2006) ..... 40

Figura 4.6 - Esquema de um neurônio biológico . (Tatibana \& Kaetsu) ............ 41

Figura 4.7 - Modelo matemático de um neurônio (cerebro\&mente) .................. 42

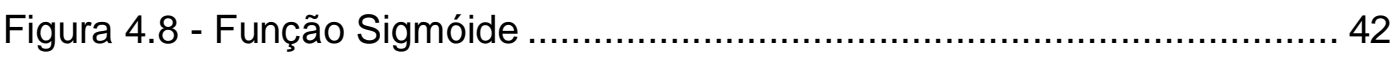

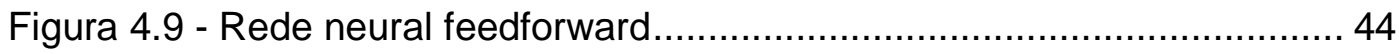

Figura 4.10 - Sensores NIR de imersão (HELLMA) ……….......................... 46

Figura 4.11 - Esquema da medição dos espectros NIR de querosene ........... 47

Figura 4.12 - "Loop" de querosene localizado no Térreo do LSCP-USP.......... 48

Figura 4.13 - Esquema do "Loop" no LSCP …………............................... 49

Figura 5.1 - Espectros NIR a comprimento total $\left(4000-14000 \mathrm{~cm}^{-1}\right)$............ 53

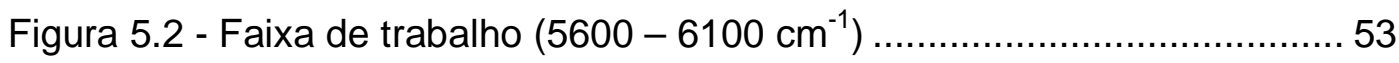

Figura 5.3 - Análises de dispersão de algumas propriedades em estudo ......... 55

Figura 5.4 - Espectro típico NIR do querosene e (b) Derivada primeira após alisamento do espectro. .......................................................... 56

Figura 5.5 - Espectros NIR a diferentes temperaturas (velocidade $=0,576 \mathrm{~m} / \mathrm{s}$ ) de uma amostra de querosene no "loop" ................................... 58

Figura 5.6 - Espectros NIR alisados a diferentes temperaturas (velocidade $=$ $0,576 \mathrm{~m} / \mathrm{s}$ ) de uma amostra de querosene no "loop" 58

Figura 5.7 - 1a derivada dos espectros NIR a diferentes temperaturas (velocidade $=0,576 \mathrm{~m} / \mathrm{s}$ ) de uma amostra de querosene no "loop" 
Figura 5.8 - Espectros residuais de temperatura em uma amostra de querosene no "loop"

Figura 5.9 - Espectros NIR a diferentes velocidades (temperatura $=25^{\circ} \mathrm{C}$ ) de uma amostra de querosene no "loop"

Figura 5.10 - Espectros NIR alisados a diferentes velocidades (temperatura = $\left.25^{\circ} \mathrm{C}\right)$ de uma amostra de querosene no "loop"

Figura $5.11-1^{\text {a }}$ derivada dos espectros NIR alisados a diferentes velocidades (temperatura $=25^{\circ} \mathrm{C}$ ) de uma amostra de querosene no "loop".. 61

Figura 5.12 - Espectros residuais de velocidade em uma amostra de querosene no "loop" 62

Figura 5.13 - RMSECV x Número de variáveis latentes para a densidade 63

Figura 5.14 - Modelo de calibração da Densidade e validação externa com PLS 64

Figura 5.15 - RMSECV x Número de variáveis latentes para o Ponto de Congelamento 65

Figura 5.16 - Modelo de calibração do Ponto de Congelamento e validação externa 65

Figura 5.17 - RMSECV x Número de variáveis latentes para a viscosidade a $20^{\circ} \mathrm{C}$ 66

Figura 5.18 - Modelo de calibração da Viscosidade a $-20^{\circ} \mathrm{C}$ e validação externa

Figura 5.19 - RMSECV x Número de variáveis latentes para a viscosidade a $40^{\circ} \mathrm{C}$ 67

Figura 5.20 - Modelo de calibração da Viscosidade a $40^{\circ} \mathrm{C}$ e validação externa 68

Figura 5.21 - Modelo de calibração do PIE e validação externa 71

Figura 5.22 - Modelo de calibração dos 5\% evaporados e validação externa . 71

Figura 5.23 - Modelo de calibração dos 10\% evaporados e validação externa 72 Figura 5.24 - Modelo de calibração dos 20\% evaporados e validação externa 72 Figura 5.25 - Modelo de calibração dos 30\% evaporados e validação externa 73 Figura 5.26 - Modelo de calibração dos 40\% evaporados e validação externa 73 Figura 5.27 - Modelo de calibração dos 50\% evaporados e validação externa 74 Figura 5.28 - Modelo de calibração dos $60 \%$ evaporados e validação externa 74 
Figura 5.29 - Modelo de calibração dos 70\% evaporados e validação externa 75 Figura 5.30 - Modelo de calibração dos $80 \%$ evaporados e validação externa 75 Figura 5.31 - Modelo de calibração dos $90 \%$ evaporados e validação externa 76 Figura 5.32 - Modelo de calibração PFE e validação externa .......................... 76

Figura 5.33 - Modelo de calibração da propriedade $S$ total e validação externa

Figura 5.34 - Modelo de calibração do Ponto de Fulgor e validação externa... 78

Figura 5.35 - Resultados da regressão linear para a Densidade .................... 81

Figura 5.36 - Resultados da regressão linear para o PIE da Destilação ........... 82

Figura 5.37 - Resultados da regressão linear para os 5\% recuperados........... 82

Figura 5.38 - Resultados da regressão linear para os $10 \%$ recuperados......... 83

Figura 5.39 - Resultados da regressão linear para os $20 \%$ recuperados......... 83

Figura 5.40 - Resultados da regressão linear para os 30\% recuperados......... 84

Figura 5.41 - Resultados da regressão linear para os $40 \%$ recuperados......... 84

Figura 5.42 - Resultados da regressão linear para os 50\% recuperados......... 85

Figura 5.43 - Resultados da regressão linear para os $60 \%$ recuperados......... 85

Figura 5.44 - Resultados da regressão linear para os 70\% recuperados......... 86

Figura 5.45 - Resultados da regressão linear para os $80 \%$ recuperados......... 86

Figura 5.46 - Resultados da regressão linear para os $90 \%$ recuperados......... 87

Figura 5.47 - Resultados da regressão linear para PFE da Destilação ............. 87

Figura 5.48 - Resultados da regressão linear para o enxofre total................... 88

Figura 5.49 - Resultados da regressão linear para o ponto de fulgor................ 88

Figura 5.50 - Resultados da regressão linear para o ponto de congelamento .89

Figura 5.51 - Resultados da regressão linear para a viscosidade a $-20{ }^{\circ} \mathrm{C}$...... 89

Figura 5.52 - Resultados da regressão linear para a viscosidade a $-40{ }^{\circ} \mathrm{C} \ldots . . .90$

Figura 5.53 - Curva de destilação da amostra Q61 .......................................92 


\section{LISTA DE TABELAS}

Tabela 1.1 Derivados destilados típicos do petróleo............................... 17

Tabela 1.2 Tipos de hidrocarbonetos no Querosene ................................. 18

Tabela 1.3 Divisão do espectro infravermelho ..................................... 22

Tabela 4.1 Principais variáveis operacionais ........................................ 50

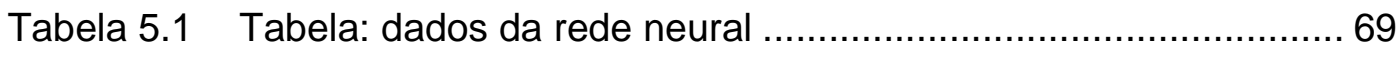

Tabela 5.2 Fator de correlação das variáveis operacionais ........................ 79

Tabela 5.3 Variância acumulada pelos Componentes Principais................... 80

Tabela 5.4 Coeficientes dos primeiros 12 Componentes Principais ............. 80

Tabela 5.5 Comparação entre erros dos modelos obtidos via NIR e via regressão linear multivariável ............................................91 


\section{LISTA DE SIGLAS}

\begin{tabular}{|c|c|}
\hline ANP & Agência Nacional de Petróleo \\
\hline ASTM & American Society for Testing and Materials \\
\hline C4, C5 & Hidrocarbonetos com 4 e 5 átomos de carbono, respectivamente \\
\hline DL & Diesel Leve \\
\hline DP & Diesel Pesado \\
\hline FAR & Infravermelho Distante (Far InfraRed) \\
\hline FBP & Ponto Final de Ebulição (Final Boiling Point) \\
\hline GC & Gás Combustível \\
\hline GLP & Gás Liquefeito de Petróleo \\
\hline GLP & Gás Liquidificado de Petróleo \\
\hline GOL & Gasóleo Leve \\
\hline GOR & Gasóleo Residual \\
\hline GORT & Gasóleo Residual de Topo \\
\hline HDT & Unidade Industrial de Hidrotratamento \\
\hline IBP & Ponto Inicial de Ebulição (Inicial Boiling Point) \\
\hline LSCP & Laboratório de Simulação e Controle de Processo \\
\hline MIR & Infravermelho Médio (Medium InfraRed) \\
\hline MLR & Regressão Linear Múltipla (Multiple Linear Regression) \\
\hline MON & Motor Octane Number \\
\hline NIR & Infravermelho Próximo (Near InfraRed) \\
\hline NL & Nafta Leve \\
\hline NP & Nafta Pesada \\
\hline PARAFAC & Parallel Factor Analysis \\
\hline $\mathrm{PC}$ & Componente Principal (Principal Component) \\
\hline PCA & $\begin{array}{l}\text { Análise por Componentes Principais (Principal Component } \\
\text { Analysis) }\end{array}$ \\
\hline PCR & $\begin{array}{l}\text { Regressão por Componentes Principais (Principal Component } \\
\text { Regression) }\end{array}$ \\
\hline PEV & Ponto de Ebulição Verdadeiro \\
\hline PLS & Mínimos Quadrados Parciais (Partial Least Squares) \\
\hline
\end{tabular}


PRESS Soma dos quadrados dos erros de previsão

Q Querosene

QAV-1 Querosene de aviação

RAT Resíduo Atmosférico

REVAP Refinaria Henrique Lage

RMSECV Raiz quadrada do erro médio quadrático de previsão para validação cruzada (Root Mean Squared Error Cross Validation)

RMSE Raiz quadrada do erro médio quadrático (Root Mean Squared Error)

RMSEP Raiz quadrada do erro médio quadrático de previsão (Root Mean Squared Error Prediction)

RV Resíduo de Vácuo

USP Universidade de São Paulo

UV Ultravioleta (Ultraviolet) 


\section{SUMÁRIO}

DEDICATÓRIA

AGRADECIMENTOS

RESUMO

ABSTRACT

LISTA DE FIGURAS

LISTA DE TABELAS

LISTA DE SIGLAS

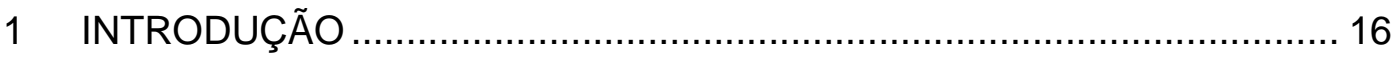

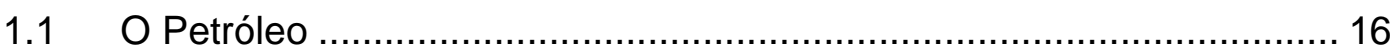

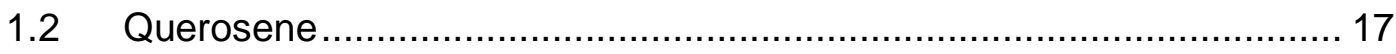

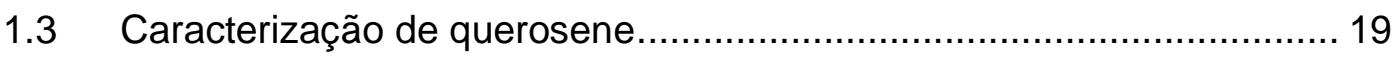

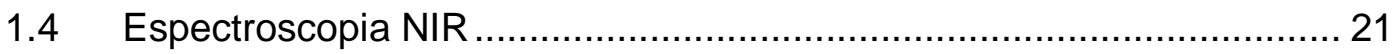

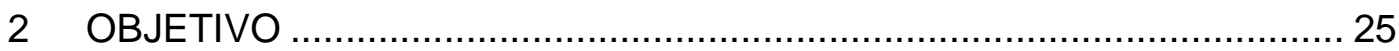

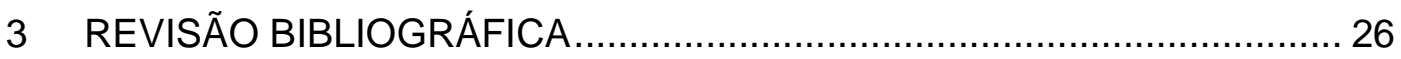

3.1 Descrição simplificada do processo de produção de Querosene ........... 30

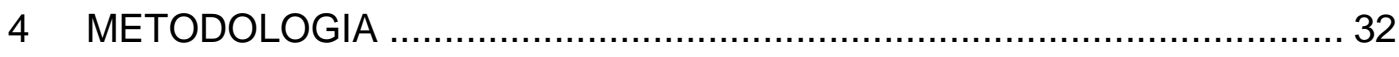

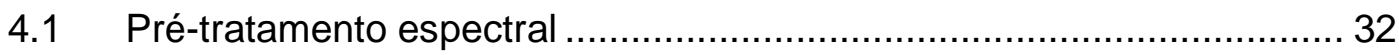

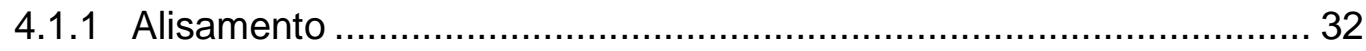

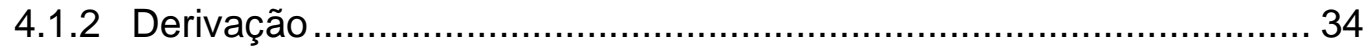

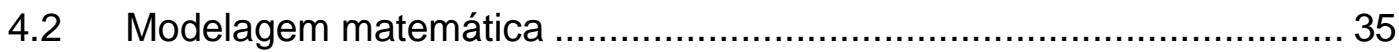




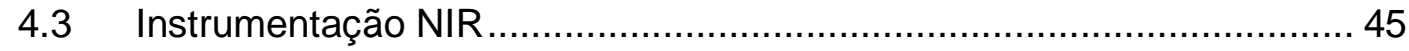

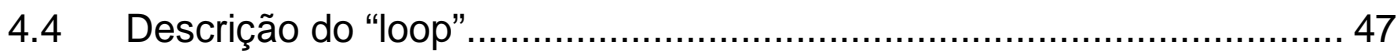

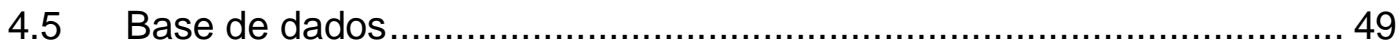

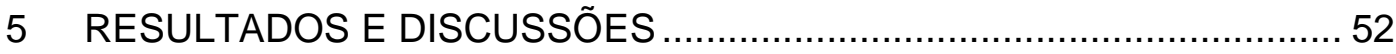

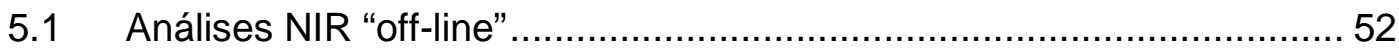

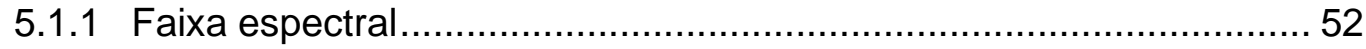

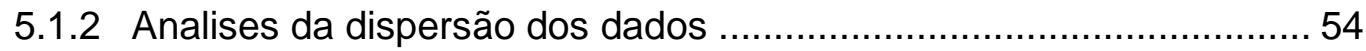

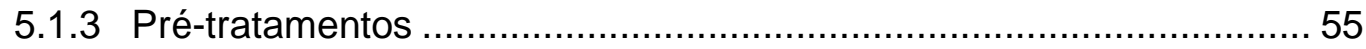

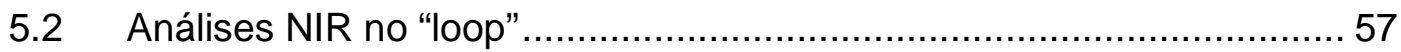

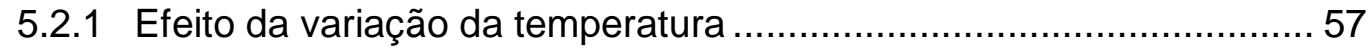

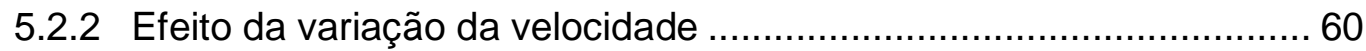

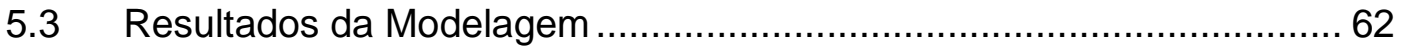

5.3.1 Calibração para a propriedade de Densidade ................................... 63

5.3.2 Calibração para a propriedade de Ponto de Congelamento ............... 64

5.3.3 Calibração para a propriedade da viscosidade a $-20^{\circ} \mathrm{C}$...................... 66

5.3.4 Calibração para a propriedade da viscosidade a $40^{\circ} \mathrm{C}$....................... 67

5.3.5 Calibração para a propriedade : Pontos da Destilação ....................... 70

5.3.6 Calibração para a propriedade Enxofre Total .................................. 76

5.3.7 Calibração para a propriedade do Ponto de Fulgor ............................ 77

5.4 Modelos obtidos a partir das condições operacionais .......................... 78

6 CONCLUSÕES E RECOMENDAÇÕES ……….................................. 93

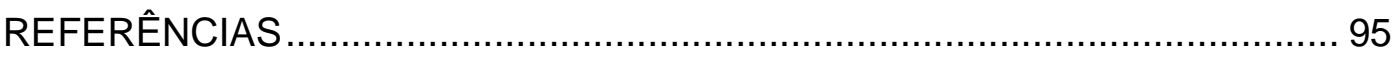

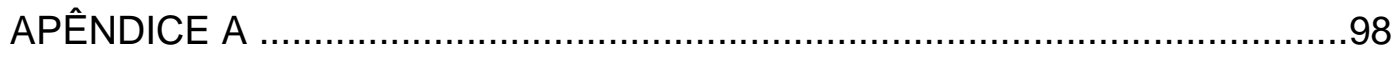

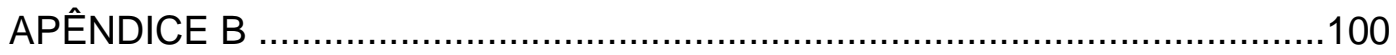




\section{INTRODUÇÃO}

\subsection{O Petróleo}

O petróleo é uma substância oleosa, inflamável, menos densa que a água, com cheiro característico e de cor variando entre o negro e o castanho escuro. Admite-se que esta origem esteja ligada à decomposição dos seres que compõem o plâncton (organismos em suspensão nas águas doces ou salgadas tais como protozoários, celenterados e outros), causada pela pouca oxigenação e pela ação de bactérias. Estes seres decompostos foram, ao longo de milhões de anos, se acumulando no fundo dos mares e dos lagos, sendo pressionados pelos movimentos da crosta terrestre e transformaram-se na substância oleosa que é o petróleo. Ao contrário do que se pensa, o petróleo não permanece na rocha que foi gerado (a rocha matriz) mas desloca-se até encontrar um terreno apropriado para se concentrar. Estes terrenos são denominados bacias sedimentares, formadas por camadas ou lençóis porosos de areia, arenitos ou calcários. O petróleo aloja-se ali, ocupando os poros rochosos, formando jazidas. Ali são encontrados o gás natural, na parte mais alta, e petróleo e água nas mais baixas.

O petróleo é uma mistura altamente complexa de milhares de compostos orgânicos contendo principalmente hidrocarbonetos (C (carbono), H (hidrogênio)), compostos orgânicos heteroatômicos (S (enxofre), $N$ (nitrogênio), $O$ (oxigênio)) de peso molecular e polaridade variável, e metais tais como $\mathrm{Ni}$ (níquel), $\mathrm{V}$ (vanádio) e $\mathrm{Pb}$ (chumbo), em menor concentração.

O petróleo necessita passar pelo processo de refino para se obter derivados com utilidade ao uso comercial. Na tabela 1.1 apresentam-se os principais derivados do processo de destilação e suas temperaturas de separação (corte) (PEV-Ponto de Ebulição Verdadeiro). 
Tabela 1.1 Derivados destilados típicos do petróleo

\begin{tabular}{|l|c|}
\hline \multicolumn{1}{|c|}{ PRODUTO } & CORTE - curva PEV ${ }^{~}$ C \\
\hline GLP & C4 \\
\hline Nafta Leve & 130 \\
\hline Nafta Pesada & $130-200$ \\
\hline Querosene & $200-255$ \\
\hline Diesel Leve & -345 \\
\hline Diesel Pesado & -370 \\
\hline Gasóleo Leve & $370+$ \\
\hline Gasóleo Pesado & -540 \\
\hline Resíduo de Vácuo & $540+$ \\
\hline
\end{tabular}

O Gasóleo Leve e Gasóleo Pesado não têm valor comercial e, portanto são enviados à unidade de Craqueamento Catalítico onde são transformados principalmente em Nafta Craqueada que irá compor a gasolina e GLP. O Resíduo de Vácuo pode ter vários destinos a depender das estratégias de cada refinaria.

\subsection{Querosene}

O querosene de aviação é o combustível utilizado nos aviões modernos, dotados de motores à turbina, sejam eles jato-puro, turbo-hélices ou turbo-fans. É constituído de hidrocarbonetos (compostos orgânicos formados por moléculas de hidrogênio e carbono), sendo os principais as parafinas, os naftênicos, os aromáticos, e as olefinas, e em concentrações muito baixas os compostos de enxofre, nitrogênio e oxigênio. Cada molécula de hidrocarboneto tem entre 9 e 16 átomos de carbono, e possui faixa de destilação ASTM D-86 de 130 a $300{ }^{\circ} \mathrm{C}$. As faixas típicas de participação dos hidrocarbonetos estão transcritas na tabela 1.2: 
Tabela 1.2 Tipos de hidrocarbonetos no Querosene

\begin{tabular}{|l|c|}
\hline Tipos de hidrocarbonetos & \%Volume \\
\hline Parafinas (alcanos) & $33-61$ \\
\hline Naftênicos (cicloalcanos) & $33-45$ \\
\hline Aromáticos & $12-25$ \\
\hline Olefinas (alcenos) & $0,5-5$ \\
\hline
\end{tabular}

A concentração de compostos de enxofre e de nitrogênio depende do tipo de petróleo dos processos de tratamento utilizados.

Os hidrocarbonetos parafínicos são saturados e possuem cadeias lineares ou ramificadas. Os olefínicos são insaturados (dupla ligação) e possuem cadeias lineares ou ramificadas. Os aromáticos contêm anel benzênico. Os naftênicos possuem cadeias cíclicas, sem conter anel benzênico.

O querosene de aviação é obtido através do fracionamento do petróleo em uma unidade de destilação atmosférica. De forma simplificada, o equipamento principal desta unidade é uma torre de destilação, no interior da qual o petróleo, já bastante aquecido, sofre a separação das suas diferentes frações. Esta separação se efetiva ao longo da torre, pois a temperatura no interior da mesma é controlada de modo a variar do fundo (mais quente) para o topo (menos quente). As diferentes frações do petróleo se separam em função de seus diferentes pontos de ebulição. Este fato ocorre ao longo da torre através de sucessivos processos de vaporização e condensação das frações em pratos localizados nos diversos níveis da torre, a cada um se associando uma correspondente temperatura. A faixa típica de destilação para o QAV-1 é de 130 a $300^{\circ} \mathrm{C}$. Também neste processo de destilação são feitas retificações e ajustes para adequar o produto às características de ponto de fulgor e ponto de congelamento.

Os processos de tratamento visam a eliminar os efeitos indesejáveis de compostos sulfurados, nitrogenados e oxigenados. Os principais processos de tratamento utilizados são os seguintes: Bender, Merox e Hidrotratamento (HDT). 
Bender: é um processo que transforma compostos agressivos de enxofre (mercaptanas) em outros menos agressivos (dissulfetos). A carga da unidade é previamente lavada com soda cáustica para retirar a acidez. Passa em seguida pelo reator contendo catalisador à base de chumbo, onde ocorrem as reações em meio alcalino e com a adição de ar e enxofre. O efluente do reator é lavado com água, para retirar impurezas e soda, vai para um vaso e aí se processa a separação da água do querosene de aviação.

Merox: difere do Bender porque o catalisador à base de quelato metálico promove mas não participa da reação de transformação das mercaptanas em dissulfetos.

Hidrotratamento: reduz as concentrações de enxofre, nitrogênio, oxigênio, olefinas, por meio de reações com hidrogênio, em presença de catalisador (níquel molibdênio ou cobalto - molibdênio) e sob condições de elevadas temperatura e pressão. No hidrotratamento, compostos de enxofre se decompõem, liberando ácido sulfídrico (H2S), que é eliminado numa torre retificadora, onde especifica o ponto de fulgor e a corrosividade do querosene.

Denomina-se querosene o produto que sai da destilação e de QAV-1 ou querosene de aviação, o produto após tratamento e pronto para consumo.

\subsection{Caracterização de querosene}

A especificação brasileira de QAV-1 é determinada pela Agência Nacional de Petróleo (ANP), sendo compatível com o Aviation Fuel Quality Requirements for Jointly Operated Systems (AFQRJOS) for Jet A-1 (apêndice A).

A seguir são apresentados os conceitos básicos de alguns ensaios previstos na especificação e suas finalidades: 


\section{Destilação}

A volatilidade do Querosene de Aviação e a capacidade de vaporização a diferentes temperaturas são determinadas pela destilação. São limitadas as temperaturas dos $10 \%$ recuperados para assegurar a presença de leves que facilitam a partida do motor e do ponto final de ebulição, para restringir as frações pesadas, que dificultam a vaporização completa do combustível.

\section{Ponto de fulgor}

A limitação do ponto de fulgor está ligada à segurança no transporte e manuseio do produto, bem como às perdas por evaporação durante a estocagem. Propicia também a detecção de eventuais contaminações por produtos mais leves.

\section{Massa específica}

A massa específica de um combustível varia de acordo com a origem do petróleo. É uma característica importante, pois está diretamente ligada ao teor energético total contido em uma determinada massa do combustível. É particularmente útil para determinar empiricamente o poder calorífico, quando utilizada com outros parâmetros tais como destilação e ponto de anilina para cálculo do conteúdo energético do combustível. A limitação de uma faixa de massa específica para o QAV-1 é importante tanto para o projeto quanto para o funcionamento adequado das turbinas.

\section{Ponto de Congelamento}

O ponto de congelamento deve ser suficientemente baixo para prevenir problemas de escoamento do combustível, por meio de linhas, filtros e válvulas no sistema de combustível da aeronave durante o vôo a grandes altitudes e baixas temperaturas.

\section{Viscosidade}

A viscosidade é limitada em um valor máximo de forma a se obter uma perda mínima de pressão no escoamento a baixa temperatura, bem como para permitir a adequada pulverização do combustível nos bicos injetores, possibilitando melhores condições para a combustão. A viscosidade pode afetar significativamente a 
propriedade de lubricidade do combustível, e, por conseqüência, a vida útil da bomba de combustível da aeronave.

Todas essas propriedades acima são especificadas na coluna de destilação a menos do Ponto de Fulgor que ainda pode ser corrigido na torre retificadora da Unidade de Hidrotratamento.

\subsection{Espectroscopia NIR}

O espectro NIR (Near InfraRed) corresponde ao intervalo de comprimentos de onda de 780 a $2500 \mathrm{~nm}$ (números de onda de 12800 a $4000 \mathrm{~cm}^{-1}$ ), região do infravermelho próxima da região do espectro visível da luz.

$\mathrm{Na}$ figura 1.1 pode-se ver a localização da radiação infravermelha em relação ao espectro da radiação eletromagnética.

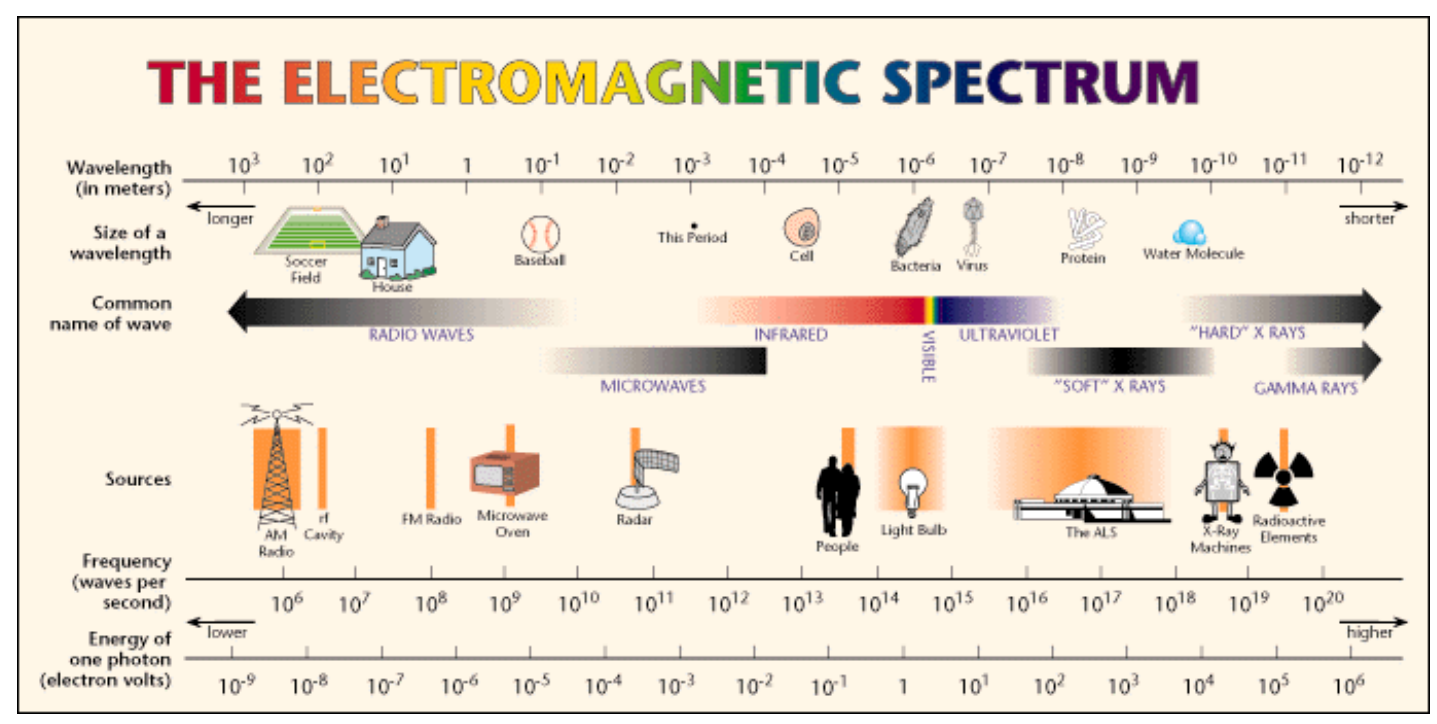

Figura 1.1 - Espectro da radiação eletromagnética (http://www.Ibl.gov/MicroWorlds/ALSTool/EMSpec/EMSpec2.html)

Na tabela 1.3 é apresentada a divisão do espectro infravermelho 
Tabela 1.3 Divisão do espectro infravermelho

\begin{tabular}{|l|c|c|c|}
\hline \multicolumn{1}{|c|}{$\begin{array}{c}\text { Região do } \\
\text { Infravermelho }\end{array}$} & $\begin{array}{c}\text { Número de } \\
\text { Onda por } \mathrm{cm} \\
\left(\mathrm{cm}^{-1}\right)\end{array}$ & $\begin{array}{c}\text { Região } \\
\text { Comprimento de } \\
\text { Onda }(\lambda)\end{array}$ & Freqüência $(\mathrm{Hz})$ \\
\hline Próximo (NIR) & 12.800 a 4.000 & 780 a $2.500 \mathrm{~nm}$ & $3,8 \times 10^{14} \mathrm{a} 1,2 \times 10^{14}$ \\
\hline Médio (MIR) & 4.000 a 200 & 2,5 a $50 \mu \mathrm{m}$ & $1,2 \times 10^{14} \mathrm{a} 6,0 \times 10^{12}$ \\
\hline Distante (FAR) & 200 a 10 & 50 a $1.000 \mu \mathrm{m}$ & $6,0 \times 10^{12}$ a $3,0 \times 10^{11}$ \\
\hline
\end{tabular}

\section{Interação molecular com a radiação infravermelha}

A radiação é absorvida por determinada molécula se a vibração dessa molécula produzir um momento de dipolo oscilante que interage com o campo elétrico da luz. Um átomo de uma molécula se desloca em relação ao outro átomo numa determinada freqüência, definida pela força da ligação e pelas massas dos átomos envolvidos. Para que uma determinada faixa de radiação NIR seja absorvida é necessário que a molécula receba radiação numa freqüência capaz de fornecer exatamente a energia necessária para a transição entre dois níveis energéticos ou para a ocorrência de sobretons ou combinações de duas ou mais vibrações. Se a radiação incidente não fornecer a quantidade exata de energia requerida, não será absorvida. A absorção da energia radiante irá aumentar a amplitude da vibração molecular, sem, entretanto, alterar sua freqüência.

As bandas de absorção na região NIR são produtos de sobretons e da combinação de bandas fundamentais de vibrações que ocorrem entre 1700 e $3000 \mathrm{~cm}^{-1}$ no MIR (Medium InfraRed). As ligações do tipo $\mathrm{C}-\mathrm{H}, \mathrm{O}-\mathrm{H}$ e N-H, possuem comprimentos de onda de absorção característicos. Estas absorções não são muito intensas, e muitas vezes sobrepõem-se, tornando largas as bandas, e com baixa absortividade molar (baixa sensibilidade). Conseqüentemente, os espectros NIR não são facilmente interpretáveis, havendo a necessidade da aplicação de métodos de calibração multivariada para extrair a informação analítica contida neles. 
$\mathrm{Na}$ figura 1.2 são apresentados os grupos funcionais e seus respectivos comprimentos de onda de absorção.

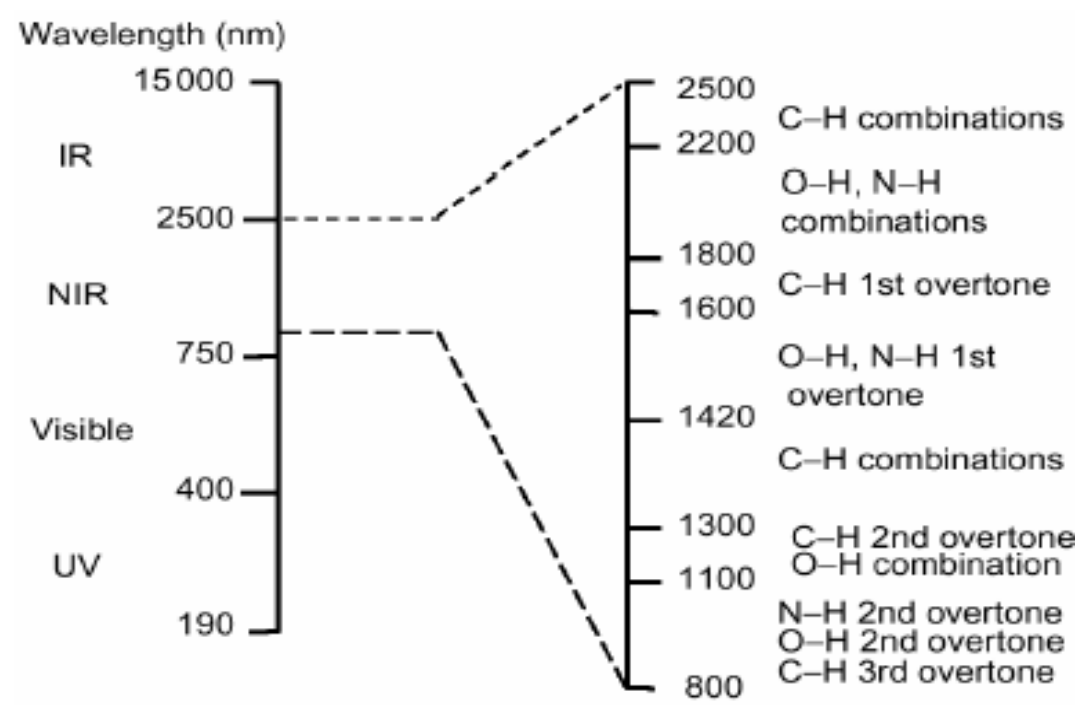

Figura 1.2 - Grupos funcionais e seus respectivos comprimentos de ondas de absorção.

Fatores que afetam o espectro: composição química, caminho ótico e temperatura.

A aplicação da análise NIR na indústria do petróleo tem sido utilizada por muitos anos. Muitas das aplicações reportadas estão associadas à previsão da qualidade para produtos destilados médios, incluindo nafta, gasolina e diesel, cobrindo propriedades tais como composição de hidrocarbonetos, densidade, destilação, número de octanagem, pressão de vapor Reid e índice de cetano. A facilidade e disponibilidade da técnica que a tornam particularmente adaptável à caracterização remota faz com que a sua utilidade e potencial econômico aumentem (Hidajat e Chong, 2000).

A espectroscopia NIR tem se tornada uma das técnicas mais utilizadas para análise química em laboratório e aplicações industriais. Dentre suas vantagens pode-se citar:

- A radiação NIR permite análise não destrutiva das amostras. Isso é muito importante porque quanto mais tratamento a amostra sofrer, antes de obter uma resposta final, maior será a introdução de erros na análise; 
- A espectroscopia NIR permite o uso de fibras óticas, facilitando a análise à distância já que o instrumento pode permanecer em um ambiente mais limpo e livre de vibração e outras interferências;

- A técnica NIR possui sistemas óticos facilmente disponíveis, detectores eficientes, simplicidade relativa na instrumentação, e o fato de quase todos os compostos orgânicos absorverem nesta região;

- A habilidade de extrair informação quantitativa, quimicamente significativa, via uso de técnicas estatísticas multivariadas. 


\section{OBJETIVO}

O objetivo é o desenvolvimento de melhores inferências para a caracterização do querosene de aviação durante 0 processo de destilação. Os resultados desta dissertação deverão ser utilizados num processo de destilação industrial, onde as propriedades do querosene serão inferidas com o uso de um analisador NIR "online". A caracterização do querosene pela espectroscopia do infravermelho próximo prescinde da planta estar em processo estacionário e isto é uma grande vantagem em relação às inferências baseadas nas condições do processo, as quais são fundamentadas e validadas somente em condições estacionárias.

A espectroscopia NIR tem se consagrado nas últimas décadas como um método rápido e factível em inúmeras aplicações industriais para a previsão de propriedades físico-químicas. No mundo todo, muitas refinarias possuem espectrômetros NIR instalados em diferentes processos. 


\section{REVISÃO BIBLIOGRÁFICA}

A espectroscopia no infravermelho próximo tem sido freqüentemente aplicada como um método analítico que fornece resultados eficientes para a determinação de moléculas orgânicas (proteínas e gorduras) e parâmetros qualitativos de produtos da agricultura e da indústria de alimentos. Aplicações mais recentes têm sido realizadas nas indústrias do petróleo, têxtil, carvão, cosméticos, polímeros, química, tintas e farmacêutica. $\mathrm{Na}$ indústria do petróleo, tem-se uma ampla gama de aplicações relacionadas a produtos destilados, tais como gasolina, diesel, nafta e querosene (Honigs et al., 1985b; Kelly e Callis, 1990; Litani-Barzilai et al., 1997; Chung et al., 1999; Kim et al., 2000; etc.).

Os primeiros trabalhos de análise do petróleo e destilados por espectroscopia NIR foram apresentados por Hidajat et al, 2000 e Chung et al, 2000.

Com o desenvolvimento das técnicas espectroscópicas do Infravermelho, surgiram técnicas e operações associadas com a manipulação matemática e interpretação de dados químicos, chamadas de técnicas quimiométricas. Estas técnicas permitem a extração de informações dos espectros completo e/ou apenas de faixas espectrais. Recentemente, estão sendo implementadas novas técnicas de tratamentos de dados químicos baseadas em inteligência artificial, principalmente em redes neurais e algoritmos genéticos, que vêm permitindo resolver problemas antes considerados insolúveis.

Xing et al. (2006) desenvolveram um método de determinação da viscosidade cinemática de querosene de aviação utilizando NIR. As vantagens desta metodologia são a sua rapidez e confiabilidade, comparadas com o investimento em tempo e necessidade de equipamentos sofisticados na análise convencional de laboratório (ASTM445). Foram coletadas 44 amostras de três diferentes fabricantes de querosene de aviação na China. Do total, 34 amostras foram utilizadas na calibração do modelo e 10 amostras foram utilizadas na validação. Os espectros NIR foram medidos na faixa $700-1100 \mathrm{~nm}\left(9090\right.$ a $\left.14280 \mathrm{~cm}^{-1}\right)$ à temperatura de $25^{\circ} \mathrm{C}$. 
Centralização, alisamento e derivação (2 ${ }^{a}$ derivada) foram os métodos de prétratamento aplicados. A calibração foi realizada utilizando PLS (mínimos quadrados parciais). Os erros de calibração e previsão obtidos foram iguais a $0.012 \mathrm{~mm}^{2} / \mathrm{s}$ e $0.027 \mathrm{~mm}^{2} / \mathrm{s}$, respectivamente, utilizando-se 2 fatores ou componentes principais no modelo. Embora os resultados apresentados tenham uma correlação linear boa, a curva de validação do modelo não revela um comportamento semelhante do sistema, mostrando uma tendência predominantemente crescente dos erros de previsão. Os autores recomendam incrementar o tamanho do conjunto de calibração para melhorar a robustez do método. Finalmente, os autores fizeram uma análise do efeito do tempo de residência $(5,10,25 \mathrm{~min})$ nos espectros NIR e determinaram que 10 min era o tempo necessário para que o valor fornecido pelo método seja mais próximo do valor de referência, onde a temperatura da amostra teria se estabilizado e não haveria mais volatilização.

Outro trabalho recente é o de Divya e Mishra (2007). Desenvolveram uma metodologia para a rápida detecção de adulteração em diesel determinando a porcentagem de querosene contida nele, através de técnicas multivariadas de calibração e espectroscopia de fluorescência. Foram utilizadas 35 amostras (misturas de diesel e querosene) de calibração e 8 amostras de predição. Os dados de fluorescência medidos representam o conjunto analisado em um arranjo tridimensional. Desta maneira, os dados foram calibrados de duas formas: a) mantendo a sua natureza tridimensional utilizando as técnicas PARAFAC (Parallel Factor Analysis, usada especialmente no caso da fluorescência) e N-PLS (extensão da PLS tradicional a conjuntos de dimensões maiores), e b) desdobrando os dados tridimensionais em dados bidimensionais, utilizando a PLS clássica. Os resultados mostraram que a N-PLS forneceu os melhores resultados: um erro de previsão de 2.01 (\%vol), comparado aos erros dos métodos PARAFAC (2.28) e PLS (3.06), respectivamente. Os autores afirmam que embora o PARAFAC seja uma técnica amplamente utilizada no tratamento de espectros de fluorescência, somente utiliza os dados espectrais para construir o modelo. No entanto, a N-PLS, ou PLS aplicada em um conjunto tridimensional neste caso, permite utilizar os dados espectrais e a informação da concentração de forma conjunta na modelagem, o que resulta em uma melhor performance. 
Andrade et al. (1997) apresentaram uma nova estratégia de controle da produção do querosene. Análises preliminares de querosene foram monitoradas durante 5 anos permitindo a extração de 9 variáveis essenciais de um grupo total de 26 utilizando PCA (Análise por Compoentes Principais). Um novo período de 5 anos foi utilizado para confirmar este propósito, revelando as boas correlações entre o grupo de dados e as conclusões. Algumas variáveis, tais como Ponto de Fulgor, Ponto de Congelamento e PFE foram consideradas importantes. Algumas variáveis foram definidas (incluindo considerações químicas e metodologias analíticas) baseadas na combinação das regressões multivariáveis (PLS, PCR, MLR) e espectroscopia FTIR. A seleção de variáveis é uma preocupação de suma importância no âmbito da produção industrial e químico analítico, porque uma boa seleção vai gerar economias no processo. A informação tem que ser além de útil, rápida e barata. Do ponto de vista quimiométrico, a utilização de muitas variáveis não garante que o sistema seja bem caracterizado. $O$ trabalho tem dois pontos principais:

1. apresentar um caminho de seleção de variáveis que tem que ser inevitavelmente supervisionadas, por exemplo, como selecionar o mínimo grupo de provas essenciais para o controle da produção do Querosene;

2. como prever estes parâmetros em uma aproximação multivariável.

Foram coletadas 184 amostras de Querosene (aviation fuel) para a calibração estatística durante 5 anos (1985 - 1990). Foram estudadas inicialmente 25 variáveis para o processo de caracterização do querosene, mas da variável 21 - 25 não foram consideradas porque eram muito similares. Para os dados de validação foram coletadas 99 amostras (1991 - 1995). Para gomas, todas as amostras apresentaram resultados similares, portanto esta variável foi descartada para análise. $O$ trabalho apresenta uma avaliação estatística na seleção das variáveis agrupando estas em 3 "clusters" segundo suas características de desempenho. Os dados de validação confirmaram a seleção de clusters realizada. A faixa MIR para o tratamento quimiometrico é de $1400-680 \mathrm{~cm}^{-1}$.

Em Gómez-Carracedo et al. (2003) oito propriedades físico-químicas do querosene foram preditas utilizando a fase vapor das amostras e a combinação das transformadas de Fourier na faixa MIR (FTMIR) com PLS. Cem amostras de 
querosene de uma refinaria da Espanha foram analisadas em 2 dispositivos geradores de fase vapor. Um é muito simples, enquanto o outro precisa controle termostático e de fluxo de gás. Os espectros FTMIR foram registrados e realizadas as calibrações de nove propriedades: curva de destilação, ponto de fulgor, ponto de congelamento, porcentagem de aromáticos e viscosidade, para cada dispositivo. Em geral, o dispositivo mais simples apresenta modelos mais satisfatórios. Vários critérios foram usados para avaliar a performance, como predição do erro médio, repetibilidade e reprodutibilidade. Das cem amostras utilizadas, 50 foram para a calibração e as outras para a validação do modelo. Não foram utilizadas técnicas de pré-tratamento. $O$ equipamento utilizado foi um Perkin Elmer da transformadas de Fourier na faixa media FTMIR $\left(4000-600 \mathrm{~cm}^{-1}\right)$. A fase vapor foi medida na faixa de $3500-2500 \mathrm{~cm}^{-1}$. O vapor foi obtido pelo aquecimento da amostra $(50 \mu)$ a $37^{\circ} \mathrm{C}$ durante $2 \mathrm{~min}$. As amostras analisadas foram classificadas em dois grupos diferentes depois de aplicada análise de componentes principais (PCA) e realizada a modelagem através de PLS, depois da exclusão dos "outliers". Em geral tem uma performance boa, com erros médios baixos e valores de precisão bons (repetibilidade ( $r$ e reprodutibilidade $(\mathrm{R})$ ). Para as analises realizadas dos resultados do segundo dispositivo, tem que atribuir-se o fato da complexidade do sistema, e que tinham que ser adicionadas outras variáveis que influenciam o sistema.

Chung et al. (1999) compararam o desempenho do NIR e MIR na determinação das temperaturas de destilação do querosene a diferentes percentagens de recuperação, usando a técnica PLS. Foram coletadas 50 amostras de cinco unidades de destilação de óleo cru, num período de três meses. Os espectros NIR foram coletados na faixa de 1100 a $2500 \mathrm{~nm}\left(9090\right.$ a $\left.4000 \mathrm{~cm}^{-1}\right)$ e os espectros MIR na região de 6234 a $16667 \mathrm{~nm}\left(3500\right.$ a $\left.600 \mathrm{~cm}^{-1}\right)$, sendo as coletas feitas a temperatura ambiente.

O trabalho de Kim et al. (2000) apresenta aplicações qualitativas do NIR. Neste trabalho afirma-se que o espectro NIR é diferente do espectro IR, porque permite detectar correlações complexas de misturas, como os produtos de petróleo, num tempo muito curto. Como em Chung e Ku (2000), nessa experiência faz-se também 
a seleção da faixa espectral baseando-se na informação espectroscópica conhecida a priori.

Com a experiência de Chung e Ku (2000) demonstrou-se a utilidade do NIR na análise do RAT (Resíduo Atmosférico), que é o produto mais pesado do petróleo na destilação atmosférica. Entre as principais dificuldades dessa experiência pode-se citar a natureza física e química da amostra, sendo totalmente escura e muito viscosa (sólida a temperatura ambiente); e apresentando usualmente suspensões sólidas e partículas, o que afeta a reprodutibilidade das medições. Além disso, os espectros vibracionais de hidrocarbonetos pesados são menos sensíveis às mudanças estruturais.

\subsection{Descrição simplificada do processo de produção de Querosene}

O processo de destilação é o processo de separação primário de qualquer refinaria de petróleo, já que é através dele que o petróleo bruto pode ser separado em frações que, dependendo das suas características e do tipo de produtos que a indústria precisa (combustíveis ou matérias primas petroquímicas, etc.), representam os produtos destilados que são alimentados aos outros processos existentes: de conversão, de tratamento, entre outros.

$\mathrm{Na}$ figura 3.1 é apresentado um fluxograma simplificado de uma unidade de destilação de petróleo. O petróleo passa primeiramente por uma $1^{\underline{a}}$ bateria de préaquecimento onde recupera calor de outras correntes a serem resfriadas; a seguir, passa por um processo de dessalgação com o objetivo de se retirar água, sal e sólidos em suspensão. Posteriormente há a $2^{\text {a }}$ bateria de pré-aquecimento, após a qual há a torre de pré-flash onde são retiradas as frações mais leves do petróleo constituídas pelo gás liquefeito de petróleo (GLP), nafta leve (NL) e gás combustível (GC).

A corrente de topo da Torre de Pré-Flash segue para a torre estabilizadora onde há a separação pelo topo (GC e GLP) e pelo fundo (NL). 
A corrente de fundo da Torre de Pré-Flash passa pelos fornos atmosféricos e a seguir pela Torre Atmosférica.

A Torre Atmosférica promoverá a separação do petróleo pré-fracionado nos seguintes produtos: nafta pesada (NP) como produto de topo, querosene $(Q)$, diesel leve (DL), diesel pesado (DP) como produtos laterais e resíduo atmosférico (RAT) como produto de fundo.

O resíduo atmosférico passa pelos fornos de aquecimento indo para a torre de destilação à vácuo onde há a separação entre o gasóleo residual de topo (GORT), gasóleo leve (GOL), gasóleo pesado (GOP), gasóleo residual $(\mathrm{GOR})$ e resíduo de vácuo $(\mathrm{RV})$.

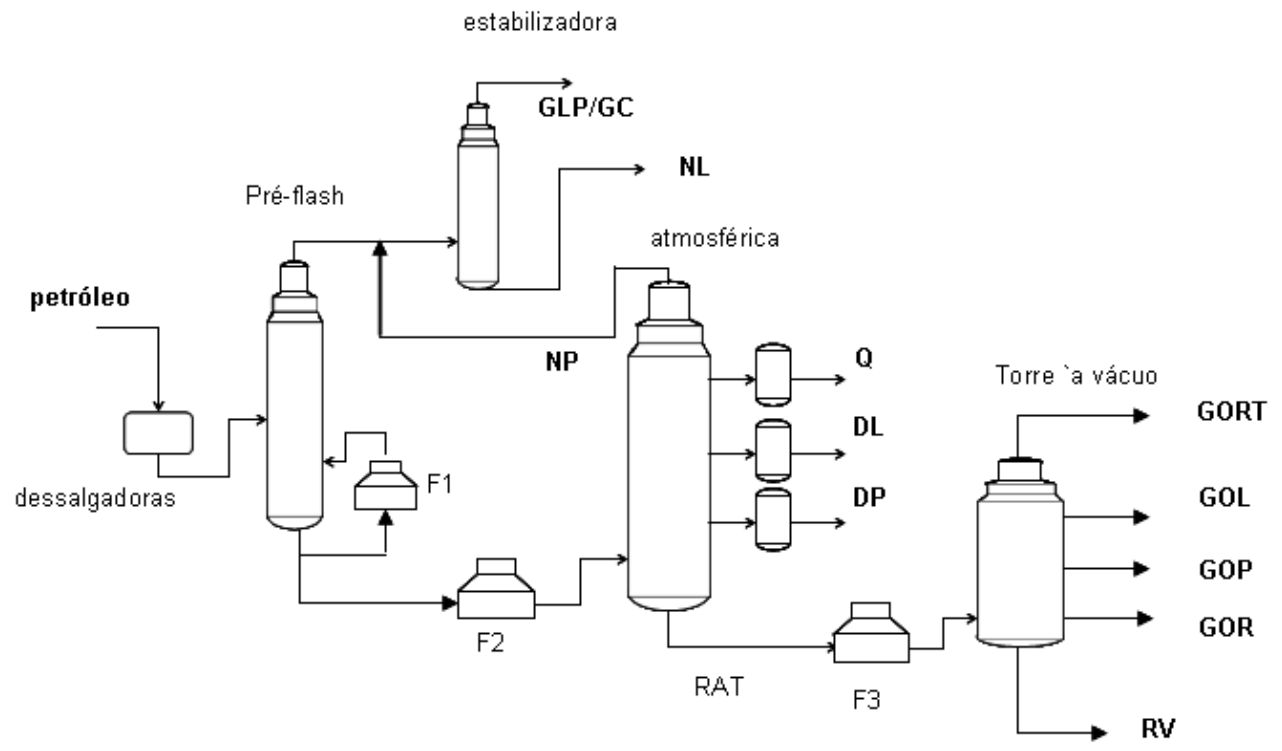

Figura 3.1 - Fluxograma simplificado de uma unidade de Destilação de Petróleo 


\section{METODOLOGIA}

\subsection{Pré-tratamento espectral}

Os espectros NIR podem ser influenciados por efeitos que não podem ser facilmente quantificados tais como interação entre componentes através de pontes de hidrogênio, distorções espectrais causadas pelo hardware como deslocamento de linha base, ruído do detector, amplificador e conversor analógico-digital, entre outros (Siesler et al., 2002).

O tratamento dos dados espectrais permite reduzir, eliminar ou padronizar o impacto dessas fontes nos espectros, sem alterar a informação espectroscópica contida neles (Siesler et al., 2002).

Medidas em diferentes comprimentos de onda e com diferentes variâncias são algumas das razões que dificultam a interpretação e extração de informações. Para contornar essa dificuldade faz-se a centralização na média, num espectro de uma das amostras ou autoescala dos dados. No primeiro caso, calcula-se a média das intensidades para cada comprimento de onda e subtrai-se cada intensidade do respectivo valor médio. No segundo caso, subtraem-se os espectros de cada amostra daquela escolhida como referência. Autoescalar significa centrar os dados na média e dividi-los pelo respectivo desvio-padrão, sendo um para cada comprimento de onda.

\subsubsection{Alisamento}

As medidas experimentais, mesmo sendo obtidas em instrumentos com alta resolução, sofrem interferências. Assim, são observados dois tipos principais de erros: sistemáticos e aleatórios. O erro aleatório é chamado de ruído e surge devido 
a variações imprevisíveis tais como vibrações, correntes de ar, movimento aleatório de moléculas, etc. (O'Haver, 2001) e pode ser considerado como perturbações de alta freqüência (Siesler et al., 2002).

O ruído nos dados de calibração conduz a erros na estimação dos parâmetros do modelo e, portanto, a erros na previsão de propriedades (Martens e Naes, 1989). Uma tentativa de solução deste problema é o alisamento, sendo o seu objetivo a redução do ruído. Isto traz como conseqüência o aumento da relação sinal-ruído, e é simplesmente a relação entre a amplitude real do sinal (por exemplo, altura do pico) e o desvio-padrão do ruído.

De maneira geral, o alisamento aumenta a relação sinal-ruído reduzindo a amplitude e incrementando a largura dos picos (mas o grau de intensidade deste efeito depende do número de pontos considerados no algoritmo respectivo); e no caso de espectros simples, permite medir de forma mais exata características espectrais do pico tais como posição, altura, largura, área, etc. (O’Haver, 2001).

Neste trabalho foi empregado o método Savitzky-Golay (Savitzky, A; Golay, M.J.E., 1964) para ajuste polinomial dos espectros. O efeito do alisamento é ilustrado na figura 4.1 .

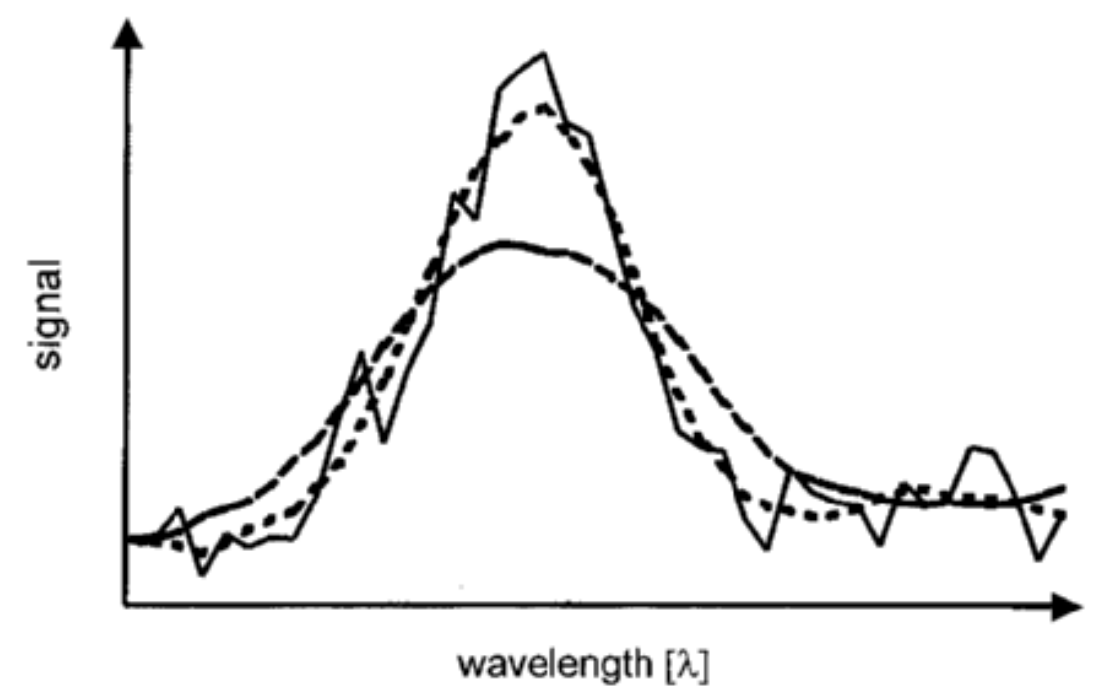

Figura 4.1 -Sinal de ruído de uma banda de absorção (linha sólida) alisada com filtro média móvel (traço longo) e alisada com o filtro Savitzky-Golay (traço curto) (ref. Siesler-2000) 


\subsubsection{Derivação}

Em espectroscopia, particularmente IR, absorção UV-visível, fluorescência e refletância, a diferenciação dos espectros é uma técnica amplamente utilizada, sendo as suas principais vantagens (O'Haver, 2001):

- Discriminação espectral; ressalta pequenas diferenças estruturais entre espectros semelhantes;

- Aumento da resolução espectral; incrementa a resolução de bandas espectrais sobrepostas;

- Análise quantitativa; correção de absorção irrelevante e como uma forma de facilitar a análise multicomponente.

As derivadas são também usadas para corrigir deslocamentos de linha base (Chaminade et al., 1998), sendo esta uma das principais finalidades de sua aplicação. Na figura 4.2 ilustra-se um efeito típico da derivação nos espectros NIR.

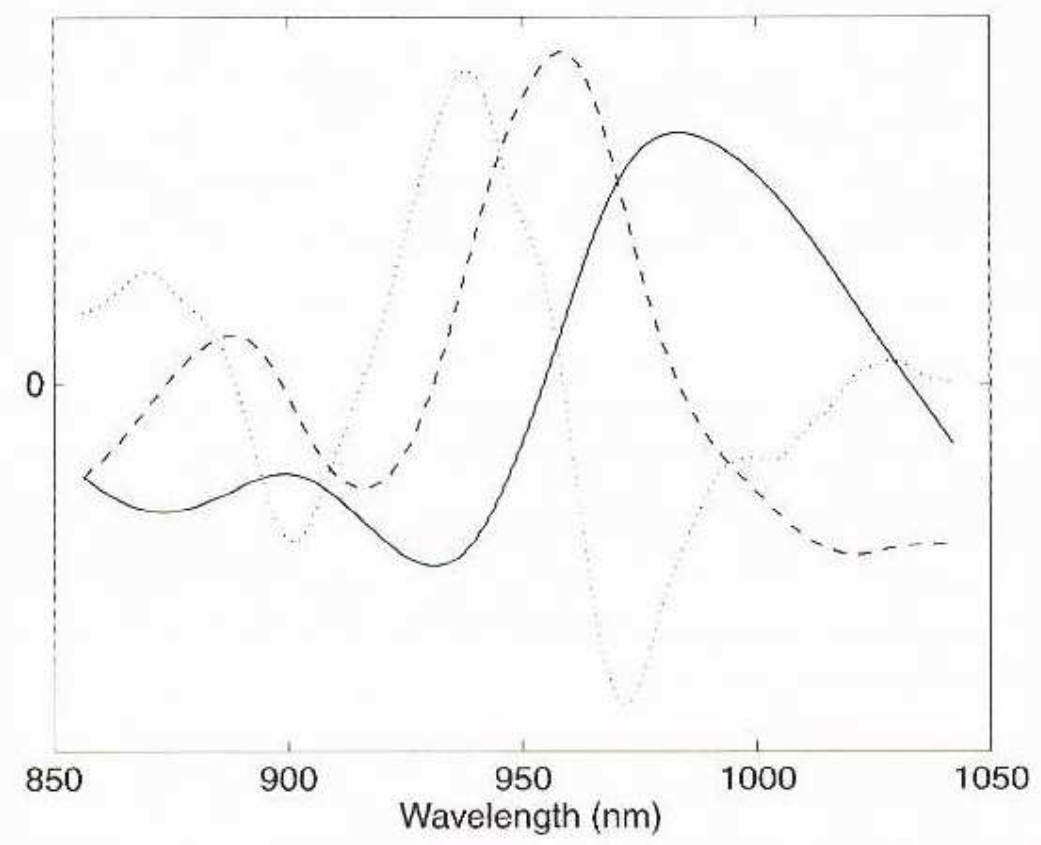

Figura 4.2 - Aumento da resolução pelo uso das derivadas sinal original (linha sólida); Derivada primeira do sinal original (linha tracejada) e derivada segunda do sinal original (linha pontilhada) (Siesler et al., 2002). 
Existem muitos métodos de diferenciação. O mais simples, o cálculo das derivadas é feito através de diferenças finitas. Processam-se sinais utilizando também o conceito de média móvel numa janela espectral de tamanho específico (número de pontos espectrais considerados). No entanto, o método de Savitzky-Golay, baseado no ajuste polinomial dos espectros, proposto em 1964, tem sido a base para os principais métodos desenvolvidos recentemente (Gorry, 1990; Barak, 1995, por exemplo).

\subsection{Modelagem matemática}

O pré-tratamento dos dados reduz a complexidade do modelo e a seguir faz-se a construção do modelo de calibração. De maneira geral, o modelo deve extrair a informação relevante contida nos espectros NIR, a qual está relacionada diretamente com a informação que se deseja conhecer no futuro, aplicando o modelo construído.

\section{PCA}

PCA (Análise por Componentes Principais) se constitui a base fundamental da maioria dos métodos modernos para tratamento de dados multivariados (Malinowski,1991), que consiste numa manipulação da matriz de dados com objetivo de representar as variações presentes em muitas variáveis, através de um número menor de "fatores". Constrói-se um novo sistema de eixos (denominados de fatores, Componentes Principais, variáveis latentes ou ainda autovetores) para representar as amostras, no qual a natureza multivariada dos dados pode ser visualizada em poucas dimensões.

O método PCA, é melhor entendido utilizando duas varáveis. A figura 4.3 (Ferreira at al.) mostra o gráfico bidimensional de um conjunto de amostras. Em termos geométricos a função das componentes principais é fazer uma rotação de eixos tal que o primeiro (primeiro Componente Principal) contém a direção da máxima variância dos dados, sendo o segundo (segundo Componente Principal) ortogonal 
ao primeiro. As novas coordenadas das amostras, no novo sistema de eixos das Componentes Principais mostradas pela linha cheia na figura 4.3 são denominadas de "scores". Cada componente principal é construída pela combinação linear das variáveis originais. Os coeficientes da combinação linear (o peso, ou quanto cada variável antiga contribui) são denominados de "loadings" e representados pela linha tracejada na figura 4.3. Note que eles são, na realidade, os cossenos dos ângulos entre os eixos originais e o novo eixo (PC).

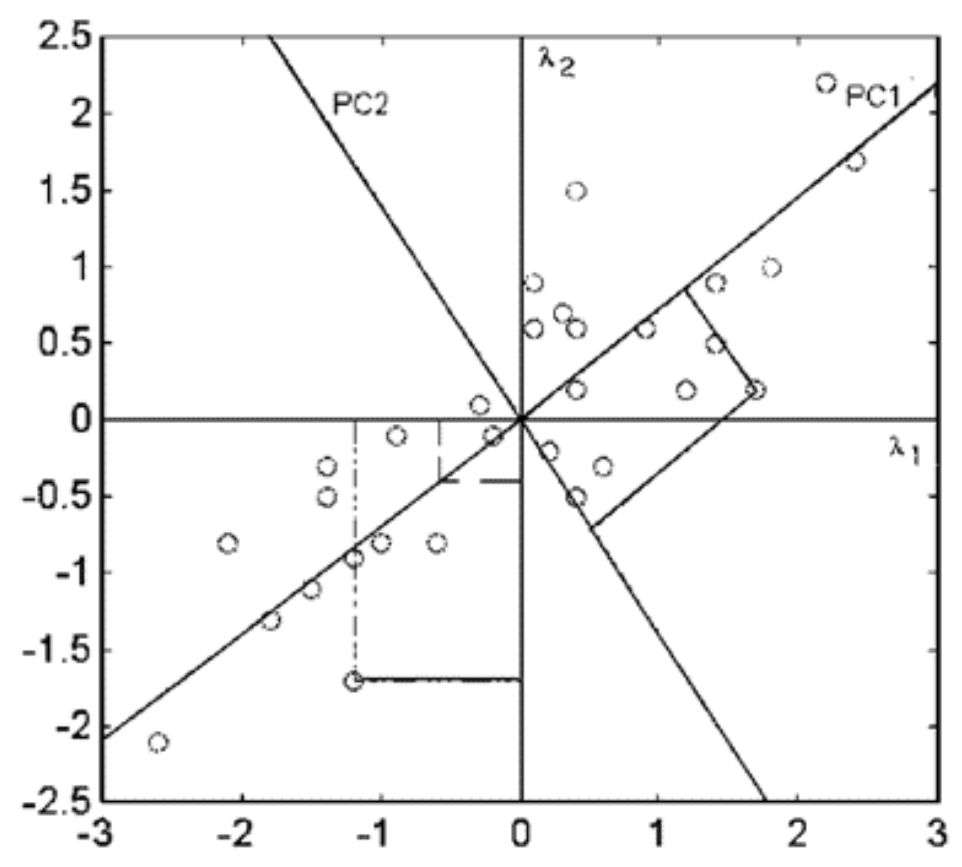

Figura 4.3 - Gráfico de um conjunto de dados bidimensionais mostrando os eixos dos Componentes Principais PC1 e PC2

* Os "scores" de uma amostra são representados por (- $(-)$ e os "loadings" por (----) As linhas tracejadas (-.._..-) respresentam as coordenadas de uma amostra em relação aos eixos originais.

\section{TÉCNICAS LINEARES}

É usual que as variáveis $X$ (variáveis espectrais) sejam capazes de conter diversos tipos de informações ao mesmo tempo, em proporções diferentes. Como conseqüência, tem-se uma redundância de dados, sendo a melhor forma de contornar este problema a compressão dessa informação através da utilização de Componentes Principais. Segundo Naes e Isaksson (1994a), essa redução é ainda 
mais necessária quando o comportamento do sistema não é conhecido, sendo as duas técnicas básicas a PCR (regressão por componentes principais) e a PLS (regressão por mínimos quadrados parciais).

O objetivo destas técnicas é representar a vasta informação contida nos espectros em outro sistema de variáveis, reduzido, sem perder informação relevante, onde as novas variáveis são chamadas de fatores ou Componentes Principais $\left(t_{s}\right.$ ou $\mathrm{PC}_{s}$, respectivamente). Os $\mathrm{PC}_{\mathrm{s}}$ são combinações lineares das variáveis originais, superando assim os problemas de seletividade (não eliminando nenhuma variável) e colinearidade (muitas variáveis contêm tipos de informação similares).

A PCR reduz a matriz dos dados considerando somente a informação em $X$; sem se interessar com a relação entre $X$ e o que se deseja estimar $(Y)$, a qual de fato deve existir. Obtêm-se, portanto $\mathrm{PC}_{\mathrm{s}}$ que explicam a variabilidade em $\mathrm{X}$. Por outro lado, a PLS utiliza também a informação em $Y$, de forma a maximizar a sua relação com os $\mathrm{PC}_{\mathrm{s}}$ calculados. Com isto, são obtidos componentes que melhor se relacionam com $\mathrm{Y}$ e, ao mesmo tempo, explicam da melhor maneira possível a variabilidade em $\mathrm{X}$.

A PLS tem a vantagem de fornecer, em alguns casos, modelos de calibração mais simples do que a PCR (número menor de $\mathrm{PC}_{\mathrm{s}}$ ). Isto ajuda à interpretação gráfica do modelo para dados com alta precisão, como no NIR, já que muita da informação relevante em $\mathrm{Y}$ relacionada com $\mathrm{X}$ é modelada pelos primeiros fatores.

Em qualquer método de compressão de dados, é importante selecionar o número ideal de variáveis ou Componentes Principais a usar. Se forem utilizados muitos componentes, haverá redundância nas variáveis $\mathrm{X}$, causando um sobreajuste ("overfitting") do modelo, que fornecerá estimativas ruins de previsão. Se um número insuficiente de componentes for utilizado, ocorrerá um subajuste ("underfitting"), significando que o modelo não é capaz de capturar variabilidade importante dos dados (Bueno,2006). Vide figura 4.4. 


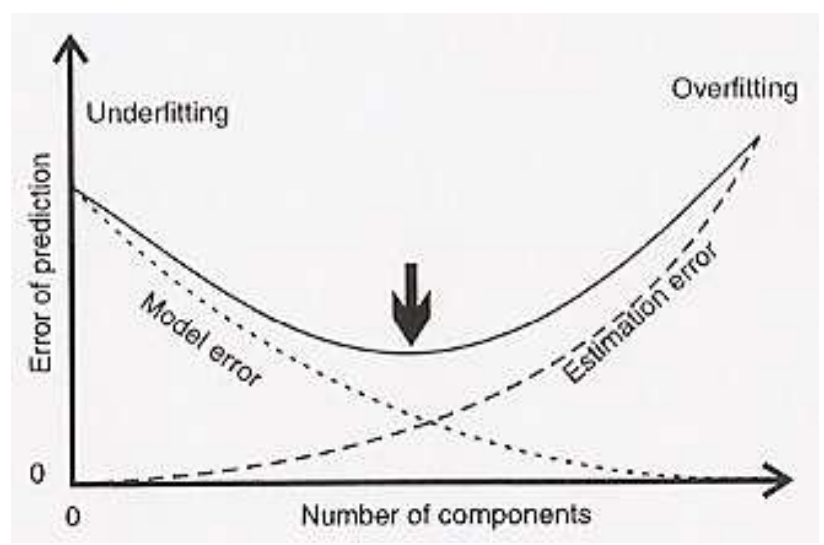

Figura 4.4 - Número ótimo de componentes em função do erro de predição

Antes da aplicação do modelo construído, o mesmo deve ser validado com o objetivo de testar a sua capacidade preditiva; sem esta etapa não há sentido em prosseguir.

A validação consiste em testar o modelo com amostras não usadas na sua construção, para estabelecer se ele de fato irá refletir o comportamento de interesse. Durante a etapa de validação dois fatores devem ser considerados:

1 - O número de fatores $k$ a ser utilizado no modelo (número de Componentes Principais ou número de variáveis latentes).

2 - Detecção de "outliers" (pontos discrepantes).

A validação de um modelo pode ser feita com um conjunto de $n$ elementos independente do conjunto de calibração e calculando-se a raiz do erro médio quadrático RMSEP ("root mean square error of prediction")(eq. 4.1)onde $c_{i}$ é o valor medido e $\hat{c}_{i}$ é o valor predito para cada elemento do conjunto de validação.

$$
R M S E P=\sqrt{\frac{\sum_{i=1}^{n}\left(c_{i}-\hat{c}_{i}\right)^{2}}{n}}
$$

Ou usando somente os elementos do conjunto de calibração, que é a validação cruzada. Esta é uma metodologia utilizada para a escolha do número de Componentes Principais baseada na avaliação da magnitude dos erros de previsão 
de um dado modelo de calibração. Esta avaliação é feita pela comparação das previsões das propriedades previamente conhecidas, e em resumo consiste do seguinte:

1 - Remove-se uma ou mais amostras i do conjunto de calibração e constrói-se o modelo como anteriormente;

2 - Usa-se o novo modelo para prever os dados removidos;

3 - Calcula-se a soma dos quadrados dos erros de previsão: PRESS (eq. 4.2) ou a raiz quadrada RMSECV (eq. 4.3), que é na realidade um desvio-padrão onde $n$ é o número de amostras do conjunto de calibração.

$$
\begin{aligned}
& \text { PRESS }=\sum_{i=1}^{n}\left(c_{i}-\hat{c}_{i}\right)^{2} \\
& \text { RMSECV }=\sqrt{\frac{\sum_{i=1}^{n}\left(c_{i}-\hat{c}_{i}\right)^{2}}{n}}
\end{aligned}
$$

O processo é repetido para modelos com uma, duas e assim por diante, Componentes Principais. Para cada sistema em estudo, o número mais adequado de fatores, k, será o correspondente ao menor valor de PRESS ou RMSECV (Kowalski,1991).

Para a detecção de "outliers", usam-se duas grandezas complementares: "leverage" (alavancagem) e resíduos.

A "leverage" é uma medida da influência de uma amostra no modelo de regressão. Um valor de "leverage" pequeno indica que a amostra em questão influencia pouco na construção do modelo de calibração. Por outro lado, se as medidas experimentais de uma amostra são diferentes das outras do conjunto de calibração, ela provavelmente terá uma alta influência no modelo, que pode ser negativa. Em geral, estas amostras solitárias estão visíveis no gráfico de "scores". A "leverage" pode ser interpretada geometricamente como a distância de uma amostra ao centróide (média) do conjunto de dados. 
A análise do gráfico dos resíduos (diferença entre o valor medido e o calculado pelo modelo) versus "leverage" para cada amostra é a melhor maneira de se determinar as amostras anômalas. Amostras com altos resíduos, mas com pequena "leverage" provavelmente têm algum erro, que deve, de preferência, ser medida novamente. Outra opção será a exclusão de tal amostra do conjunto de calibração. Amostras com resíduo e "leverage" altos devem sempre ser excluídas e o modelo de calibração reconstruído. A figura 4.5 apresenta exemplos de pontos discrepantes com diferentes "leverages"

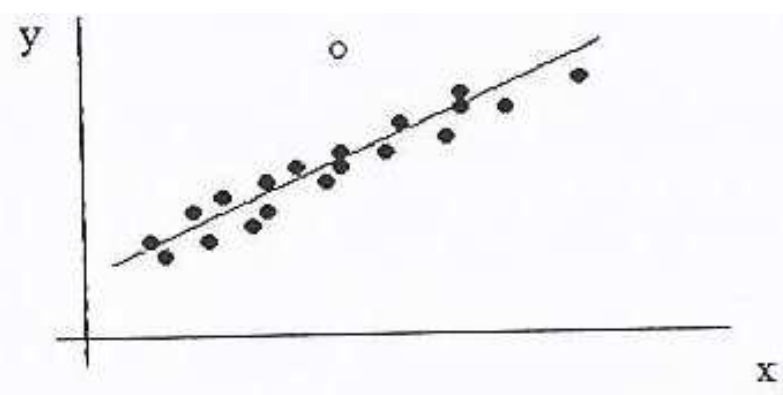

(a) ponto discrepante de alto resíduo e baixa influência

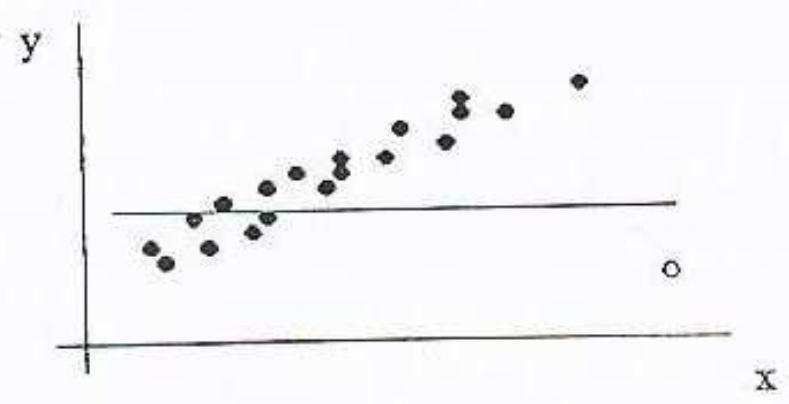

(b) ponto discrepante de alto resíduo e alta influência

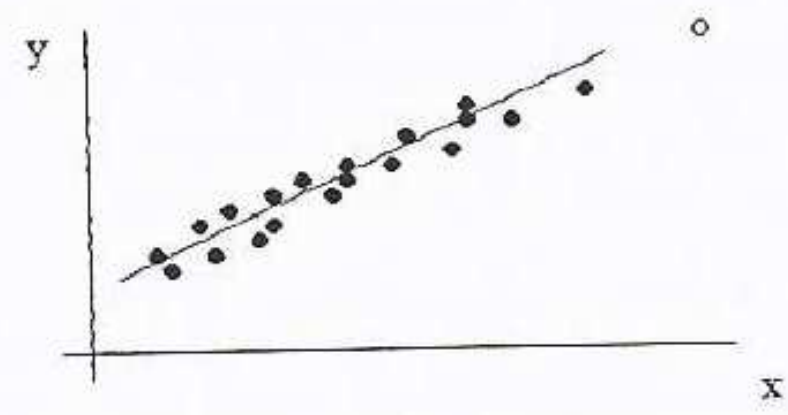

(c) ponto discrepante de baixo residuo e baixa influência

Figura 4.5 - Pontos discrepantes com diferentes leverages (Bueno, 2006) 
Uma vez validado e otimizado o modelo está pronto, isto é, o número de fatores $\mathrm{k}$ está definido e as amostras anômalas foram detectadas e excluídas.

\section{MÉTODO NÃO LINEAR: REDES NEURAIS}

Uma rede neural busca inspiração na estrutura do cérebro. A unidade básica de nosso cérebro, o neurônio, apresenta uma região onde informações são processadas (o soma), algumas entradas (os dendritos) e uma saída (o axônio). Os impulsos elétricos recebidos nos dendritos são processados pelo soma e o resultado deste processamento é colocado no axônio. O modelo matemático de neurônio (figura 4.7) no qual se baseiam as redes neurais possui uma estrutura análoga ao biológico (figura 4.6). Basicamente, a ativação (saída) de um neurônio artificial é uma função da soma ponderada de suas entradas:

$S=T\left(W j 0 * X 0+W j 1^{*} X 1+W j 2{ }^{*} X 2 \ldots\right)$, onde $S$ é a saída, $X$ as entradas e $W j$ os pesos das entradas no neurônio j.

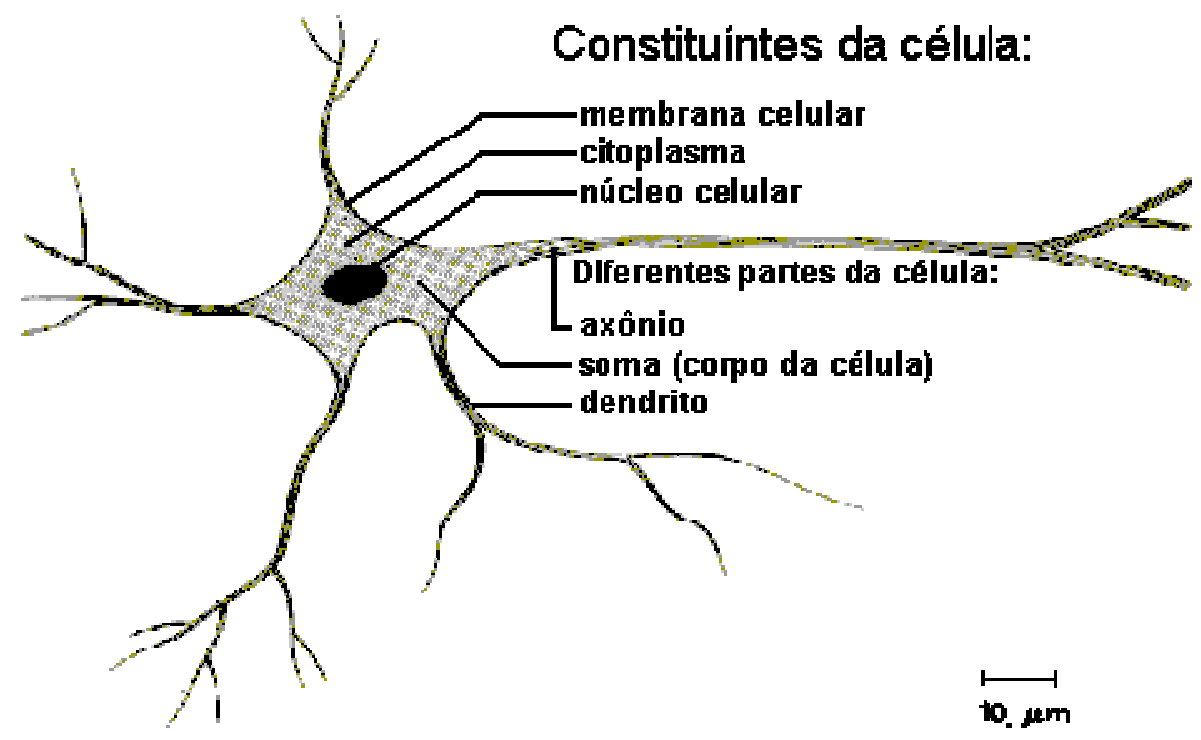

Figura 4.6 - Esquema de um neurônio biológico . (Tatibana \& Kaetsu, 2008) 


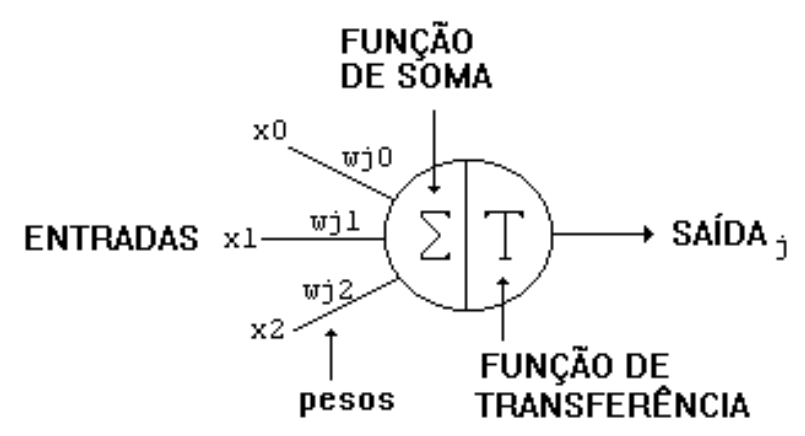

Figura 4.7 - Modelo matemático de um neurônio (TAFNER, 1998)

A função T, utilizada para obter a saída do neurônio, é chamada de função de ativação. As funções de ativação mais utilizadas são funções do tipo sigmoidal (com forma de S). A mais utilizada de todas é a função logística (figura 4.8):

$$
f(x)=\frac{1}{1+e^{-x}} \quad=\quad\left(1+e^{-x}\right)^{-1}
$$

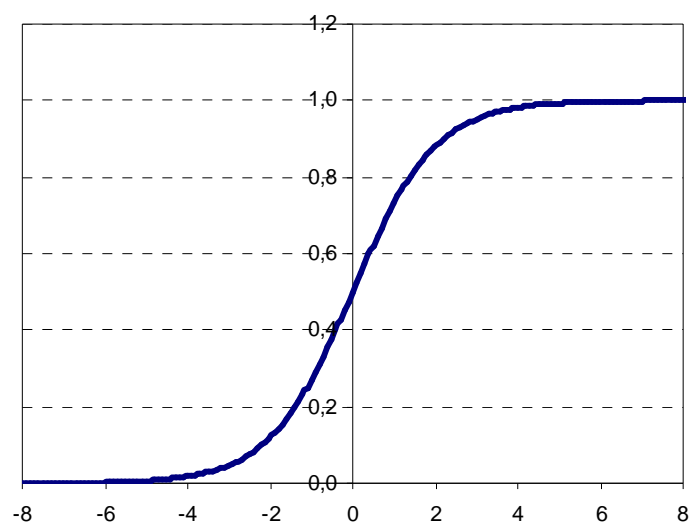

Figura 4.8 - Função Sigmóide

Um único neurônio não é capaz de resolver nenhum problema prático. Porém, muitos neurônios adequadamente conectados e com os pesos das conexões devidamente ajustados são capazes de resolver complexos problemas nãodeterminísticos. Quanto maior a complexidade do problema a ser resolvido, maior será o número de neurônios utilizados; para se ter uma idéia, o cérebro humano é formado por cerca de 100 bilhões de neurônios e o número de conexões entre estes neurônios está na casa das dezenas de trilhões. 
As pesquisas sobre redes neurais iniciaram em 1943, quando Warrem McCulloch e Walter Pitts estabeleceram as bases da neurocomputação, concebendo procedimentos matemáticos análogos ao funcionamento dos neurônios biológicos.

Em 1949 Donald Hebb deu um passo muito importante na história das redes neurais. Ele propôs um modo de proporcionar capacidade de aprendizado às redes neurais artificiais. Sua proposta, traduzida matematicamente, viabilizou o desenvolvimento de redes neurais eficazes. Nos anos 50 já existiam várias implementações de Redes Neurais através de circuitos analógicos e, naquela época, acreditou-se que o caminho para o entendimento da inteligência humana havia sido descoberto (HECHT-NIELSEN,1991). Para reproduzir o comportamento do cérebro humano pensava-se que bastaria construir uma rede neural suficientemente grande. Uma rigorosa análise matemática, no entanto, comprovou o baixo poder computacional dos modelos de redes neurais utilizados na época, levando as pesquisas neste campo a ficarem esquecidas desde os anos 60 até o início da década de 80 .

Nos anos 80 o interesse pela área retornou devido, em grande parte, ao surgimento de novos modelos neurais como, por exemplo, os modelos propostos por Hopfield (1982) e de algoritmos de aprendizado mais poderosos. Além disso, nesta mesma época, ocorreu o surgimento de computadores mais rápidos e poderosos, facilitando a implementação das redes neurais. Nesta década, surgiu um forte e crescente interesse dentro da comunidade de engenharia química em computação neural, o que pode ser observado pelo número cada vez maior de publicações descrevendo o uso de redes neurais artificiais em problemas de engenharia química como, por exemplo, deteç̧ão de falhas, processamento de sinais, modelagem de processo e controle.

Há várias razões para a aceitação e desenvolvimento das redes neurais:

- Avanços na área de tecnologia de computadores;

- O modelo de rede neural tem muitos neurônios conectados por pesos com capacidade de adaptação que podem ser arranjados em uma estrutura paralela. Por causa deste paralelismo, a falha de algumas entradas não causa efeito significante para a performance de todo o sistema, o que é chamado de tolerância a falhas;

- A principal força na estrutura de redes neurais reside em sua habilidade de adaptação e aprendizagem. A habilidade de adaptação e aprendizagem pelo ambiente significa que modelos de redes neurais podem lidar com dados imprecisos 
e situações não totalmente definidas. Uma rede treinada de maneira razoável tem a habilidade de generalizar quando é apresentada à entradas que não estão presentes em dados já conhecidos por ela;

- A característica mais significante de redes neurais está em sua habilidade de aproximar qualquer função continua não linear de um grau de correção desejado. Redes Neurais podem ter várias entradas e várias saídas.

É possível conectar os neurônios de uma rede neural de modos variados, dando origem a diversas topologias. A topologia mais utilizada atualmente em problemas práticos é a "feedforward", que pode ser implementada em processadores comuns e, comparando-se com outras topologias, não exige muita memória. Uma rede deste tipo está representada na figura 4.9.

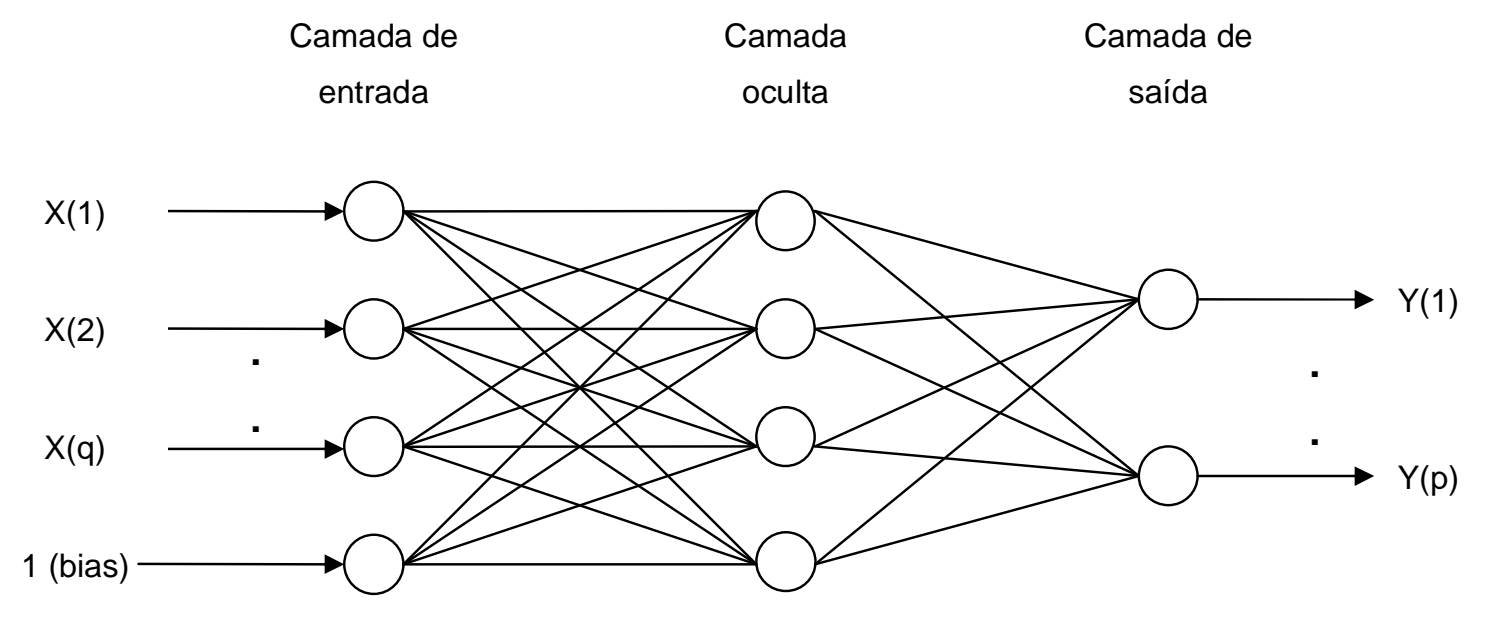

Figura 4.9 - Rede neural feedforward

Uma rede neural "feedforward" é composta de algumas camadas. Cada neurônio de uma camada está conectado a todos os neurônios das camadas adjacentes. A camada de entrada deve conter tantos neurônios quanto o número de variáveis conhecidas a serem utilizadas pelo modelo, acrescida de neurônio bias. Há pesquisadores como HECHT - NIELSEN (1991), que afirmam que com apenas uma camada oculta já é possível calcular uma função arbitrária qualquer a partir de dados fornecidos. A camada de saída deve conter tantos neurônios quanto o número de variáveis a serem preditas. Uma rede neural deste tipo, depois de pronta, é capaz de associar uma série de valores que são colocados em suas entradas a determinadas 
saídas. Ela não se trata, porém, simplesmente de uma memória, pois tem a capacidade da generalização; ela pode encontrar respostas corretas mesmo quando os dados disponíveis para as entradas estão incompletos ou danificados ou mesmo quando a relação entre entrada e saída não é concreta. Sabe-se, por exemplo, que há empresas utilizando redes neurais para previsão financeira: nas entradas são colocados dados sobre diversos indicadores econômicos e na saída obtém-se informações como a tendência das bolsas valores para o próximo dia. O grande problema para a utilização de redes neurais têm sido encontrar regras que permitam determinar o valor que os pesos das conexões devem ter para que a rede neural realize a função desejada. $O$ processo pelo qual os pesos de uma rede neural são determinados é conhecido por treinamento.

O treinamento de redes "feedforward" é do tipo supervisionado. Neste tipo de treinamento é preciso possuir um conjunto de dados para treinamento, ou seja, uma série de pares de entradas e saídas desejadas. As entradas são apresentadas à rede e seus pesos são alterados de modo que a saída se aproxime da saída desejada. Pode-se dizer que a rede neural aprende a fazer seu trabalho observando uma série de exemplos que the são exibidos. $O$ algoritmo mais utilizado para alterar os pesos da rede neural "feedforward" durante o treinamento é o "Error backpropagation" (retropropagação de erros). A idéia é atualizar os pesos utilizando as derivadas dos erros em relação aos pesos. O estudo destas derivadas foi publicado por Rumelhart e McClelland em 1986.

Neste trabalho é utilizada a topologia "feedforward" com função de ativação sigmóide que segundo Cybenko(1989) é uma função de aproximação universal.

\subsection{Instrumentação NIR}

A seguir serão descritos os equipamentos e a metodologia experimental empregada para realizar as análises NIR por meio dos sensores de transmitância.

Quanto aos componentes básicos deste espectrofotômetro, tipo Transformada de Fourier (FT); têm-se uma lâmpada de tungstênio-halogênio como fonte de radiação, 
um detector de diodo de Ge e um dispositivo de luz laser He-Ne. As análises de transmitância foram realizadas no espectrômetro NIR, modelo FTLA2000-160 (ABB Bomem - Canadá). As análises foram realizadas na faixa do infravermelho próximo $\left(4000-14000 \mathrm{~cm}^{-1}\right)$, dotado de detector DTGS.

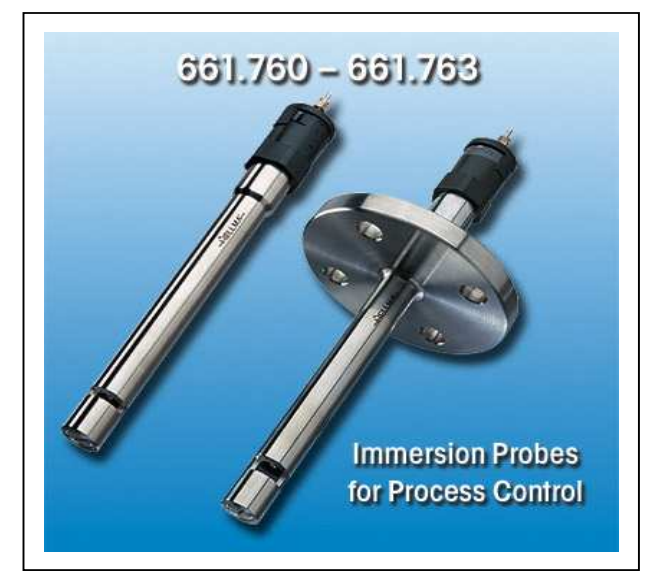

Figura 4.10 - Sensores NIR de imersão (HELLMA)

Dois tipos de fibra óptica foram utilizados na realização dos experimentos: a primeira é o modelo 041.202 - NIR de $6 \mathrm{~m}$ de comprimento, utilizada nos testes "offline", e a segunda é o modelo 041.302-NIR de $50 \mathrm{~m}$ de comprimento, utilizada nos experimentos no "loop de Querosene" (a ser descrito no item 4.4). Ambas as fibras são da Hellma.

O sensor NIR de transmissão, modelo 661.760-NIR (Hellma) (figura 4.10) utilizado, apresenta um caminho óptico de $1 \mathrm{~mm}$. O material em contato com a amostra é de aço inoxidável com $\mathrm{Ti}$ (316). Sua profundidade de imersão é de 30 até $240 \mathrm{~mm}$, tendo um comprimento total de $250 \mathrm{~mm}$. A faixa de temperatura da amostra pode ser de 5 até $300^{\circ} \mathrm{C}$, e a faixa de pressão pode variar até 35 bar. A figura 4.11 apresenta o esquema da medição dos espectros.

A metodologia experimental implementada considerou as recomendações feitas nos manuais de fabricante dos instrumentos, sendo os principais aspectos:

- Quanto às amostras, necessidade de agitação para favorecer a sua homogeneização, coletando 3 espectros; 
- A limpeza do sensor NIR é realizada com ciclohexano;

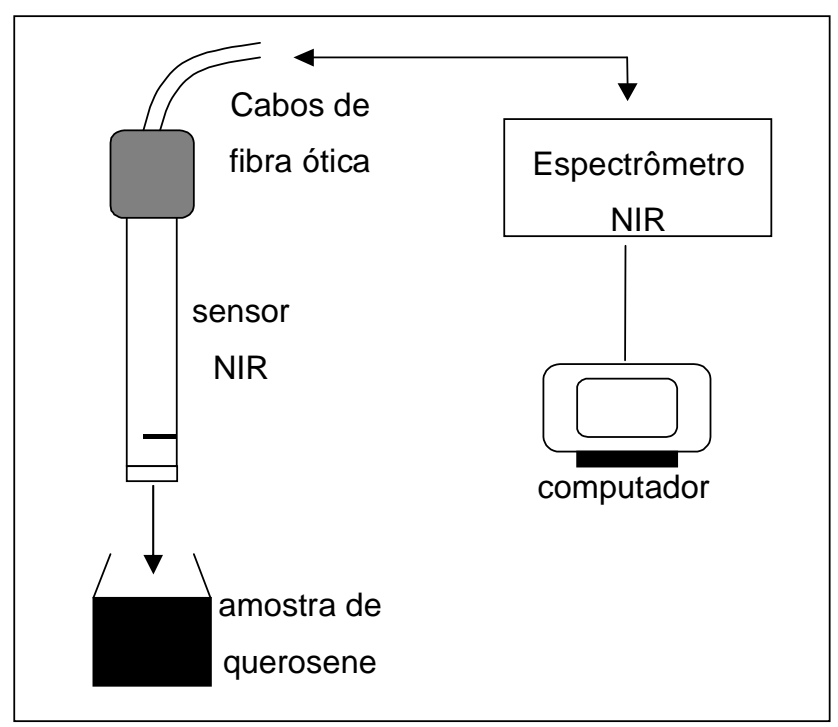

Figura 4.11 - Esquema da medição dos espectros NIR de querosene

- Quanto ao espectrômetro, utilizou-se o ar para a medição do "background". A água não é recomendada porque a forma das bandas do seu espectro tem alta dependência da temperatura. As medidas foram feitas em modo de transmitância ( $T$ ) e os espectros apresentados em modo de absorbância ( $\log (1 / T)$ ), numa faixa espectral de 13000.12 - $3999.741 \mathrm{~cm}^{-1}(769.224$ - $2500.162 \mathrm{~nm})$, com $1.929 \mathrm{~cm}^{-1}$ de intervalo entre números de onda consecutivos.

\subsection{Descrição do “loop"}

Com a finalidade de reproduzir o comportamento do querosene em condições reais, está instalado no Departamento de Engenharia Química de EPUSP (CESQ - USP), apresentado na Figura 4.12, um circuito "modelo" para a aquisição dos espectros do querosene em linha. $\mathrm{O}$ "loop" de querosene é composto por um tanque que alimenta uma bomba (tipo Moineau, deslocamento positivo, da marca Netzsch, modelo NE20A). A bomba é impulsionada por um motor Weg controlado por um acionador de velocidade variável Siemens MM440. O querosene, ou fluído a ser estudado, circula em circuito fechado. 


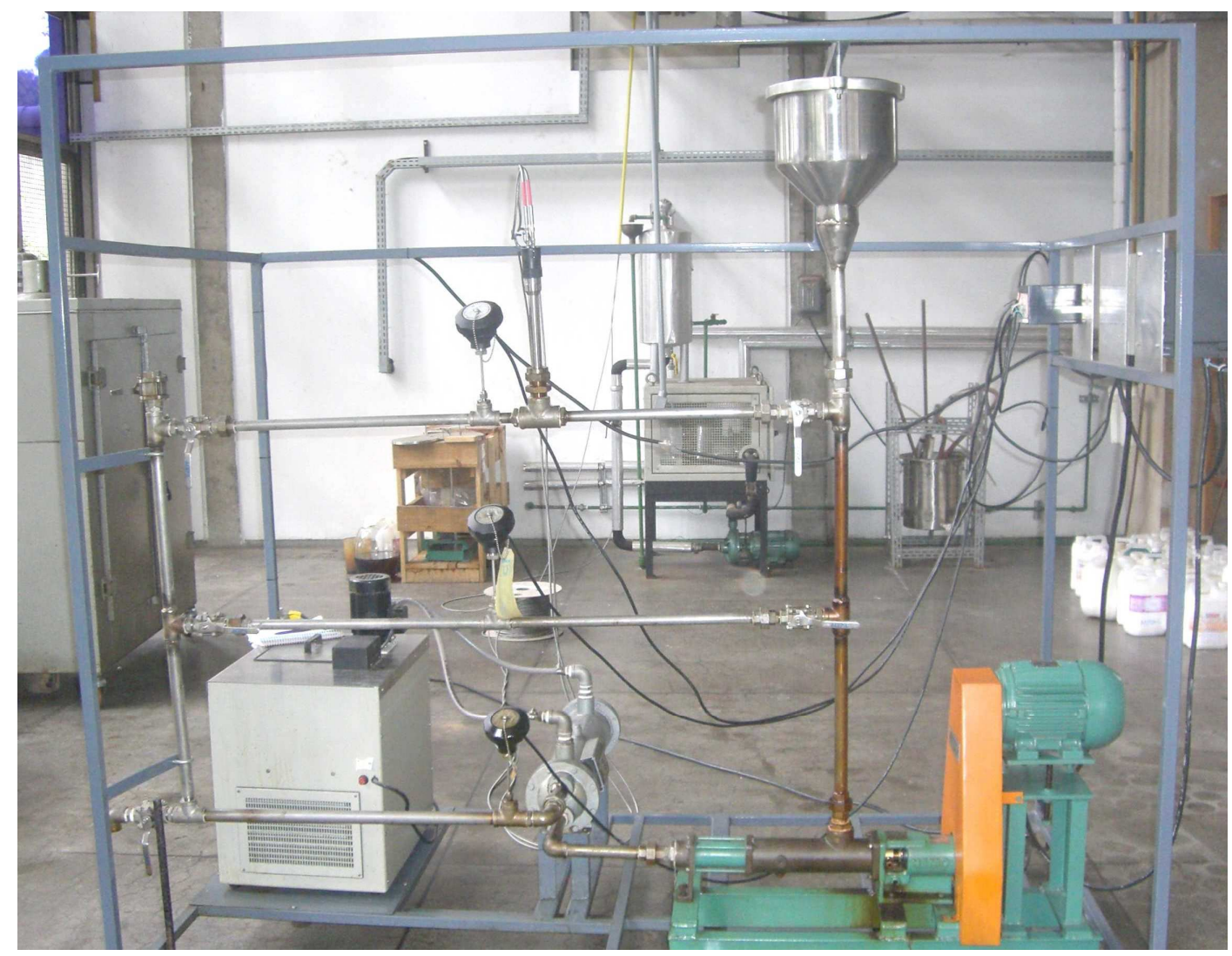

Figura 4.12 - “Loop” de querosene localizado no Térreo do LSCP-USP

$\mathrm{Na}$ linha de alimentação está instalado um trocador de calor (tipo casco tubo, com duas passagens: lado tubo para o querosene e lado carcaça para a água) com uma área de $0,50 \mathrm{~m}^{2}$ e um banho termocriostático (microprocessador Quimis modelo Q$214 \mathrm{~S} 2$, com faixa de trabalho de $-20^{\circ} \mathrm{C}$ a $120^{\circ} \mathrm{C}$ ), ambos permitem o controle da temperatura no sistema. A coleta dos espectros foi feita utilizando os equipamentos citados no item 4.3 de instrumentação.

O esquema completo do "loop" de querosene apresenta-se na Figura 4.13. 


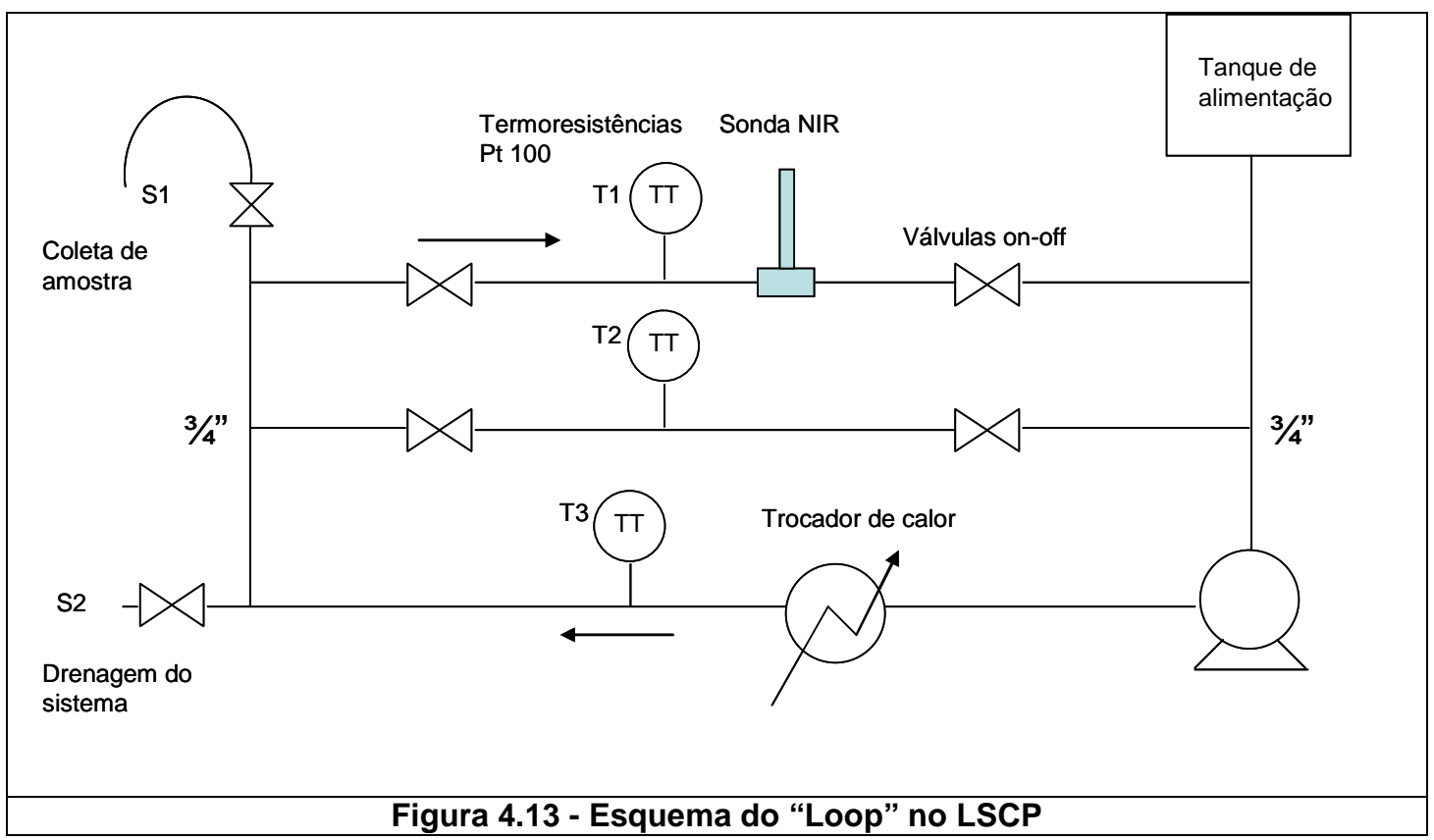

As linhas do "loop" são de aço inoxidável 304. Há duas saídas instaladas no sistema: S2 para a drenagem e S1 para a coleta de amostras. Os sensores de temperatura instalados nas linhas (T1 a T3) são do tipo PT100 e estão conectadas a um indicador de temperatura da marca IOPE (precisão de $0,1^{\circ} \mathrm{C}$.).

\subsection{Base de dados}

A amostragem do querosene ocorre pelo menos 6h após a troca de tanque de carga da Unidade de Destilação industrial. Pela experiência operacional sabe-se que esse período permite que todo o inventário até os pontos de amostragem sejam renovados.

Para a amostragem foi verificada a estabilidade do processo, de acordo com as principais variáveis operacionais da tabela 4.1, no período de 1 hora antes. Assim a amostra de querosene coletada reflete as condições operacionais de produção. 
Tabela 4.1 Principais variáveis operacionais

\begin{tabular}{|c|l|l|}
\hline Número & "Tag" & Descrição \\
\hline 1 & FC 21004PV & Refluxo de topo da torre pré-flash \\
\hline 2 & FC 21037PV & Refluxo de topo da torre atmosférica \\
\hline 3 & FC 21039PV & Vazão de produção de querosene \\
\hline 4 & FC 21041PV & Vazão de produção de diesel leve \\
\hline 5 & FC 21613PV & Vazão de diesel pesado para torre 06 \\
\hline 6 & FC 21631PV & Vazão de diesel pesado saída da torre atmosférica \\
\hline 7 & TC 21002PV & Temperatura de topo da torre de pré-flash \\
\hline 8 & TC 21009PV & Temp. de saída do F02A \\
\hline 9 & TC 21010PV & Temp. de saída do F02B \\
\hline 10 & TC 21011PV & Temperatura de topo da torre atmosférica \\
\hline 11 & TC 21226PV & Temp. de saída do F02C \\
\hline 12 & TI 21048AO & Temp. de fundo da torre de pré-flash \\
\hline 13 & TI 21133AO & Temp. querosene saída da torre atmosférica \\
\hline 14 & TI 21141AO & Temp. diesel leve saída da torre atmosférica \\
\hline 15 & TI 21152AO & Temp. diesel pesado saída da torre atmosférica \\
\hline 16 & TI 21125AO & Temperatura de topo da torre atmosférica \\
\hline 17 & PC 21004PV & Pressão do vaso de topo da torre de pré-flash \\
\hline 18 & PI 21651AO & Pressão de topo da torre atmosférica \\
\hline & & \\
\hline 16 & & \\
\hline 13 &
\end{tabular}

Essas variáveis operacionais serão utilizadas para se elaborar inferências por regressão linear multivariável que serão comparadas com as obtidas a partir dos espectros NIR.

De janeiro/08 a agosto/08 foram coletadas 60 amostras de querosene na saída da torre de destilação atmosférica 6 horas após a troca de tanque de carga da Unidade. As amostras foram enviadas ao laboratório para se obter as seguintes propriedades físicas:

Densidade D20/4, Destilação ASTM-D86, Enxofre total, Ponto de Congelamento, Viscosidade a $40^{\circ} \mathrm{C}$, Viscosidade a $-20^{\circ} \mathrm{C}$ e Ponto de Fulgor.

As propriedades espectroscópicas foram obtidas em laboratório da USP. 
Foram coletadas 3 amostras para avaliação no "loop de querosene".

Em outubro e novembro de 2008 a unidade de destilação da refinaria passou por manutenção programada após um período de operação contínua de 5 anos. Normalmente após a manutenção programada as torres de destilação operam com melhor eficiência e as condições operacionais são diferentes daquelas de final de campanha. Considera-se campanha o período entre manutenções programadas que vão de 4 a 6 anos de operação contínua. 


\section{RESULTADOS E DISCUSSÕES}

Apresentam-se os resultados dos espectros NIR do querosene, dividindo-se em duas etapas: análises "off-line" e "on-line". Também são apresentados os resultados obtidos por regressão linear multivariável baseados nas variáveis operacionais.

As análises "off-line" foram utilizadas para caracterização do querosene e comparação com os modelos obtidos por regressão linear multivariável. As análises "on-line" foram utilizadas para verificar a influência da variação da temperatura e escoamento do fluido de processo sobre os espectros NIR.

\subsection{Análises NIR "off-line"}

\subsubsection{Faixa espectral}

A escolha da faixa espectral é importante para o processo de calibração. Ao longo de todo o espectro NIR existem regiões onde se apresenta ruído, apesar de que a informação contida nela seja rica, os resultados não são satisfatórios nem utilizando técnicas de pré-tratamento adequadas (CHUNG, 2000). Além disso, evidências, tanto teóricas como experimentais, indicam que a escolha das regiões espectrais pode melhorar significativamente a eficiência das técnicas de calibração.

Os espectros NIR de cada amostra de querosene foram resultados de três medidas obtendo-se o valor médio do espectro. Os espectros médios são apresentados na figura 5.1 .

No presente trabalho foi considerada como região espectral, a faixa de $5600-6100$ $\mathrm{cm}^{-1}$ de número de onda (figura 5.2), que correspondem às regiões de sobretons do NIR para os hidrocarbonetos (FALLA et al, 2005). Esta região apresenta maior intensidade de absorbância e picos com melhor discriminação na derivada primeira. 


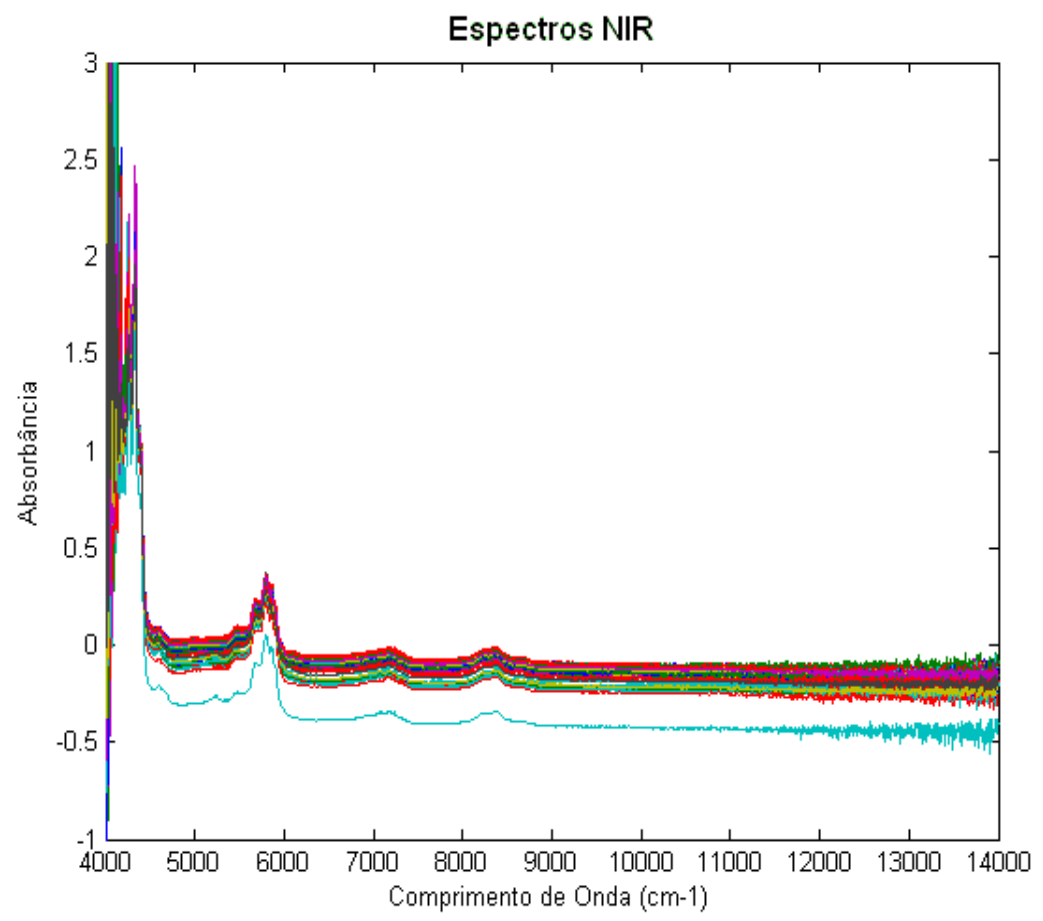

Figura 5.1 - Espectros NIR a comprimento total $\left(4000-14000 \mathrm{~cm}^{-1}\right)$

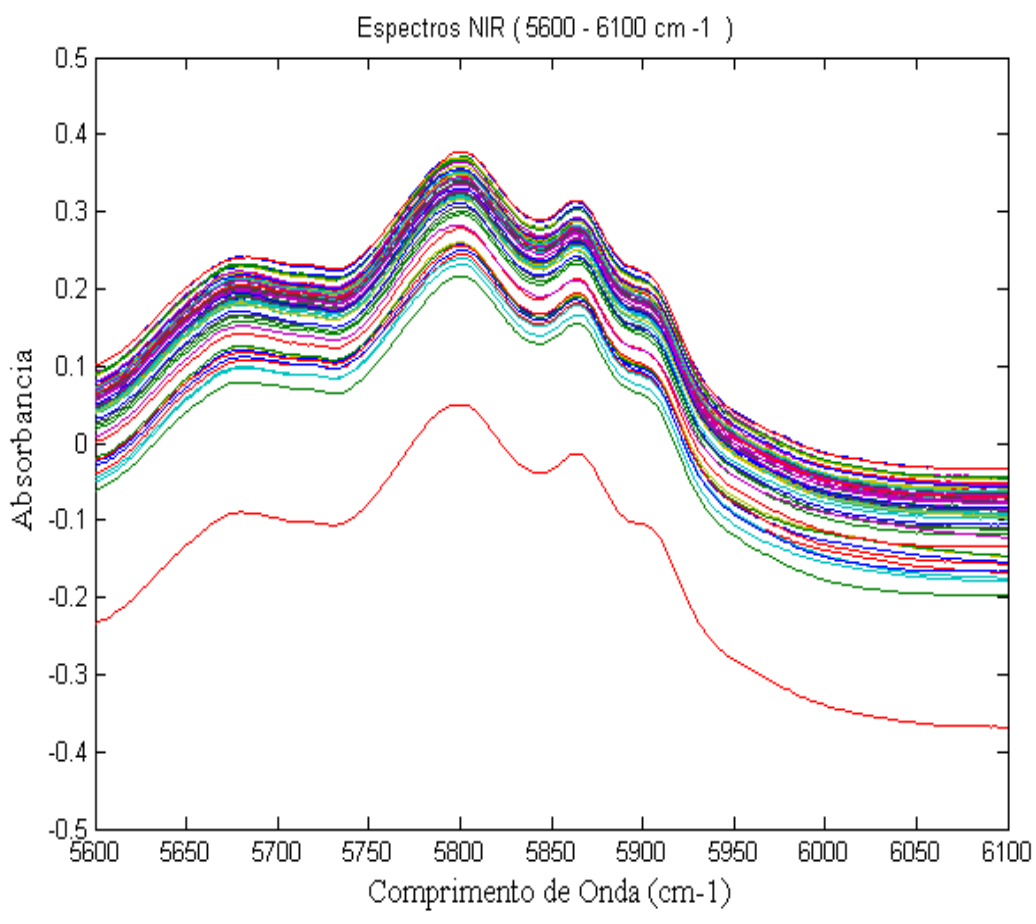

Figura 5.2 - Faixa de trabalho $\left(5600-6100 \mathrm{~cm}^{-1}\right)$ 


\subsubsection{Analises da dispersão dos dados}

Antes de iniciar a construção dos modelos é importante realizar análises da dispersão dos dados a serem correlacionados, para verificar que estes serão significativos na construção do modelo.

Foram coletadas 60 amostras de querosene e numeradas de QI a QVIII e de Q9 a Q78 para calibração e predição ou teste e mais 4 para validação externa, denominadas Q79 a Q82 que foram amostradas em campanha após manutenção programada da unidade de destilação. A numeração seqüencial das 60 amostras utilizadas é superior a $60 \mathrm{em}$ virtude de amostras repetidas e outras perdidas.

Foram realizadas as análises de dispersão de todas as propriedades físicas obtidas. $\mathrm{Na}$ figura 5.3 pode-se observar que a amostra Q19 está fora do agrupamento em todos os casos, portanto foi considerada "outlier". Essa amostra foi tomada numa campanha de produção de querosene para diluente de asfalto; as demais em campanha de querosene de aviação. Portanto, restaram 59 amostras para a construção dos modelos.

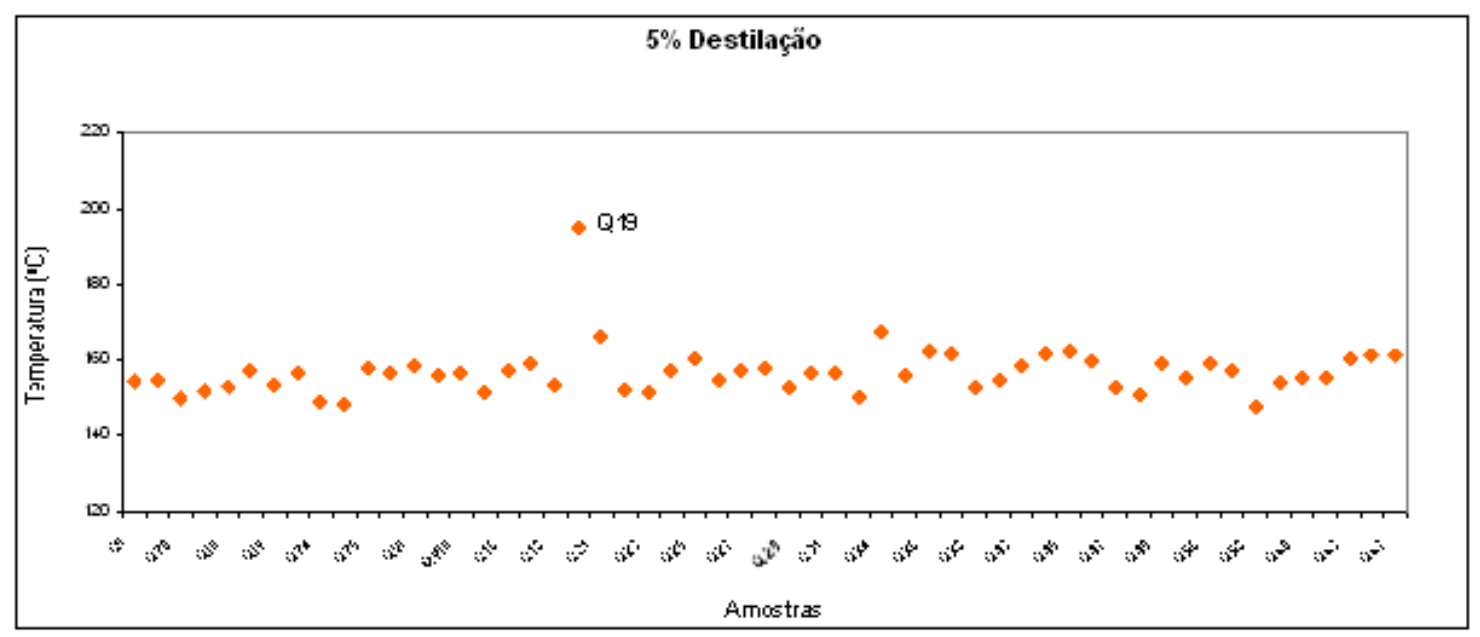



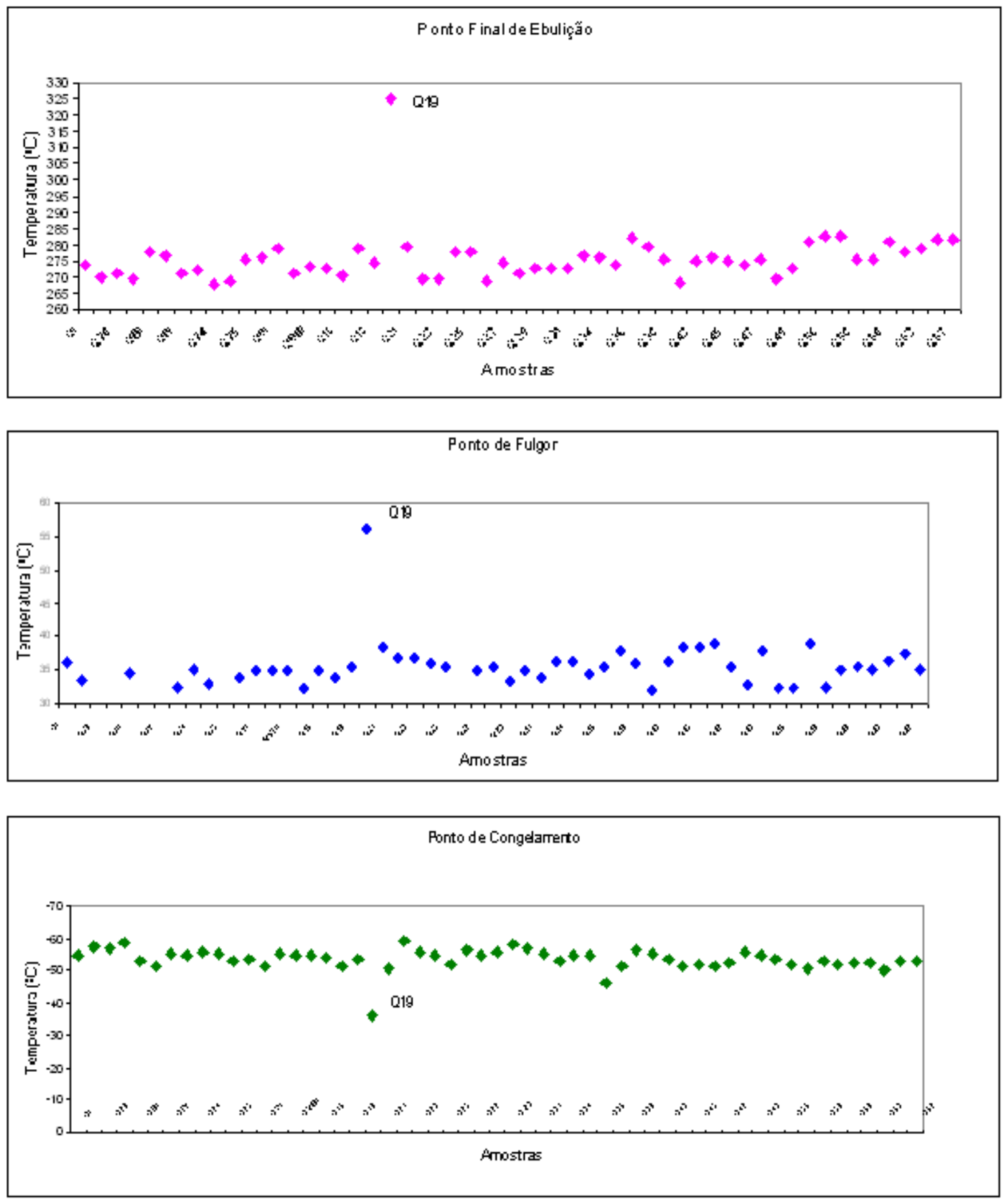

Figura 5.3 - Análises de dispersão de algumas propriedades em estudo (a) 5\% Destilado (D86), (b) Ponto Final de Ebulição (D86), (c) Ponto de Fulgor e (d) Ponto de Congelamento

\subsubsection{Pré-tratamentos}


Utilizou-se o método de Savitzky-Golay para o alisamento e a derivada primeira dos espectros. A figura 5.4 mostra uma representação gráfica destes pré-tratamentos para uma amostra aleatória. Pode-se observar que o gráfico da derivada primeira mostra picos bem definidos, mas em um conjunto de amostras ainda existem similaridades e pequenas diferenças na altura relativa dos picos que estão mascarados. Para solucionar este problema, é comum praticar as análises dos resíduos (diferença de espectros) relacionando todo o conjunto de dados (espectros) para uma dada amostra. As diferenças entre espectros revelam os discriminantes de cada amostra para a calibração do modelo o que permite predizer várias propriedades. Esta análise foi realizada para as amostras do processo realizado no "loop".
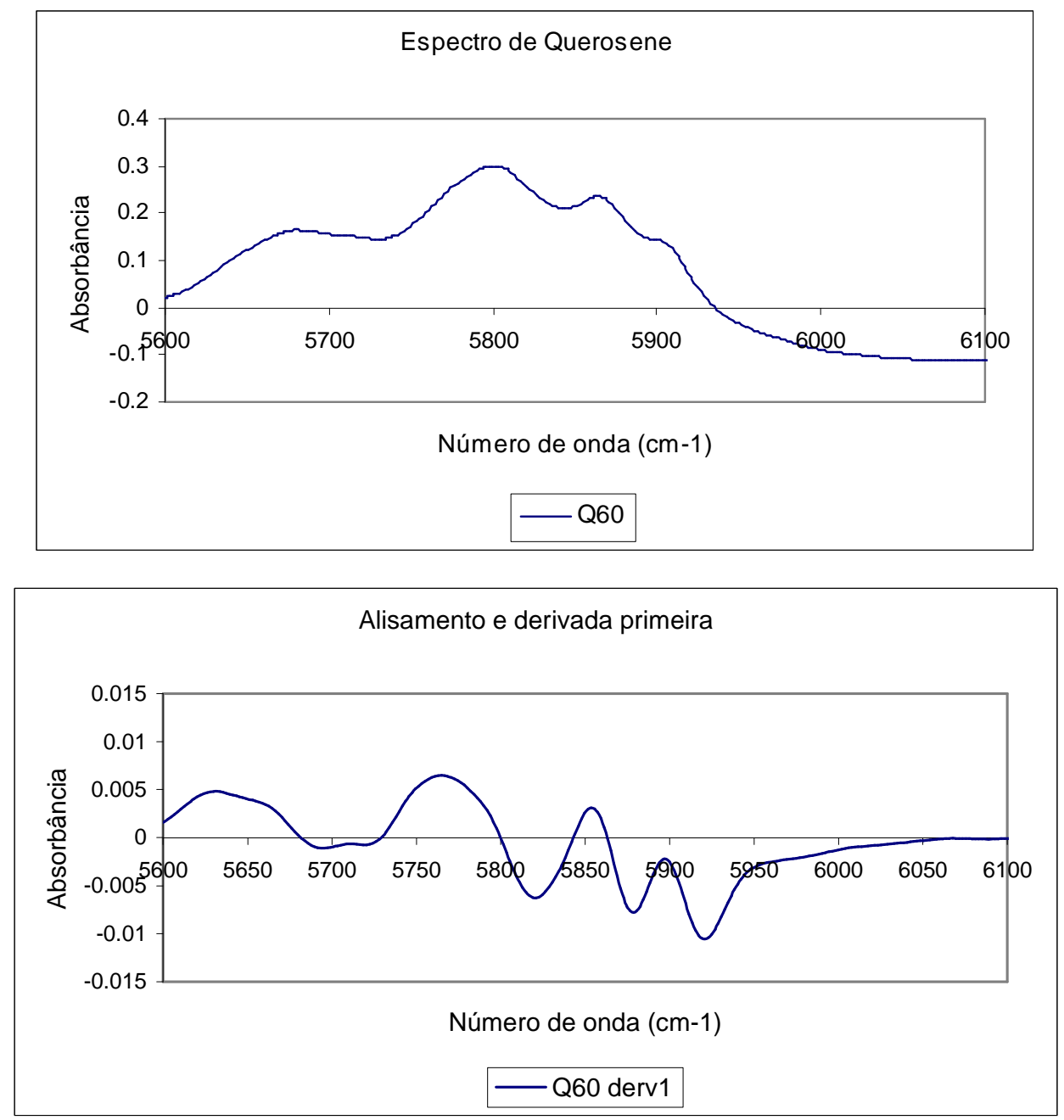

Figura 5.4 - (a) Espectro típico NIR do querosene e (b) Derivada primeira após alisamento do espectro. 


\subsection{Análises NIR no "loop”}

As medições de espectros NIR no "loop" foram realizadas com o objetivo de avaliar a estabilidade da técnica em condições mais próximas das reais, em termos de variação de temperatura e vazão. $O$ volume de amostra necessário para ser analisado no loop corresponde a 10 litros aproximadamente.

Foram coletadas 3 amostras para análise no "loop" e para cada amostra, os espectros obtidos foram resultados da média de 3 medidas. Os resultados apresentados, a seguir, correspondem às análises realizadas com uma amostra de querosene (os resultados obtidos com as outras amostras são muito similares). Foram feitas dois tipos de análises: a) mantendo a velocidade constante e medindo espectros a diferentes temperaturas, e b) mantendo a temperatura constante e medindo espectros a diferentes velocidades. Assim, é possível avaliar o efeito da variação da temperatura e velocidade, respectivamente, nos espectros NIR do querosene.

\subsubsection{Efeito da variação da temperatura}

O procedimento experimental é similar ao seguido nas análises "off-line". Após a medição dos espectros NIR aplica-se o pré-tratamento, que consiste em alisamento e derivação. Na figura 5.5 apresenta-se o conjunto de espectros a diferentes temperaturas, onde se observa principalmente o deslocamento de linha base. Após o alisamento, os espectros resultantes (figura 5.6) apresentam menor ruído e picos melhor definidos. Finalmente, a derivação (figura 5.7) permite realçar diferenças não observadas nos espectros originais. Isto pode ser utilizado na determinação (e/ou confirmação, como no caso deste trabalho) da faixa espectral a ser utilizada na construção dos modelos. Assim, na figura 5.7 observa-se que na faixa $5600-6100$ $\mathrm{cm}^{-1}$ há maior quantidade de informação útil representada pela amplitude dos picos. 


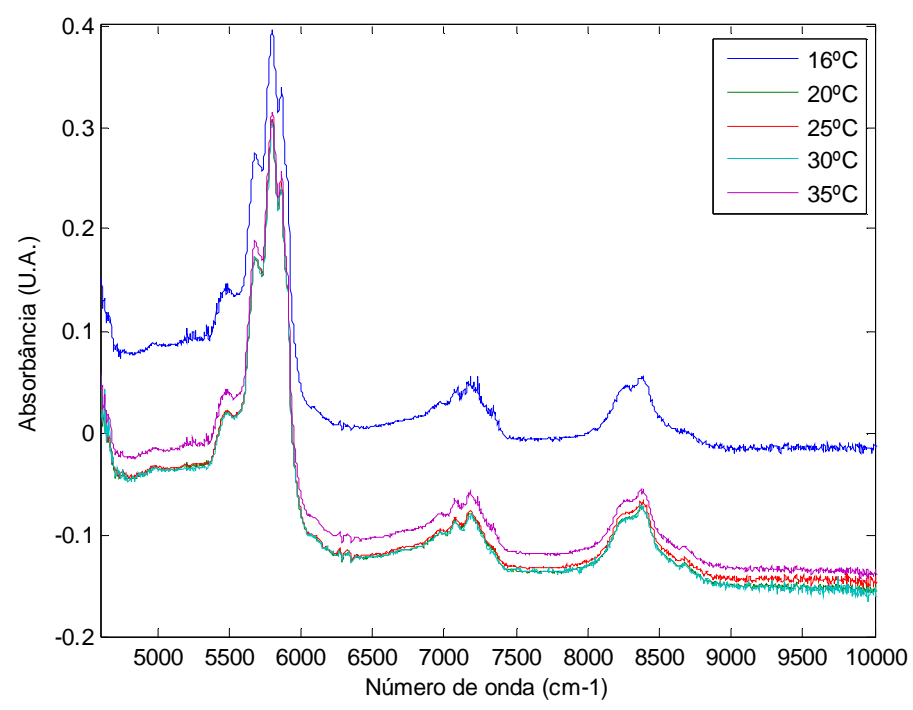

Figura 5.5 - Espectros NIR a diferentes temperaturas (velocidade $=0,576 \mathrm{~m} / \mathrm{s}$ ) de uma amostra de querosene no "loop"

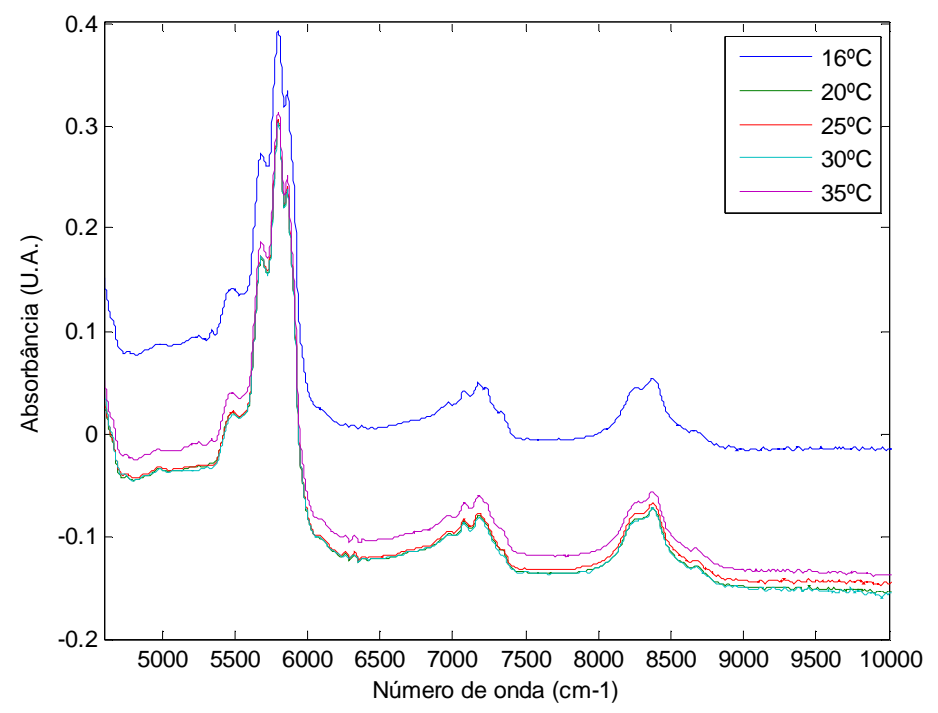

Figura 5.6 - Espectros NIR alisados a diferentes temperaturas (velocidade $=0,576 \mathrm{~m} / \mathrm{s}$ ) de uma amostra de querosene no "loop" 


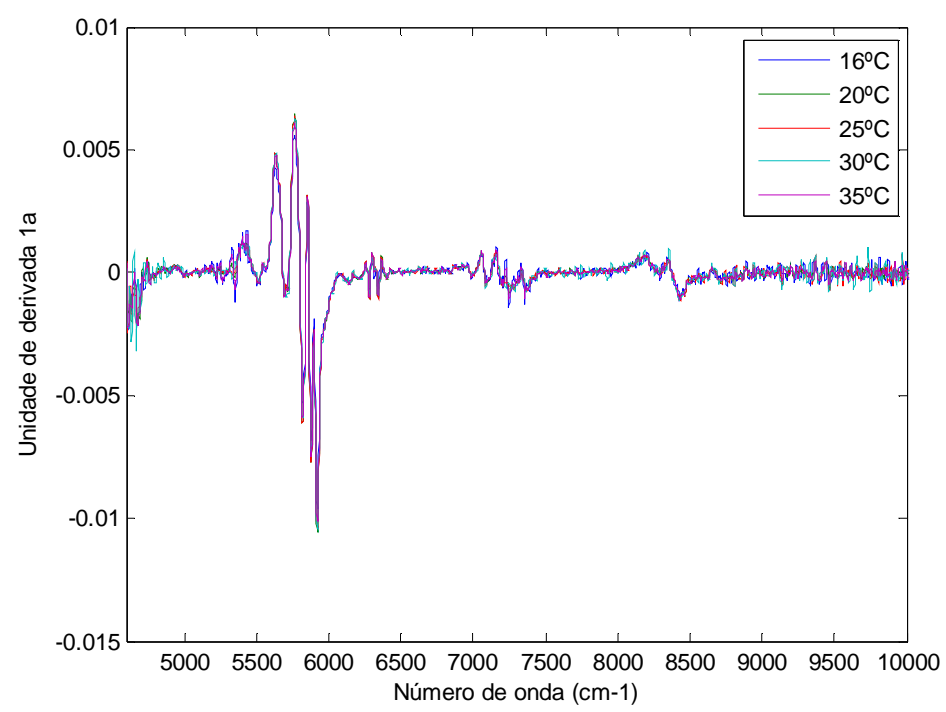

Figura 5.7 - 1a derivada dos espectros NIR a diferentes temperaturas (velocidade $=0,576$ $\mathrm{m} / \mathrm{s}$ ) de uma amostra de querosene no "loop"

Contudo, para avaliar o efeito da variação da temperatura o procedimento adotado é a análise dos espectros residuais, que consiste na subtração de todos os espectros entre si a diferentes temperaturas. Na figura 5.8 apresentam-se os espectros residuais representando várias das diferenças de temperaturas observadas no conjunto espectral. Observa-se que conforme maior a diferença de temperatura, regiões de instabilidade identificam-se, principalmente nas faixas $5000-5700 \mathrm{~cm}^{-1} \mathrm{e}$ $7000-7500 \mathrm{~cm}^{-1}$. Porém, a magnitude deste efeito é desprezível em relação à magnitude da absorbância dos espectros originais, podendo concluir que a faixa espectral selecionada para construir os modelos nas análises off-line (5600 - 6100 $\mathrm{cm}^{-1}$ ) não apresenta problemas de ocorrência de variação de temperatura, o que é uma grande vantagem na implementação da técnica em escala industrial. 


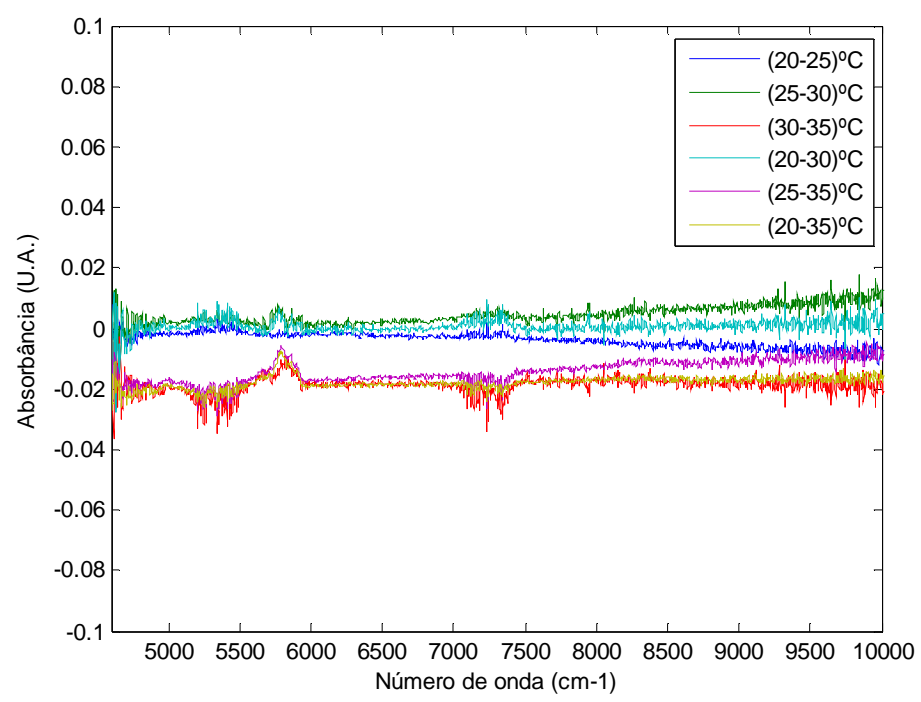

Figura 5.8 - Espectros residuais de temperatura em uma amostra de querosene no "loop"

\subsubsection{Efeito da variação da velocidade}

A variação da velocidade tem um efeito significativamente menor nos espectros NIR on-line. O procedimento foi o mesmo que no caso das temperaturas e os resultados apresentados nas figuras 5.9 a 5.11 .

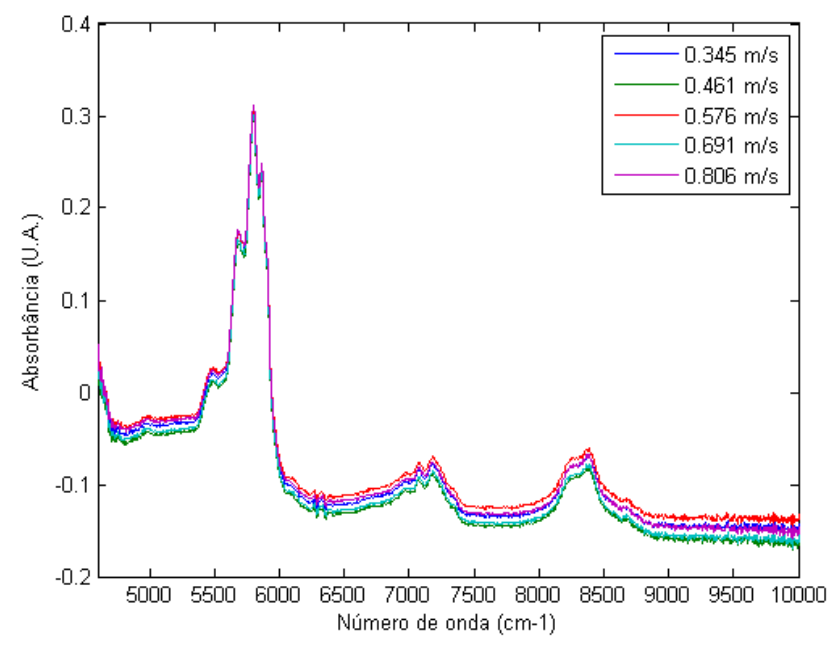

Figura 5.9 - Espectros NIR a diferentes velocidades (temperatura $=25^{\circ} \mathrm{C}$ ) de uma amostra de querosene no "loop" 


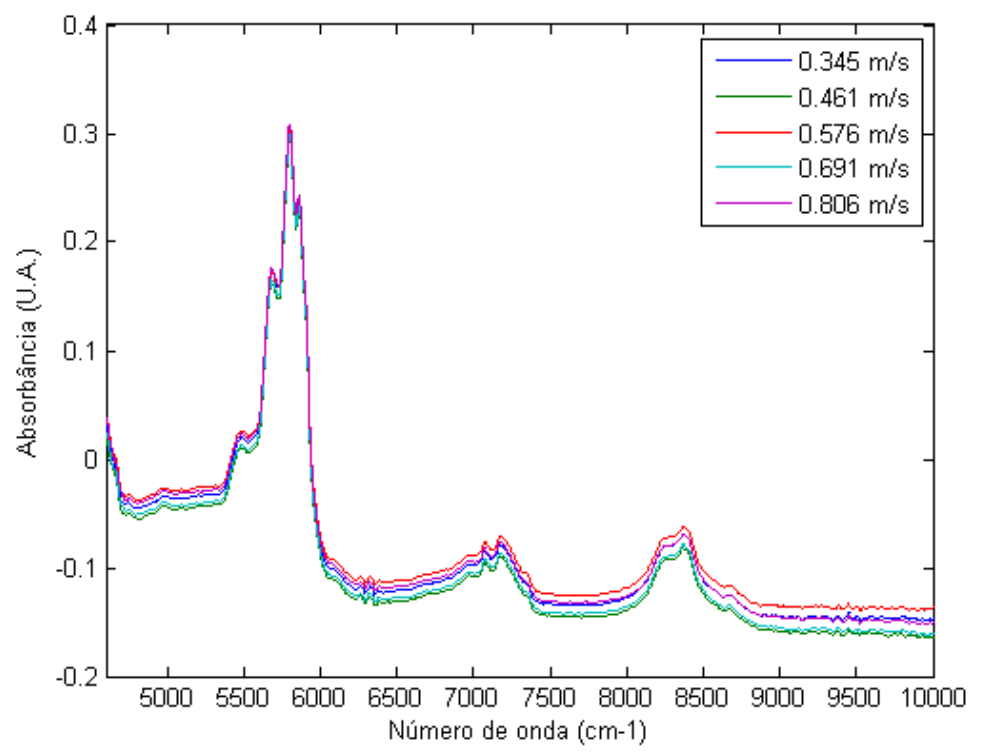

Figura 5.10 - Espectros NIR alisados a diferentes velocidades (temperatura $=25^{\circ} \mathrm{C}$ ) de uma amostra de querosene no "loop"

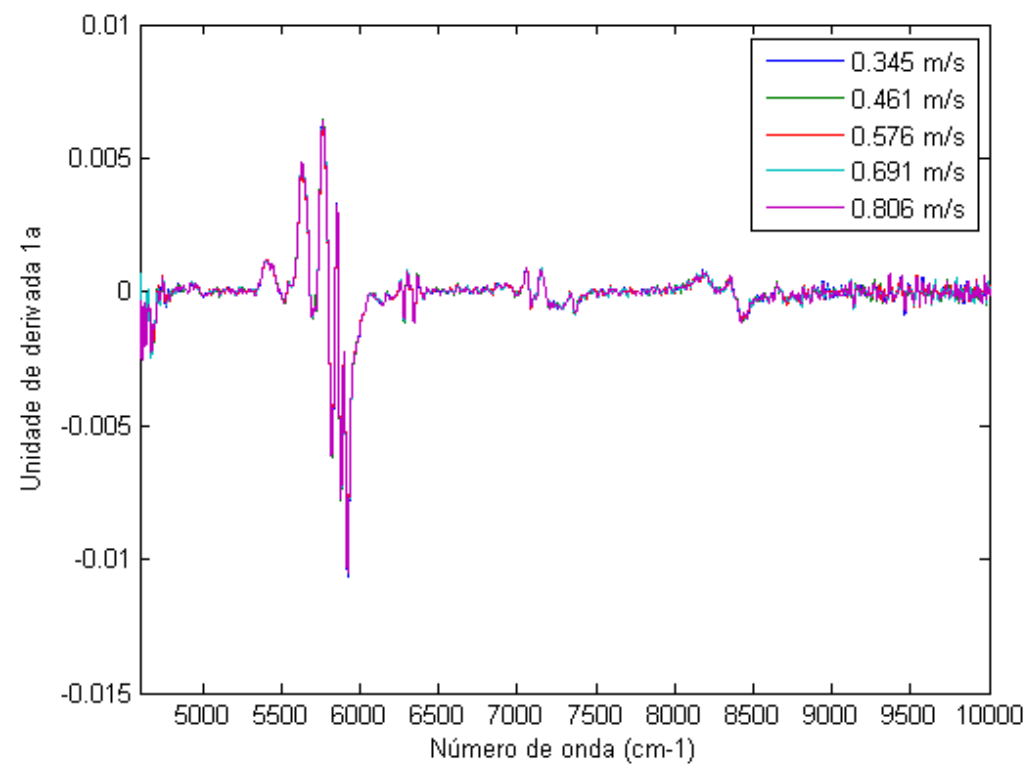

Figura $5.11-1^{\mathrm{a}}$ derivada dos espectros NIR alisados a diferentes velocidades (temperatura $=25^{\circ}$ C) de uma amostra de querosene no "loop"

O deslocamento de linha base é menor que o observado quando a temperatura varia e a primeira derivada dos espectros aponta a faixa $5600-6100 \mathrm{~cm}^{-1}$ como a mais significativa para a calibração dos modelos. Uma análise dos espectros residuais 
também foi realizada observando-se uma influência menor da variação da velocidade, sendo desprezível em termos práticos.

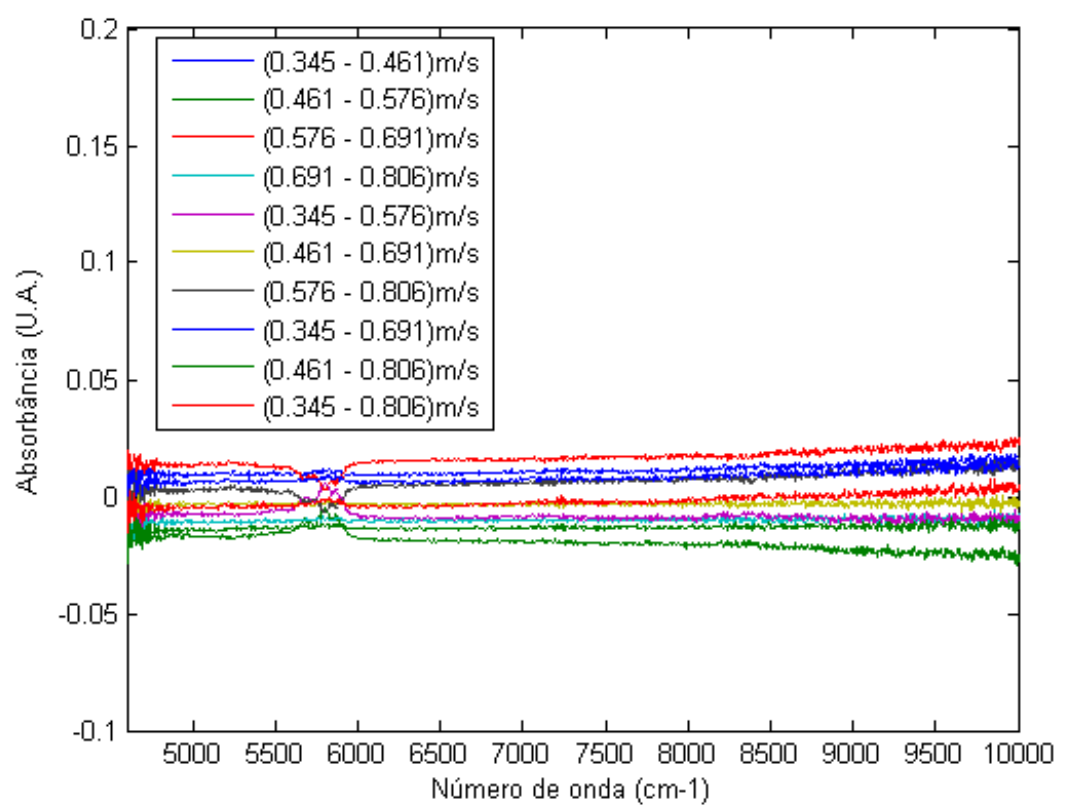

Figura 5.12 - Espectros residuais de velocidade em uma amostra de querosene no "loop"

\subsection{Resultados da Modelagem}

Foi utilizada a técnica de calibração linear PLS para as propriedades: densidade, ponto de congelamento, viscosidades a $-20^{\circ} \mathrm{C}$ e a $40^{\circ} \mathrm{C}$. Para as propriedades de enxofre total, ponto de fulgor e destilação a calibração por PLS não se mostrou adequada. Para essas propriedades foi utilizada a calibração por redes neurais.

Para o pré tratamento dos espectros utilizados no PLS executou-se um alisamento com uma janela de 25 pontos espectrais, derivada primeira por Savitzky-Golay com um polinômio de grau 3 seguido de centralização na média.

O número de variáveis latentes obtidos para modelagem utilizando o PLS foi função do menor RMSECV (raiz quadrada do erro médio utilizando validação cruzada) 
calculado utilizando todos os dados de calibração e excluindo-se um para a predição.

\subsubsection{Calibração para a propriedade de Densidade}

Conforme figura 5.13 foram escolhidas 5 variáveis latentes para o PLS que correspondem ao menor erro médio quadrático entre os valores medidos e os valores preditos

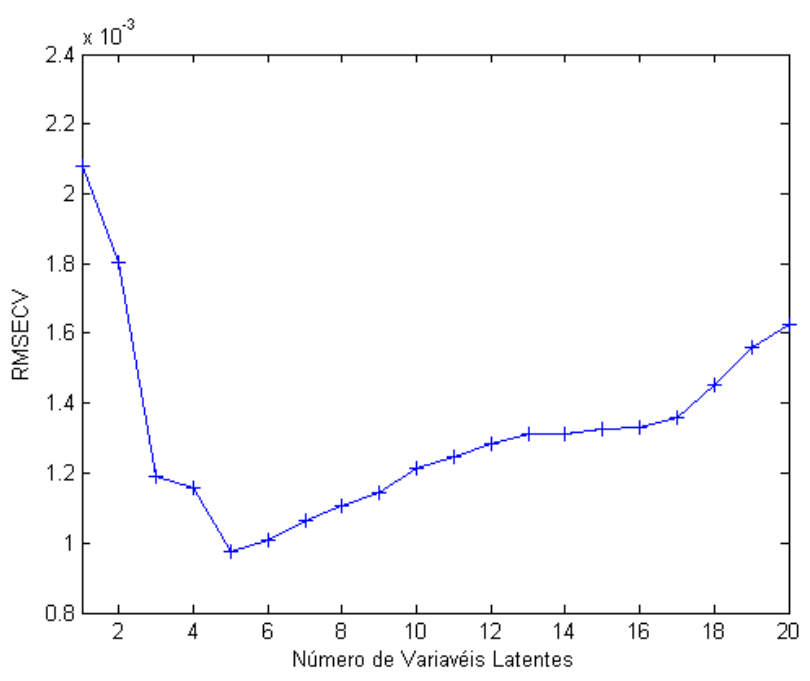

Figura 5.13 - RMSECV x Número de variáveis latentes para a densidade

Nos gráficos predito $\mathrm{x}$ medido a serem apresentados, os pontos com as barras de erro correspondem às quatro amostras de validação externa obtidas após a manutenção programada da unidade de destilação. As barras de erro correspondem à reprodutibilidade dos ensaios em laboratório (vide tabela de reprodutibilidade no apêndice B).

$\mathrm{Na}$ figura 5.14 são apresentados os resultados do modelo PLS de calibração e validação externa para a propriedade da densidade. A predição através do modelo (PLS) mostrou ser adequada, mostrando que os valores obtidos estão dentro da reprodutibilidade das medidas de laboratório. 


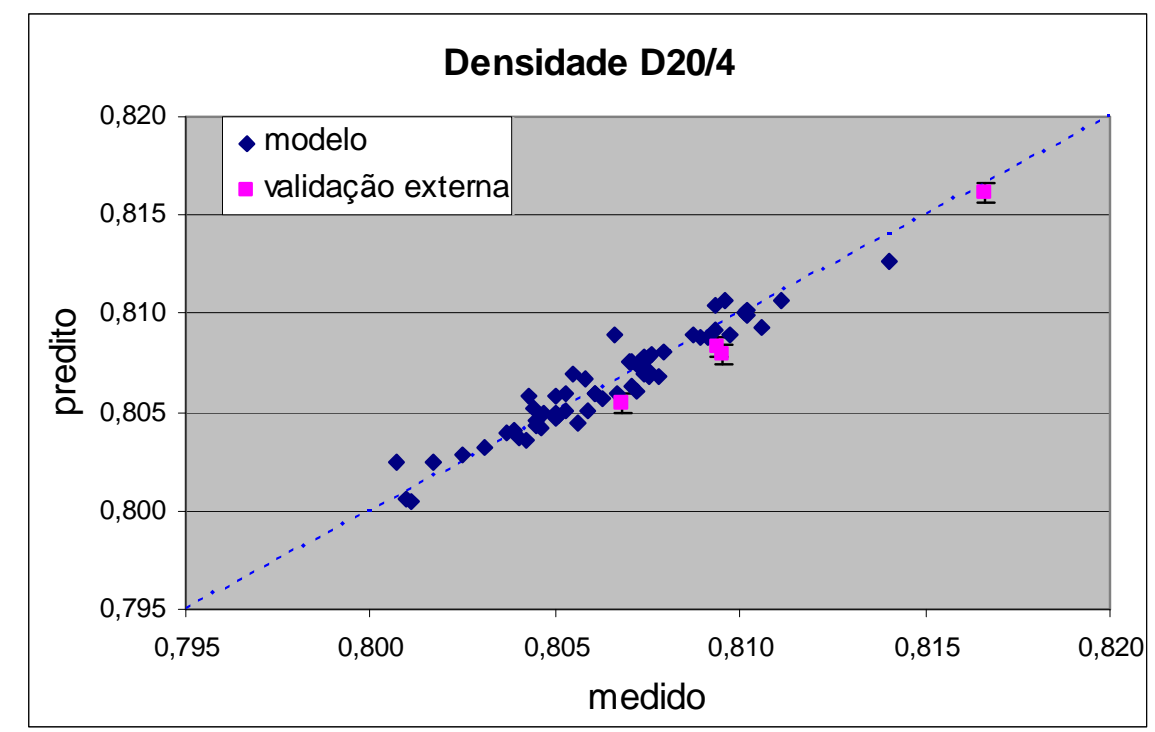

Figura 5.14 - Modelo de calibração da Densidade e validação externa com PLS

RMSE da calibração $=0,0007$

RMSEP da validação externa $=0,0012$

\subsubsection{Calibração para a propriedade de Ponto de Congelamento}

$\mathrm{Na}$ figura 5.15 é apresenta o RMSECV em função das variáveis latentes para a calibração do ponto de congelamento. Foram escolhidas 5 variáveis latentes em função do menor RMSECV. 


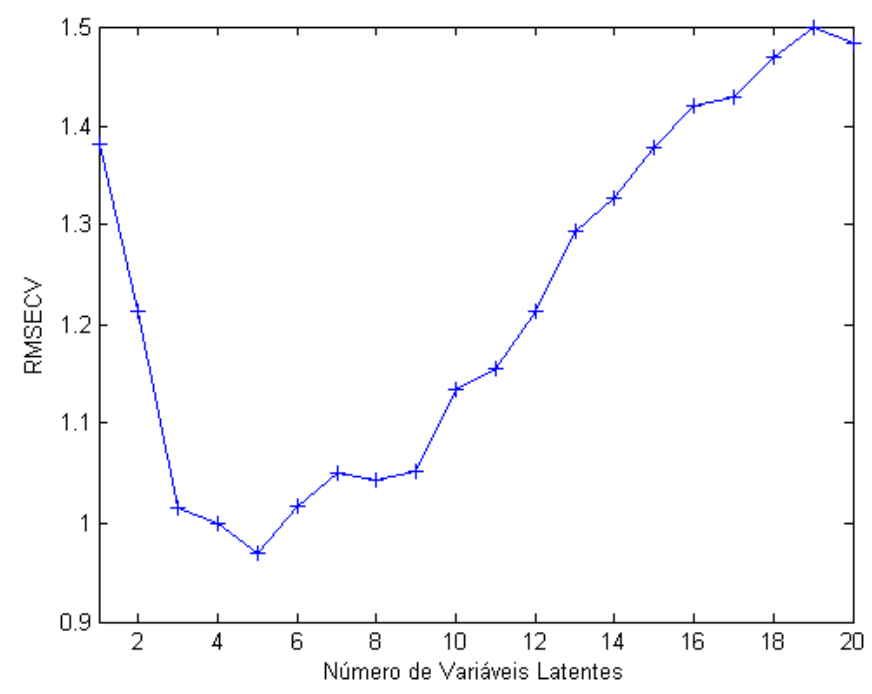

Figura 5.15 - RMSECV x Número de variáveis latentes para o Ponto de Congelamento

Na figura 5.16 são apresentados os resultados do modelo de calibração e validação externa para a propriedade do ponto de congelamento. A predição através do modelo (PLS) mostrou ser adequada, mostrando que os valores obtidos estão dentro da reprodutibilidade das medidas de laboratório. A calibração mostrou ser adequada, uma vez que a especificação estabelece valor máximo de $-47^{\circ} \mathrm{C}$ (portanto a predição do modelo é conservativa com respeito à especificação).

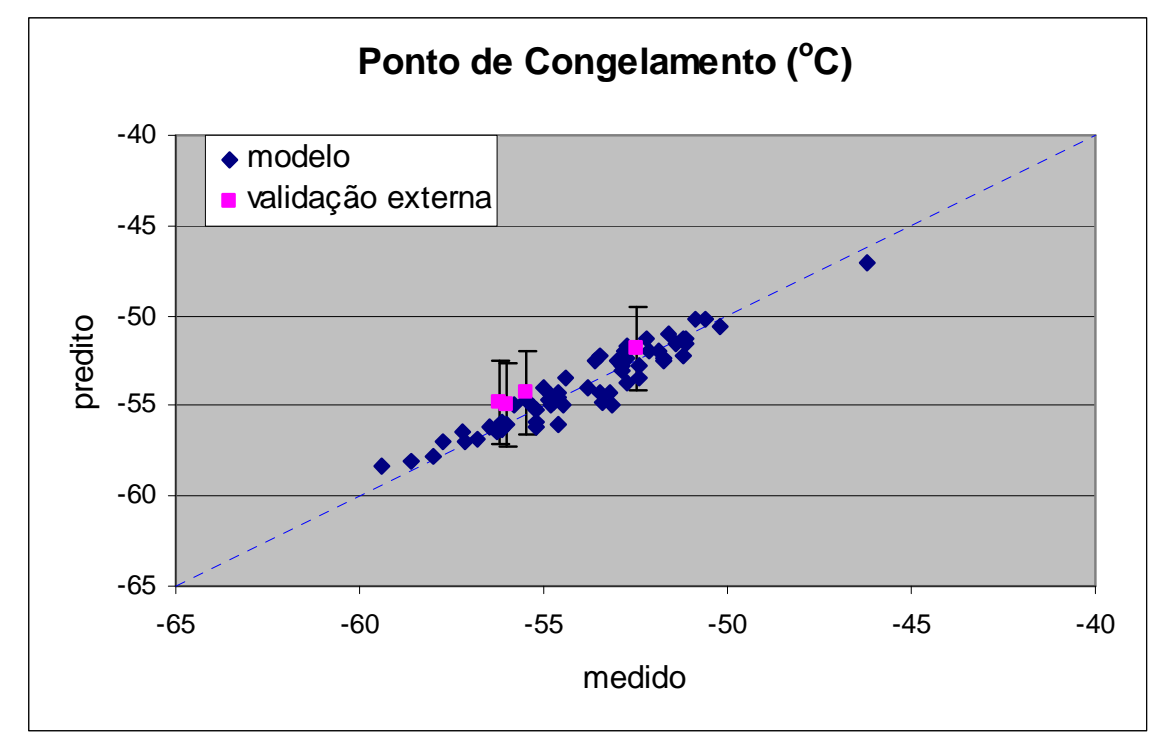

Figura 5.16 - Modelo de calibração do Ponto de Congelamento e validação externa 
RMSE da calibração $=1,13^{\circ} \mathrm{C}$

RMSEP da validação externa $=0,71^{\circ} \mathrm{C}$

\subsubsection{Calibração para a propriedade da viscosidade a $-20^{\circ} \mathrm{C}$}

Na figura 5.17 é apresenta o RMSECV em função das variáveis latentes para a calibração da propriedade viscosidade a $-20{ }^{\circ} \mathrm{C}$. Foram escolhidas 5 variáveis latentes em função do menor RMSECV

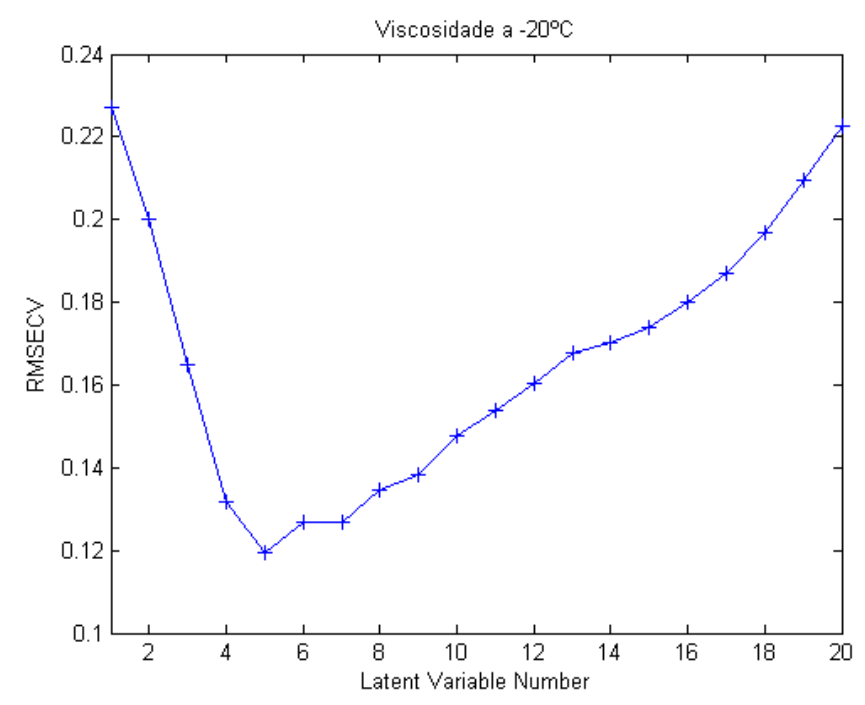

Figura 5.17 - RMSECV x Número de variáveis latentes para a viscosidade a $-20^{\circ} \mathrm{C}$

$\mathrm{Na}$ figura 5.18 são apresentados os resultados do modelo de calibração e validação externa para a propriedade: viscosidade a $-20^{\circ} \mathrm{C}$. A predição através do modelo (PLS) mostrou ser adequada, mostrando que os valores obtidos na sua maioria estão dentro da reprodutibilidade das medidas de laboratório. Levando em conta o valor da especificação do produto (menor que $8 \mathrm{cSt}$ ) a predição pelo modelo é conservativa. 


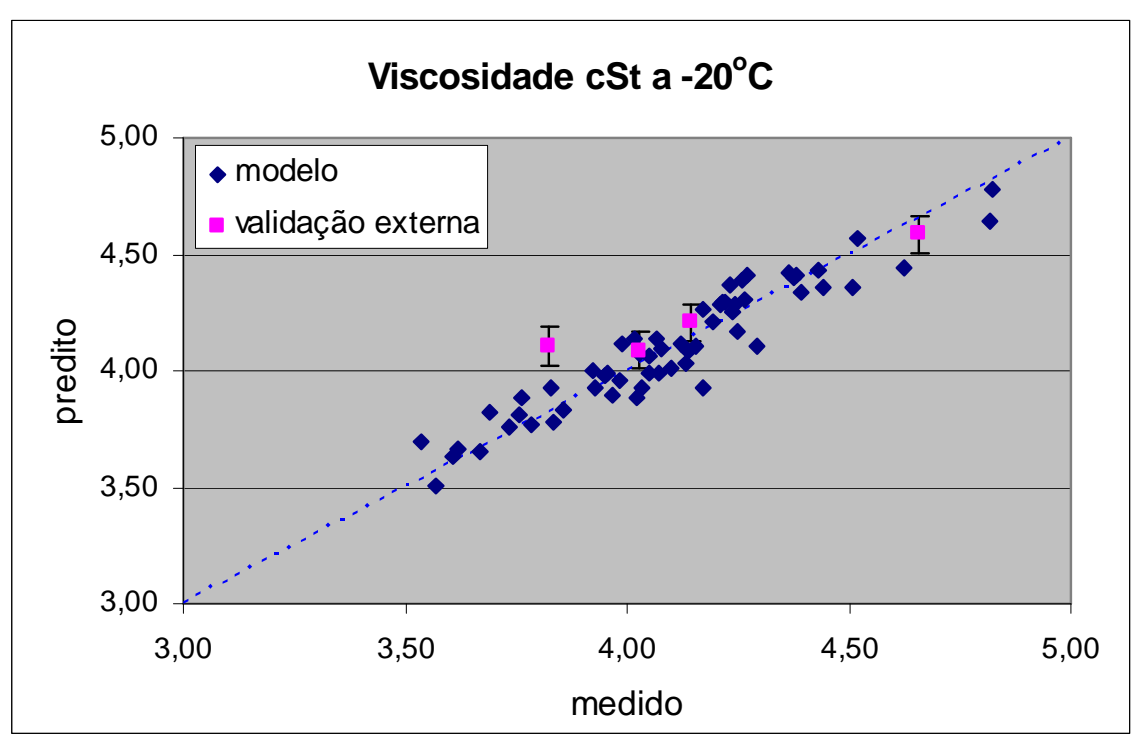

Figura 5.18 - Modelo de calibração da Viscosidade a $-20^{\circ} \mathrm{C}$ e validação externa

RMSE da calibração $=0,0908$ cSt

RMSEP da validação externa $=0,1523 \mathrm{cSt}$

\subsubsection{Calibração para a propriedade da viscosidade a $40^{\circ} \mathrm{C}$}

Na figura 5.19 é apresenta o RMSECV em função das variáveis latentes para a calibração da propriedade viscosidade a $40{ }^{\circ} \mathrm{C}$. Foram escolhidas 5 variáveis latentes em função do menor RMSECV

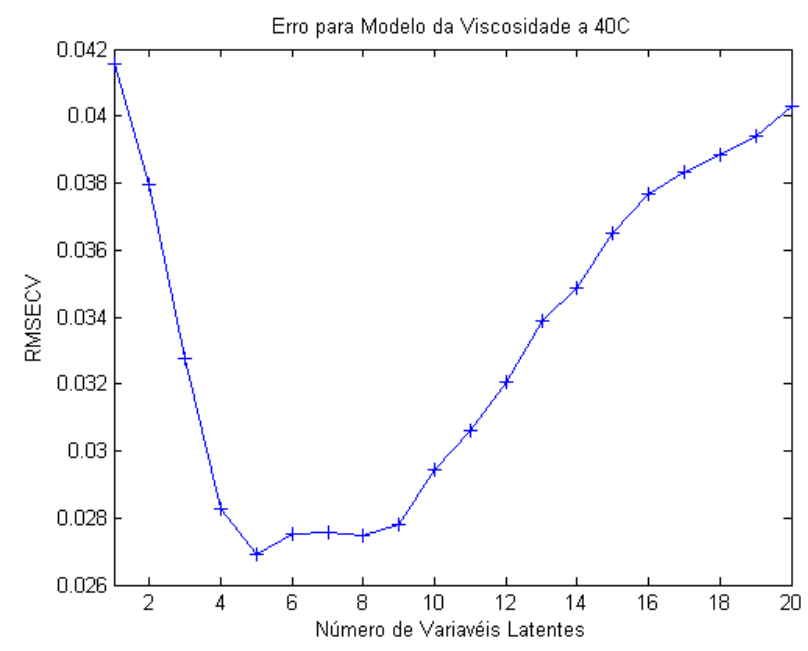

Figura 5.19 - RMSECV x Número de variáveis latentes para a viscosidade a $40^{\circ} \mathrm{C}$ 
Na figura 5.20 são apresentados os resultados do modelo de calibração e validação externa para a propriedade: viscosidade a $40^{\circ} \mathrm{C}$.

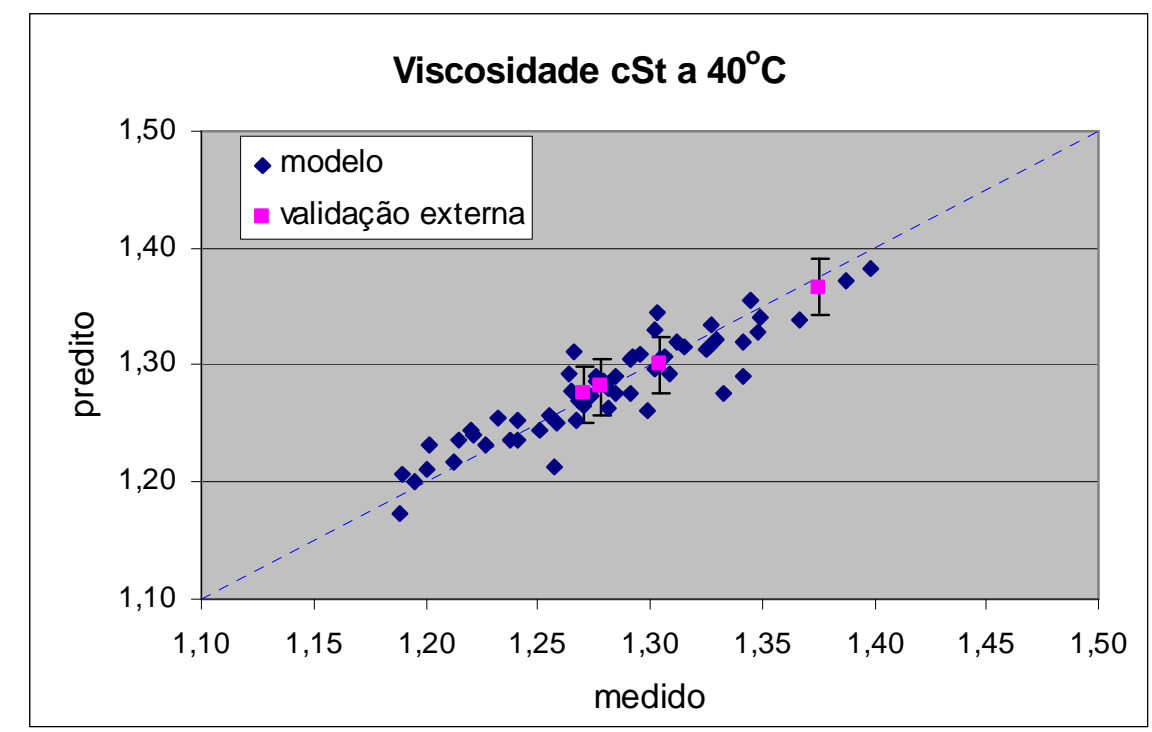

Figura 5.20 - Modelo de calibração da Viscosidade a $40^{\circ} \mathrm{C}$ e validação externa

RMSE da calibração $=0,0200$ cSt

RMSEP da validação externa $=0,0052 \mathrm{cSt}$

A predição através do modelo (PLS) mostrou ser adequada, mostrando que os valores obtidos estão dentro da reprodutibilidade das medidas de laboratório. Esta propriedade não é utilizada na especificação do produto, mas é um parâmetro importante nos dados em simuladores de processo.

Modelagem utilizando redes neurais

Para a modelagem da curva de destilação, das propriedades de enxofre total e ponto de fulgor utilizou-se modelos de redes neurais. Foi gerada uma rede neural para cada ponto da curva de destilação (temperaturas nos pontos: inicial e final da destilação (PIE e PFE) e nos pontos de 5\%, 10\%, 20\%, 30\%, 40\%, 50\%, 60\%, 70\%, $80 \%$ e $90 \%$ em volume da destilação). O conjunto de dados foi dividido inicialmente em dois grupos, um conjunto para aprendizado e outro para teste, e posteriormente 
foram coletados dados em campanha após a parada programada da refinaria na qual foi formado o conjunto de validação externa. Foi utilizado o software neuro14 (Nascimento e Guardani, 1998). Foram utilizados pontos espectrais na faixa de 5600 a $6100 \mathrm{~cm}^{-1}$ igualmente espaçados em $20 \mathrm{~cm}^{-1}$ (27 informações do espectro). Para 0 pré tratamento dos espectros utilizados nas redes neurais, executou-se um alisamento e derivada primeira por Savitzky-Golay com um polinômio de grau 3 e uma janela de 5 pontos . Em seguida, fez-se a centralização na amostra Q63.

A seguir apresenta-se uma tabela contendo o número de neurônios na camada oculta, número de apresentações, RMSE da calibração, RMSE do teste e RMSEP da validação externa para a cada uma das propriedades e temperaturas da curva de destilação. O número de neurônios na camada oculta e o número de apresentações foram determinados baseando-se na minimização do somatório dos erros quadráticos de previsão do conjunto de teste utilizando os pesos do conjunto de calibração.

Tabela 5.1 Tabela: dados da rede neural

\begin{tabular}{|c|c|c|c|c|c|}
\hline & $\begin{array}{l}\text { Número de } \\
\text { neurônios } \\
\text { na camada } \\
\text { oculta }\end{array}$ & $\begin{array}{l}\text { Número de } \\
\text { apresentações }\end{array}$ & $\begin{array}{l}\text { RMSE do } \\
\text { conjunto de } \\
\text { calibração }\end{array}$ & $\begin{array}{l}\text { RMSE do } \\
\text { conjunto de } \\
\text { teste }\end{array}$ & $\begin{array}{l}\text { RMSEP do } \\
\text { conjunto de } \\
\text { validação } \\
\text { externa }\end{array}$ \\
\hline PIE & 4 & 900 & 2,01 & 4,59 & 6,15 \\
\hline $5 \%$ & 3 & 600 & 2,19 & 3,06 & 4,73 \\
\hline $10 \%$ & 3 & 800 & 2,20 & 3,91 & 3,73 \\
\hline $20 \%$ & 8 & 850 & 1,28 & 3,45 & 3,84 \\
\hline $30 \%$ & 8 & 1000 & 1,37 & 3,38 & 3,95 \\
\hline $40 \%$ & 10 & 700 & 2,63 & 3,24 & 3,63 \\
\hline $50 \%$ & 10 & 850 & 1,23 & 2,64 & 3,84 \\
\hline $60 \%$ & 10 & 900 & 1,54 & 3,14 & 2,90 \\
\hline $70 \%$ & 10 & 700 & 1,25 & 3,30 & 1,79 \\
\hline $80 \%$ & 12 & 700 & 1,51 & 2,63 & 2,18 \\
\hline $90 \%$ & 4 & 1100 & 1,67 & 4,85 & 2,13 \\
\hline PFE & 4 & 1100 & 1,02 & 1,82 & 5,45 \\
\hline Enxofre Total & 4 & 600 & 0,0082 & 0,0096 & 0,0272 \\
\hline Ponto de & 5 & 800 & 0,77 & 0,94 & 1,91 \\
\hline Fulgor & & & & & \\
\hline
\end{tabular}




\subsubsection{Calibração para a propriedade: Pontos da Destilação}

As temperaturas da curva de destilação experimentais e preditas pelos modelos de redes neurais são mostradas nas figuras de 5.21 a 5.32 dos pontos inicial e final da destilação (PIE e PFE) e das temperaturas dos pontos $5 \%, 10 \%, 20 \%, 30 \%, 40 \%$, $60 \%, 70 \%, 80 \%, 90 \%$ em volume de destilado recuperado.

O ajuste dos modelos de redes neurais apresentou um ajuste razoável para o conjunto de aprendizado e de teste. No caso dos dados experimentais do conjunto de validação externa (aqueles obtidos posteriormente ao conjunto de dados de aprendizado e teste e após a parada programada de manutenção da unidade de destilação) uma parte dos dados não mostrou muita aderência ao modelo. Uma das curvas de destilação está apresentando um desvio sistemático em quase toda a sua extensão. De maneira que é uma medida em que se pode considerar suspeita. As outras medidas foram adequadamente preditas. Deve-se ressaltar que em alguns pontos houve desvios significativos. Na previsão de PIE os dados de validação externa têm desvios apreciáveis, mas observando-se a figura 5.21 pode-se ver que estes pontos estão em uma região com poucas informações no conjunto de dados de aprendizado (inclusive uma das informações está fora do domínio do conjunto de aprendizado). Este mesmo problema ocorre na predição do PFE (figura 5.32). Um dos dados está fora do domínio do conjunto de aprendizado. Só lembrando que os modelos de redes neurais empregados não permitem a extrapolação de resultados fora do domínio dos dados do conjunto de aprendizado.

Com relação às propriedades que dão a especificação do produto no caso do querosene de aviação, as temperaturas de destilação importantes são o ponto final de destilação (PFE) e a temperatura após a recuperação de $10 \%$ em volume da destilação (10\% recuperados). As previsões nesses pontos foram adequadas.

A melhoria das previsões pode ser obtida, provavelmente, com um maior número de dados e o aumento do domínio do conjunto de aprendizado. Estas informações foram obtidas no processo industrial. Isto dificulta a obtenção de dados fora dos limites operacionais. 


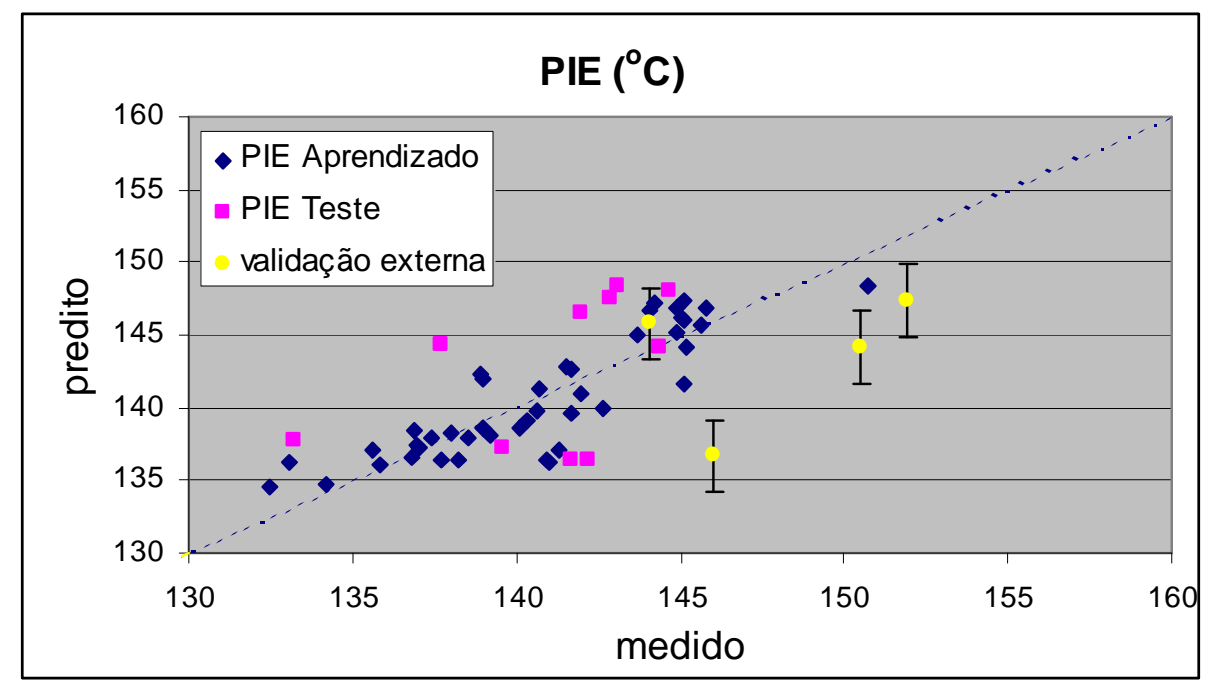

Figura 5.21 - Modelo de calibração do PIE e validação externa

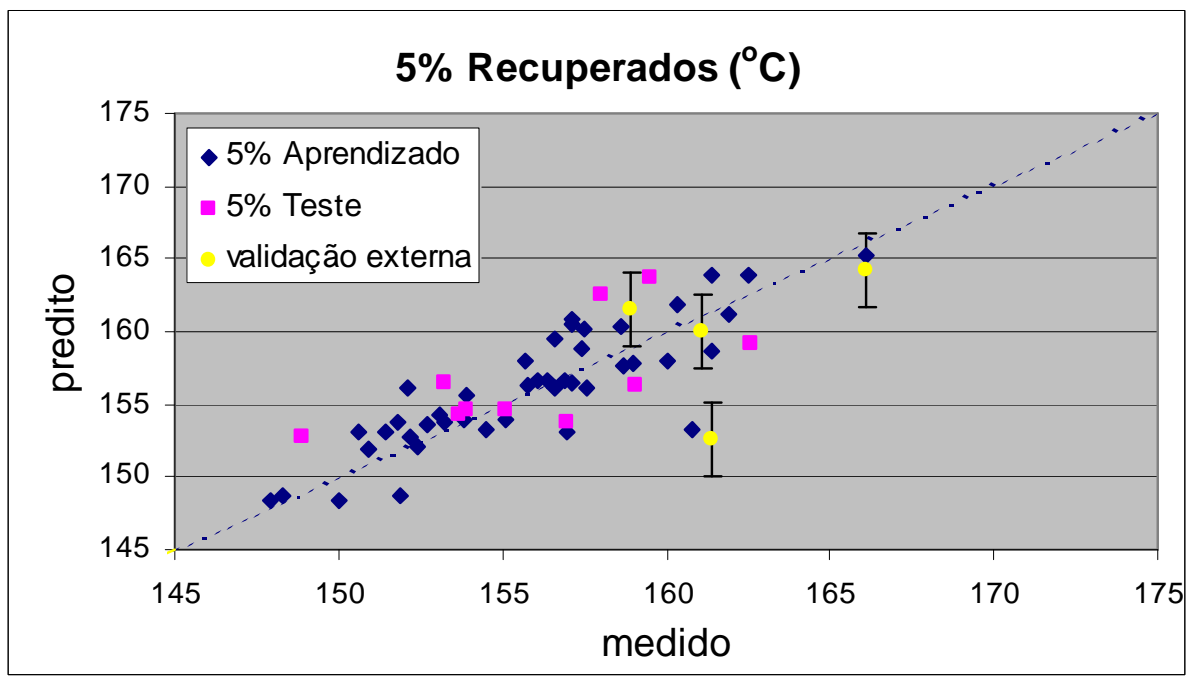

Figura 5.22 - Modelo de calibração dos $5 \%$ evaporados e validação externa 


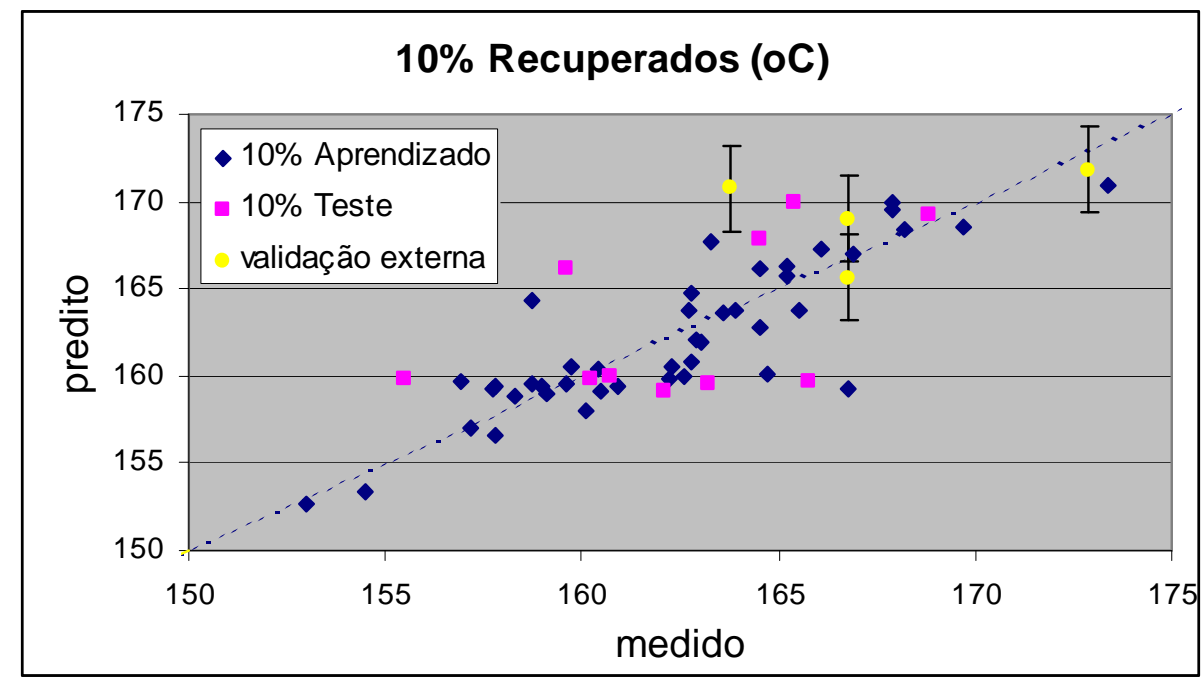

Figura 5.23 - Modelo de calibração dos $10 \%$ evaporados e validação externa

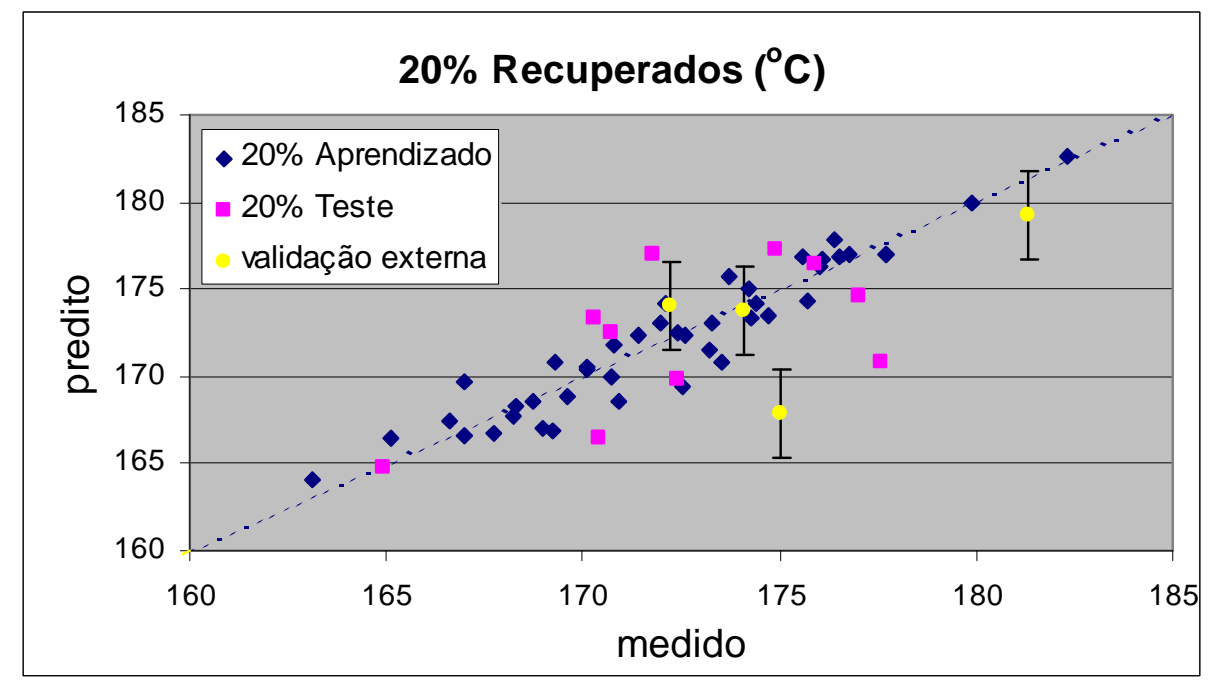

Figura 5.24 - Modelo de calibração dos $20 \%$ evaporados e validação externa 


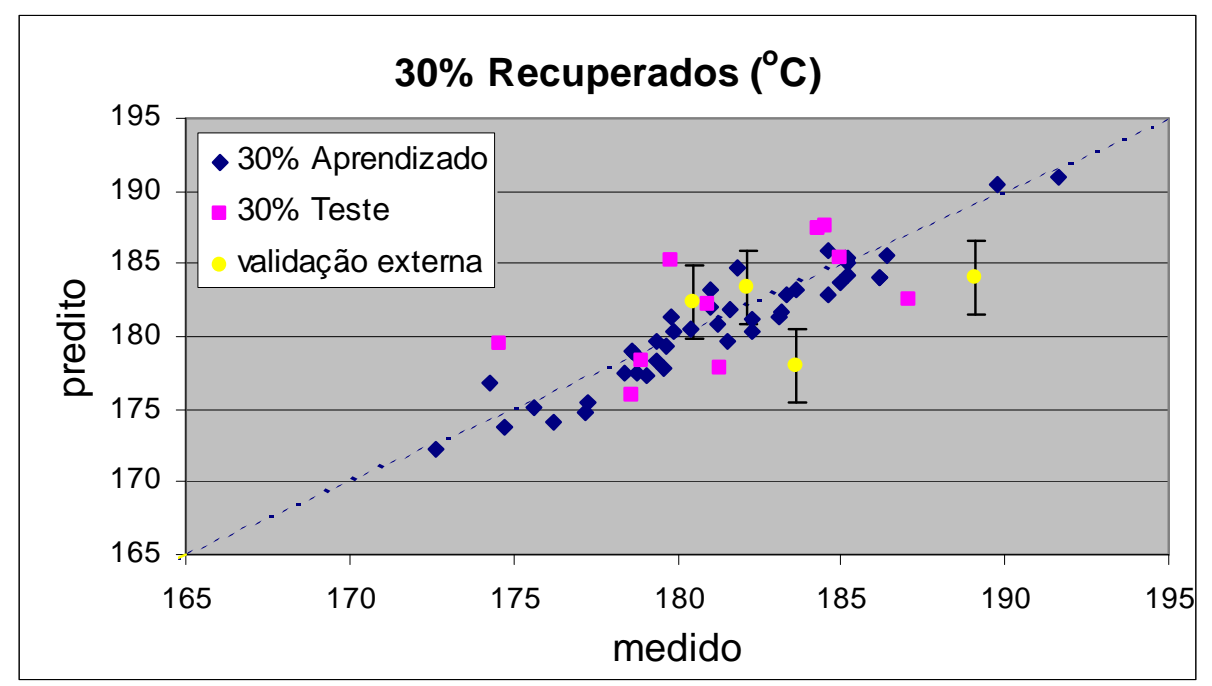

Figura 5.25 - Modelo de calibração dos $30 \%$ evaporados e validação externa

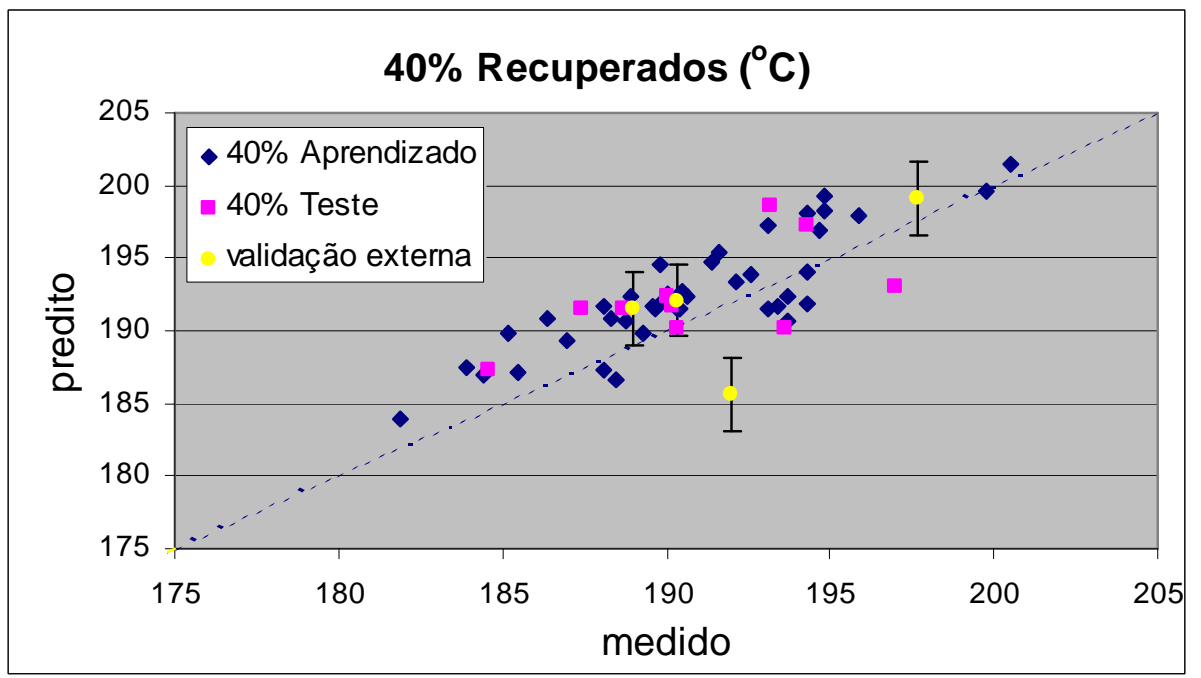

Figura 5.26 - Modelo de calibração dos $40 \%$ evaporados e validação externa 


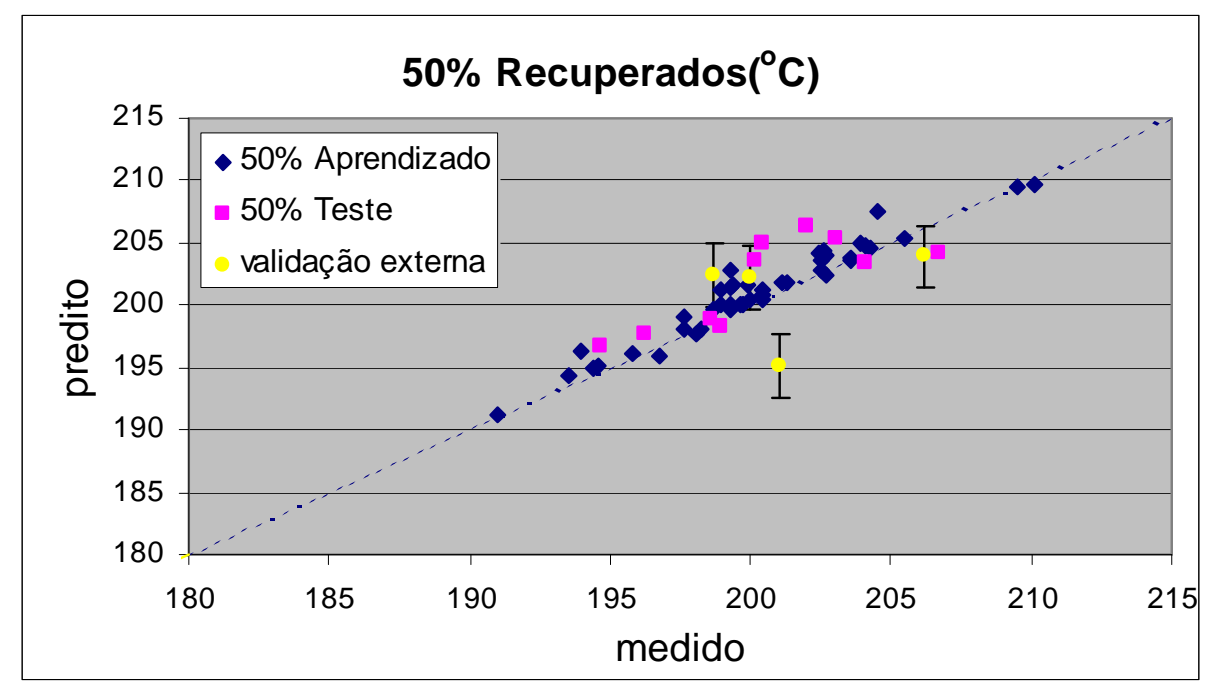

Figura 5.27 - Modelo de calibração dos $50 \%$ evaporados e validação externa

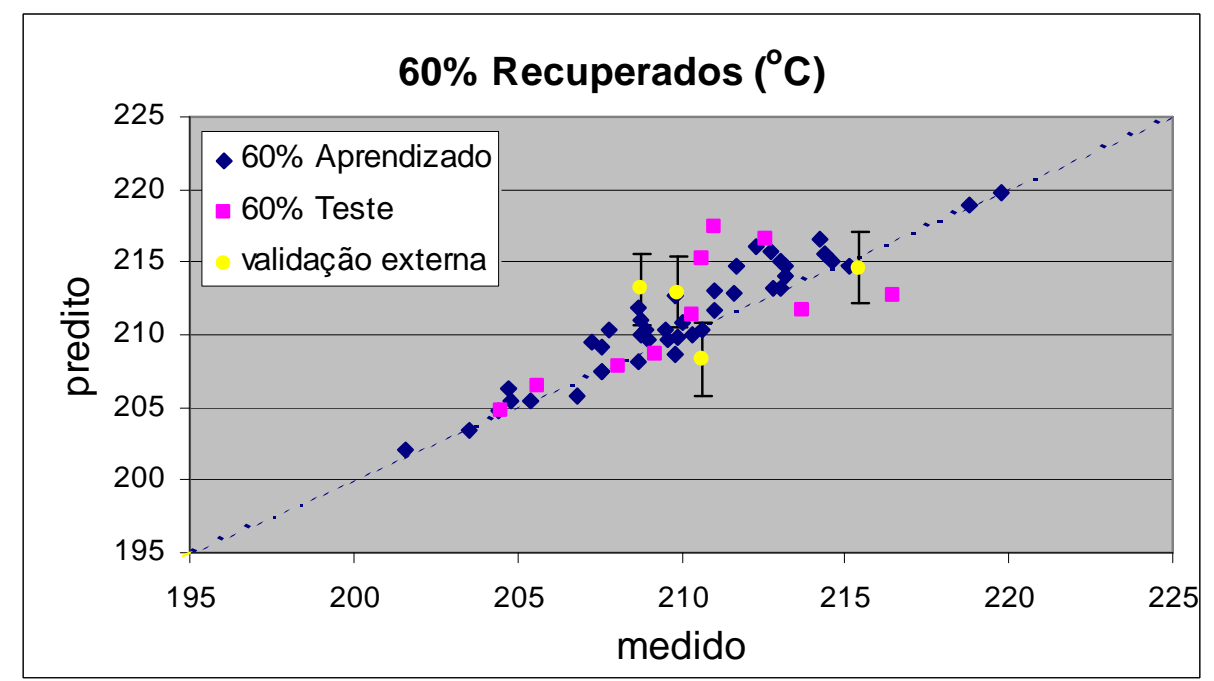

Figura 5.28 - Modelo de calibração dos $60 \%$ evaporados e validação externa 


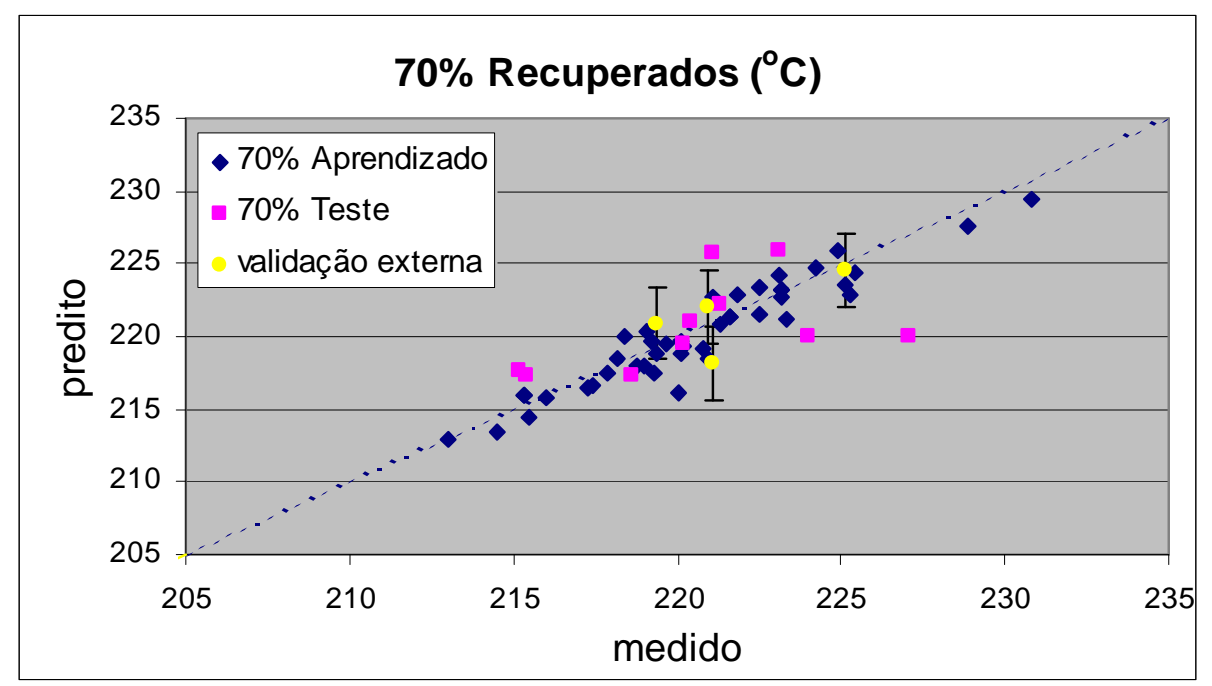

Figura 5.29 - Modelo de calibração dos $70 \%$ evaporados e validação externa

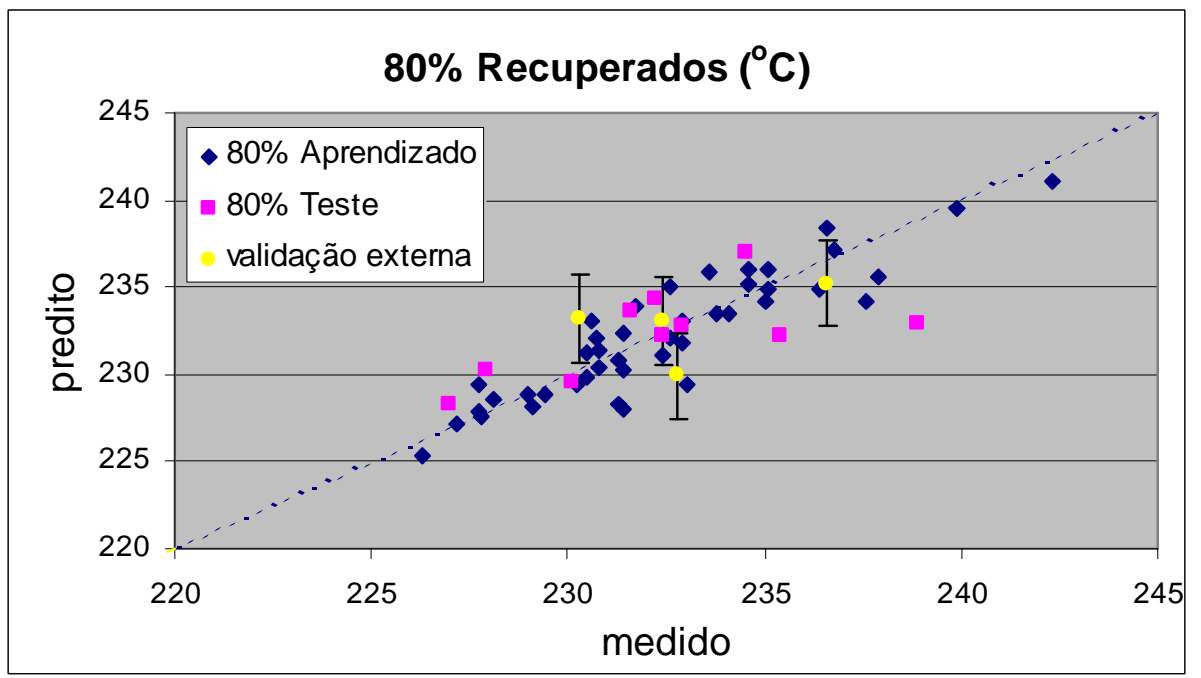

Figura 5.30 - Modelo de calibração dos $80 \%$ evaporados e validação externa 


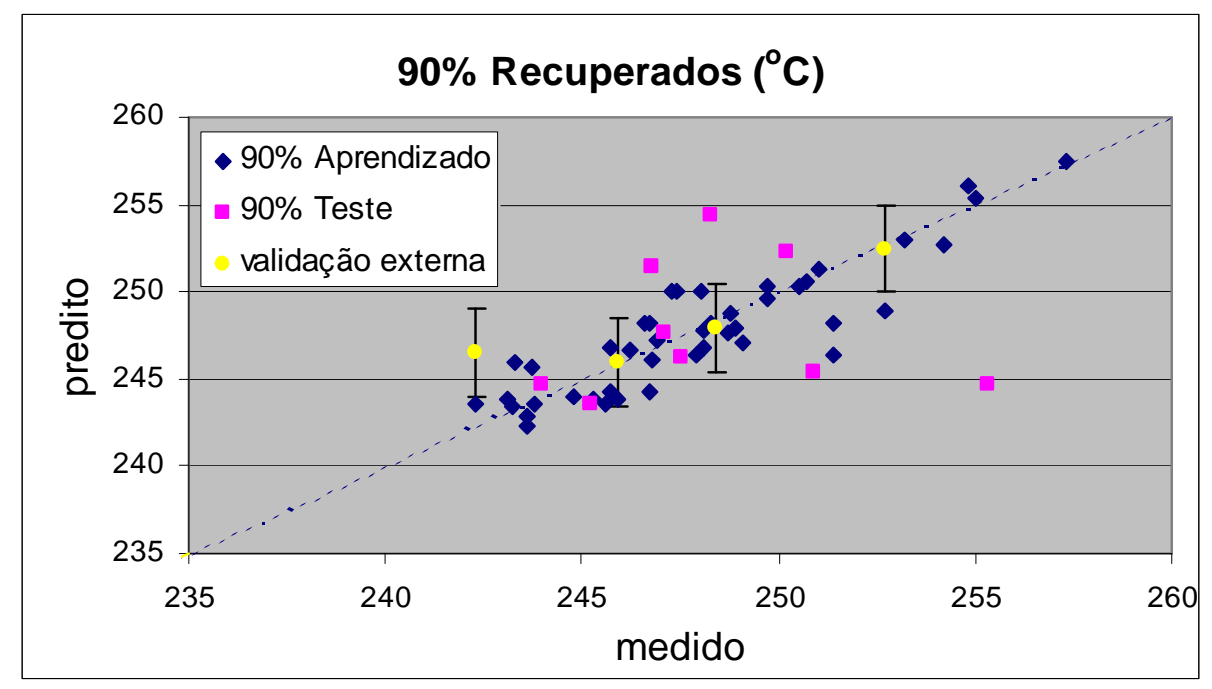

Figura 5.31 - Modelo de calibração dos $90 \%$ evaporados e validação externa

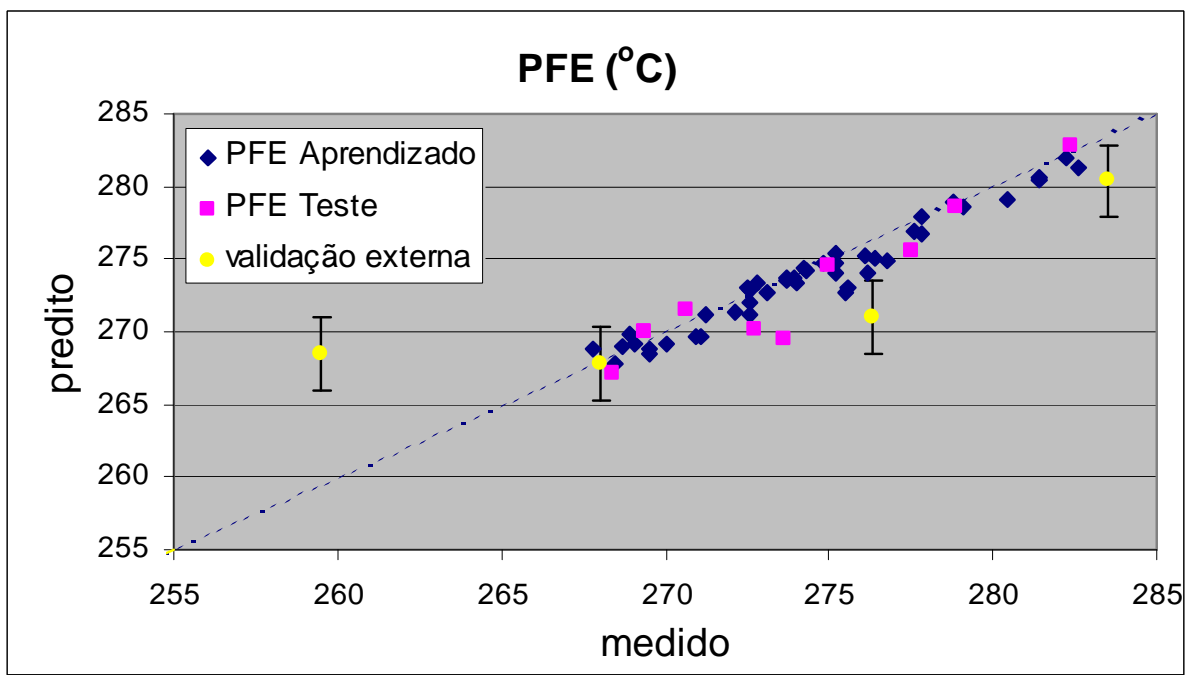

Figura 5.32 - Modelo de calibração PFE e validação externa

\subsubsection{Calibração para a propriedade Enxofre Total}

Para a modelagem do enxofre total foram utilizados 16 pontos espectrais na faixa de 5049 a $5078 \mathrm{~cm}^{-1}$ igualmente espaçados em $4 \mathrm{~cm}^{-1}$. Essa é a faixa de detecção das ligações S-H e P-SH (Workman and Weyer, 2008). 
A figura 5.33 apresenta o resultado da modelagem da propriedade enxofre total. $\mathrm{O}$ conjunto de dados de validação externa apresentou em um dos experimentos desvio substancial, bem maior que a reprodutibilidade dos dados de laboratório. De qualquer maneira o valor do enxofre determinado na saída da unidade de destilação não necessita atender a especificação de QAV-1, é apenas um parâmetro para a unidade de hidrotratamento onde o mesmo será removido.

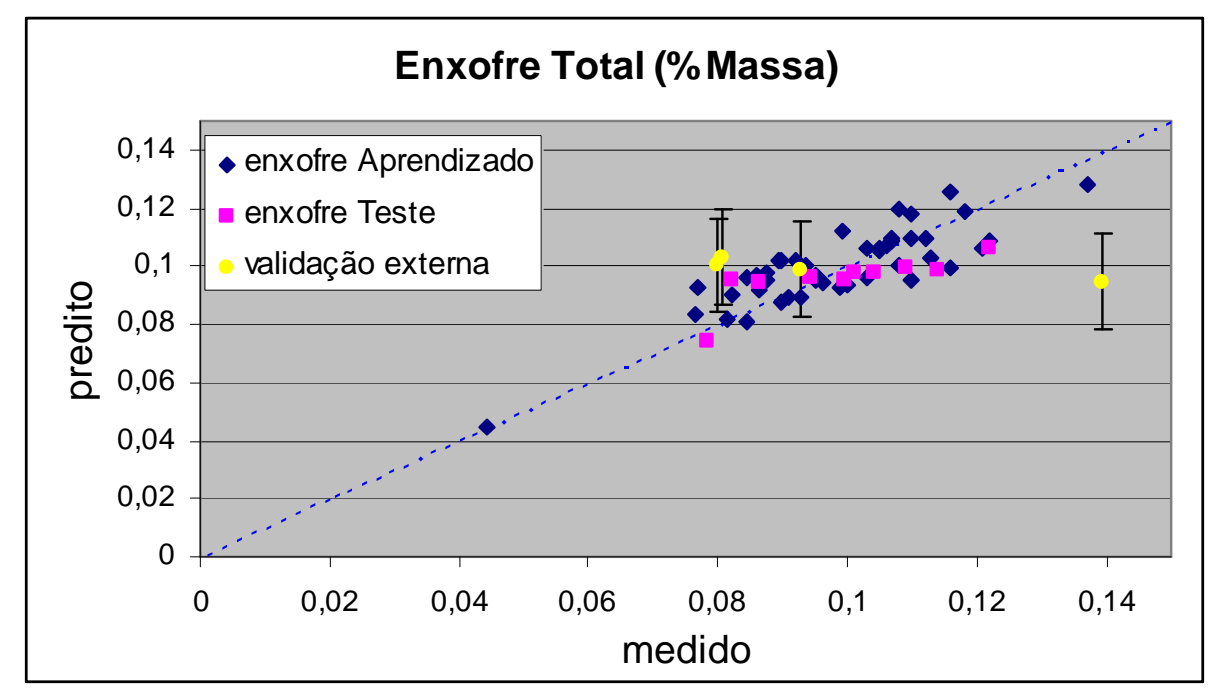

Figura 5.33 - Modelo de calibração da propriedade $S$ total e validação externa

\subsubsection{Calibração para a propriedade do Ponto de Fulgor}

A figura 5.34 mostra os dados de previsão do modelo para a propriedade ponto de fulgor.

O conjunto de validação externa mostrou um pequeno desvio sistemático dos dados, mas quase dentro do erro de reprodutibilidade. Os resultados, no entanto mostraram adequados, pois mesmo com este erro (que pode eventualmente ser corrigido através de uma constante) satisfazem a especificação do produto (min $40^{\circ} \mathrm{C}$ ). $\mathrm{O}$ ponto de fulgor ainda pode ser corrigido na retificadora da unidade de hidrotratamento. 


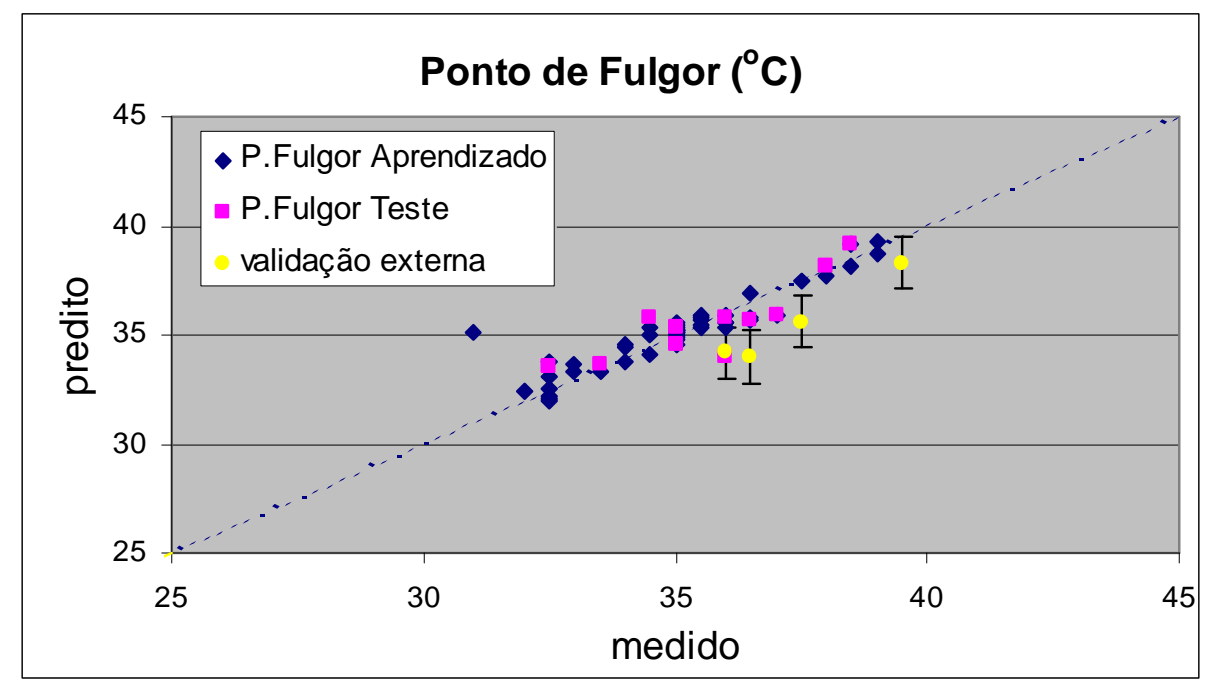

Figura 5.34 - Modelo de calibração do Ponto de Fulgor e validação externa

\subsection{Modelos obtidos a partir das condições operacionais}

Baseando-se na experiência foram selecionadas variáveis operacionais que podem influenciar a produção do querosene; sendo listadas na tabela 4.1. Uma variável que influencia no ponto de fulgor é a vazão de vapor de retificação do querosene. Durante o período estudado, essa vazão esteve em valor zero devido a torre atmosférica estar com problemas internos. Variáveis correlacionadas são desnecessárias, pois não agregam informação e podem ser fonte de problemas se um dos instrumentos de medição apresentar problemas. Para a exclusão, foram verificadas as que apresentavam fator de correlação acima de 0,70.

A tabela 5.2 apresenta os fatores de correlação entre todas as variáveis. Observa-se que a variável TI22125AO e a TC 21011PV estão fortemente correlacionadas. Neste caso escolheu-se suprimir a variável TI22125AO. 
Tabela 5.2 Fator de correlação das variáveis operacionais

\begin{tabular}{|c|c|c|c|c|c|c|c|c|c|c|}
\hline & DD & & & & & FC 21631PV & & & TC 2 & \\
\hline FC 21004PV & 1 & 0,32326 & 0,26291 & 0,19773 & 0,10827 & $-0,08635$ & $-0,54728$ & 0,17801 & $-0,15078$ & 879 \\
\hline C 21037PV & 0,32326 & 1 & 60995 & 0,12732 & -0 & 667 & $-0,54781$ & 5625 & 0064 & 231 \\
\hline C 21039PV & 0,26291 & 95 & 1 & 0,20139 & $-0,26468$ & 0,23225 & $-0,56189$ & 21049 & 3257 & 346 \\
\hline C 21041PV & 773 & 732 & 139 & 1 & 0 , & 434 & 32 & 44 & 318 & 74 \\
\hline $3 P V$ & 827 & $-0,1671$ & $-0,26468$ & 06 & 1 & 057 & 3641 & 7982 & 798 & 159 \\
\hline C 21631PV & $-0,0$ & 67 & 225 & 34 & $-0,6$ & 1 & 704 & 93 & 65 & \\
\hline PV & 728 & $-0,5$ & $-0,56189$ & $-0,2$ & 0,2 & 704 & 1 & 02 & 66 & 39 \\
\hline 009PV & 01 & 625 & 0,2 & 44 & -0, & 93 & 02 & 1 & 118 & 746 \\
\hline OPV & $-0,1$ & 0,10064 & $-0,18257$ & 0 & $-0,3$ & 0,165 & $-0,10066$ & 3118 & 1 & 169 \\
\hline PV & $-0,0$ & 0,0 & $-0,1$ & -0, & -0 & 0,0 & 039 & 746 & & 1 \\
\hline $26 \mathrm{PV}$ & -0, & $-0,00824$ & $-0,2085$ & & & 245 & 6227 & 812 & 073 & 371 \\
\hline I 21048AO & 67 & $-0,3$ & $-0,21418$ & 21 & 0 & 12 & 773 & 005 & 499 & 112 \\
\hline I 21133AO & 0,02446 & $-0,24472$ & $-0,02811$ & & 0,2 & $-0,0$ & 0856 & 768 & 452 & 743 \\
\hline $\mathrm{I} 21141 \mathrm{AO}$ & 013 & 0,43462 & 0,58009 & 77 & $-0,6$ & 41 & 45 & 09 & 003 & 837 \\
\hline I 21152AO & $-0,04234$ & 0,43285 & 0,37438 & 0 & $-0,40$ & 0,48911 & $-0,40712$ & 0,52866 & 0,38854 & 0,10833 \\
\hline I21125AO & 864 & 0,06207 & $-0,09549$ & $-0,07244$ & -0 , & 0,07182 & $-0,12955$ & $-0,01594$ & 0,27343 & 0,99566 \\
\hline C 21004PV & 0,21891 & $-0,19296$ & $-0,14306$ & $-0,06596$ & 0,42 & $-0,19335$ & 0,12766 & $-0,14962$ & $-0,32167$ & $-0,09184$ \\
\hline I 21651AO & 0,20225 & 0,65089 & 0,21282 & 0,08864 & 0,30302 & $-0,07819$ & $-0,15405$ & $-0,0671$ & $-0,05161$ & $-0,03786$ \\
\hline
\end{tabular}

$\begin{array}{lrrrrrrrr} & \text { TC 21226PV } & \text { TI 21048AO } & \text { TI 21133AO } & \text { TI 21141AO } & \text { TI 21152AO } & \text { TI21125AO } & \text { PC 21004PV PI 21651AO } \\ \text { FC 21004PV } & -0,05256 & 0,27167 & 0,02446 & -0,013 & -0,04234 & 0,00864 & 0,21891 & 0,20225 \\ \text { FC 21037PV } & -0,00824 & -0,35579 & -0,24472 & 0,43462 & 0,43285 & 0,06207 & -0,19296 & 0,65089 \\ \text { FC 21039PV } & -0,2085 & -0,21418 & -0,02811 & 0,58009 & 0,37438 & -0,09549 & -0,14306 & 0,21282 \\ \text { FC 21041PV } & 0,06367 & 0,08221 & 0,03134 & 0,05277 & 0,11109 & -0,07244 & -0,06596 & 0,08864 \\ \text { FC 21613PV } & 0,09943 & 0,14681 & 0,21241 & -0,63386 & -0,40307 & -0,1594 & 0,42783 & 0,30302 \\ \text { FC 21631PV } & 0,0245 & -0,0512 & -0,06394 & 0,57241 & 0,48911 & 0,07182 & -0,19335 & -0,07819 \\ \text { TC 21002PV } & 0,06227 & 0,25773 & 0,20856 & -0,39045 & -0,40712 & -0,12955 & 0,12766 & -0,15405 \\ \text { TC 21009PV } & 0,21812 & -0,10005 & -0,13768 & 0,62109 & 0,52866 & -0,01594 & -0,14962 & -0,0671 \\ \text { TC 21010PV } & 0,24073 & -0,1499 & -0,1452 & 0,37003 & 0,38854 & 0,27343 & -0,32167 & -0,05161 \\ \text { TC 21011PV } & -0,05371 & -0,06112 & 0,09743 & -0,00837 & 0,10833 & 0,99566 & -0,09184 & -0,03786 \\ \text { TC 21226PV } & 1 & 0,11286 & 0,02891 & 0,10033 & 0,28875 & -0,05177 & 0,25978 & 0,1665 \\ \text { TI 21048AO } & 0,11286 & 1 & 0,22336 & -0,3326 & -0,24346 & -0,04571 & 0,17951 & -0,1142 \\ \text { TI 21133AO } & 0,02891 & 0,22336 & 1 & -0,01283 & 0,0348 & 0,11248 & 0,17793 & 0,0456 \\ \text { TI 21141AO } & 0,10033 & -0,3326 & -0,01283 & 1 & 0,69601 & 0,02293 & -0,36179 & -0,06607 \\ \text { TI 21152AO } & 0,28875 & -0,24346 & 0,0348 & 0,69601 & 1 & 0,12727 & -0,21717 & 0,19957 \\ \text { TI21125AO } & -0,05177 & -0,04571 & 0,11248 & 0,02293 & 0,12727 & 1 & -0,1142 & -0,00665 \\ \text { PC 21004PV } & 0,25978 & 0,17951 & 0,17793 & -0,36179 & -0,21717 & -0,1142 & 1 & 0,12993 \\ \text { PI 21651AO } & 0,1665 & -0,1142 & 0,0456 & -0,06607 & 0,19957 & -0,00665 & 0,12993 & 1\end{array}$

Com as variáveis remanescentes foi executada uma análise por Componentes Principais (PCA) utilizando-se o software Minitab.

Pela tabela 5.3, gerada pelo software, observa-se que os primeiros 12 Componentes Principais respondem por $95,4 \%$ da variância total do sistema que são dadas pelos autovalores. 
Tabela 5.3 Variância acumulada pelos Componentes Principais

\begin{tabular}{|l|c|c|c|}
\hline & Autovalores & proporção & acumulativo \\
\hline PC1 & 4,5571 & 0,268 & 0,268 \\
\hline PC2 & 2,4600 & 0,145 & 0,413 \\
\hline PC3 & 1,6726 & 0,098 & 0,511 \\
\hline PC4 & 1,4446 & 0,085 & 0,596 \\
\hline PC5 & 1,2665 & 0,074 & 0,671 \\
\hline PC6 & 1,1374 & 0,067 & 0,738 \\
\hline PC7 & 1,0574 & 0,062 & 0,800 \\
\hline PC8 & 0,7896 & 0,046 & 0,846 \\
\hline PC9 & 0,6375 & 0,037 & 0,884 \\
\hline PC10 & 0,4960 & 0,029 & 0,913 \\
\hline PC11 & 0,3759 & 0,022 & 0,935 \\
\hline PC12 & 0,2272 & 0,019 & 0,954 \\
\hline PC13 & 0,1958 & 0,013 & 0,968 \\
\hline
\end{tabular}

Pela tabela 5.4, escolhe-se as primeiras variáveis cujos valores absolutos dos maiores coeficientes de cada Componente Principal, ou seja, são as variáveis que mais contribuem para os Componentes Principais. Pode-se escolher o segundo maior valor absoluto se julgar que a variável seja mais importante para o processo, como ocorrido com o PC5 da tabela 5.4, onde a FC 21041PV foi julgada ter mais importância que a TC 21010PV.

\section{Tabela 5.4 Coeficientes dos primeiros 12 Componentes Principais}

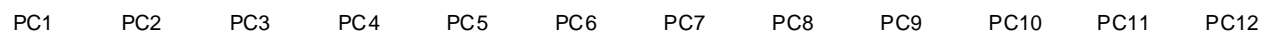

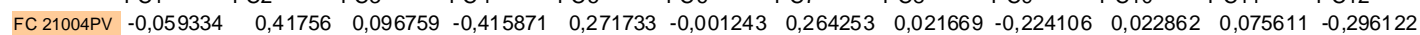

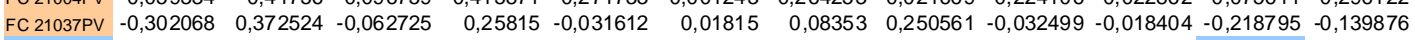
$\begin{array}{llllllllllllll}\text { FC 21039PV } & -0,283805 & 0,309669 & -0,244496 & -0,1569 & -0,202622 & 0,048373 & -0,202008 & -0,102283 & 0,112429 & 0,177452 & -0,448727 & 0,187137\end{array}$ $\begin{array}{llllllllllllll}\text { FC 21041PV } & -0,063836 & 0,190666 & 0,154589 & -0,095438 & 0,402993 & -0,064644 & -0,64666 & -0,026831 & 0,446051 & -0,313459 & 0,068278 & -0,088485\end{array}$ $\begin{array}{llllllllllllll}\text { FC 21613PV } & 0,320785 & 0,298199 & 0,163557 & 0,200003 & 0,004962 & -0,000025 & -0,080583 & -0,154829 & -0,228981 & 0,091548 & 0,119319 & 0,372978\end{array}$ $\begin{array}{llllllllllllll}\text { FC 21631PV } & -0,292307 & -0,223031 & -0,001046 & -0,229744 & -0,299871 & 0,045197 & 0,182688 & 0,270359 & 0,273284 & -0,337615 & 0,329919 & -0,061358\end{array}$ $\begin{array}{llllllllllllll}\text { TC 21002PV } & 0,300335 & -0,301346 & 0,064448 & 0,13711 & -0,254758 & -0,00682 & -0,178576 & 0,275479 & -0,026812 & -0,188867 & -0,428426 & -0,090882\end{array}$ $\begin{array}{llllllllllllll}\text { TC 21009PV } & -0,332898 & -0,114125 & 0,263009 & -0,170455 & 0,072547 & -0,209367 & 0,129101 & -0,104462 & -0,360059 & -0,238317 & -0,077195 & 0,09677\end{array}$ $\begin{array}{llllllllllllll}\text { TC 21010PV } & -0,210867 & -0,265848 & 0,307086 & 0,237118 & 0,410682 & -0,001322 & -0,045415 & 0,022687 & -0,288511 & -0,214409 & -0,235194 & 0,099754\end{array}$ \begin{tabular}{l|llllllllllllll} 
TC 21011PV & $-0,04772$ & $-0,109668$ & 0,022579 & 0,121598 & 0,358995 & 0,697393 & 0,337042 & $-0,042951$ & 0,312979 & 0,084975 & $-0,190723$ & 0,034542
\end{tabular} $\begin{array}{llllllllllllll}\text { TC 21226PV } & -0,027231 & -0,033924 & 0,633791 & 0,145937 & -0,130883 & -0,189312 & 0,043304 & -0,05226 & 0,266582 & 0,496514 & -0,002361 & -0,387542\end{array}$ $\begin{array}{llllllllllllll}\text { TI21048AO } & 0,180016 & -0,004287 & 0,256213 & -0,511965 & 0,086894 & 0,023505 & -0,023895 & 0,577215 & 0,020747 & 0,225777 & -0,208582 & 0,34288\end{array}$ $\begin{array}{lllllllllllllll}\text { TI21133AO } & 0,102475 & 0,01949 & 0,21884 & -0,22164 & -0,282996 & 0,621084 & -0,340168 & -0,146726 & -0,353284 & -0,086987 & 0,11256 & -0,257353\end{array}$ $\begin{array}{lllllllllllll}\text { TI21141AO } & -0,408915 & -0,097853 & 0,011921 & -0,075598 & -0,188715 & 0,022452 & -0,159825 & -0,149715 & -0,098306 & 0,136236 & -0,295753 & -0,119397\end{array}$ $\begin{array}{lllllllllllllll}\text { TI21152AO } & -0,361706 & -0,02603 & 0,248231 & 0,090507 & -0,171469 & 0,146226 & -0,106613 & -0,041066 & 0,078109 & 0,157037 & 0,315839 & 0,547818\end{array}$ $\begin{array}{lllllllllllllll}\text { PC 21004PV } & 0,198671 & 0,203443 & 0,313835 & -0,139725 & -0,25032 & -0,053007 & 0,320859 & -0,407155 & 0,287057 & -0,433517 & -0,296557 & 0,169302\end{array}$ $\begin{array}{lllllllllllll}\text { PI 21651AO } & -0,057806 & 0,419796 & 0,18071 & 0,386103 & -0,177794 & 0,118468 & 0,045934 & 0,43821 & -0,063035 & -0,255232 & 0,068993 & -0,03524\end{array}$ 
As doze variáveis selecionadas foram: FC 21039PV, FC 21041PV, FC 21631PV, TC 21009PV, TC21011PV, TC 21226PV, TI 21048AO, TI 21133AO, TI 21141AO, TI 21152AO, PC 21004PV e PI 21651AO.

Foram obtidas regressões lineares multivariáveis para cada propriedade a ser predita: Densidade D20/4, Destilação (PIE, 5\%, 10\%, 20\%, 30\%, 40\%, 50\%, 60\%, $70 \%, 80 \%, 90 \%$ e PFE), Enxofre total, Ponto de Fulgor, Ponto de Congelamento, viscosidade cSt a $-20{ }^{\circ} \mathrm{C}$ e viscosidade cSt a $40{ }^{\circ} \mathrm{C}$.

Foram segregados conjunto de dados para a elaboração do modelo, outro conjunto para validação e 4 amostras ditas para validação externa (amostras obtidas após manutenção programada da unidade de destilação.

Às amostras de validação e validação externa foi aplicada uma correção de bias para melhorar o ajuste. A seguir são apresentados nas figuras 5.35 a 5.52 os resultados obtidos.

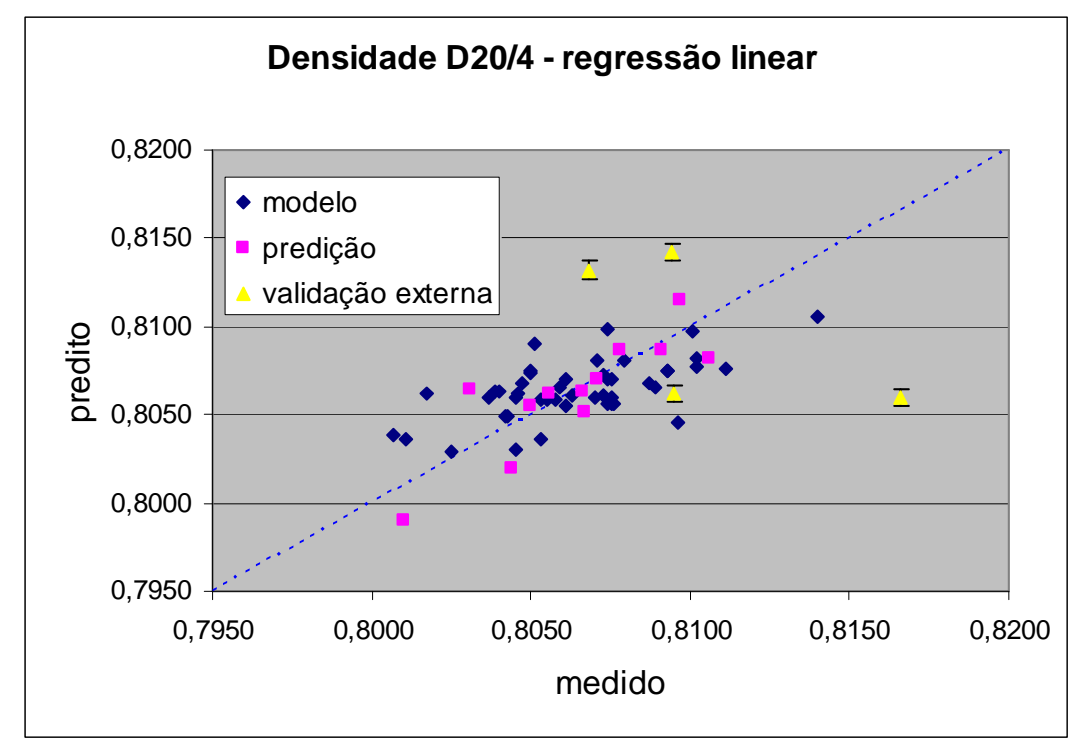

Figura 5.35 - Resultados da regressão linear para a Densidade

RMSE da calibração $=0,0017$

RMSEP da predição $=0,0021$

RMSEP da validação externa $=0,0069$ 


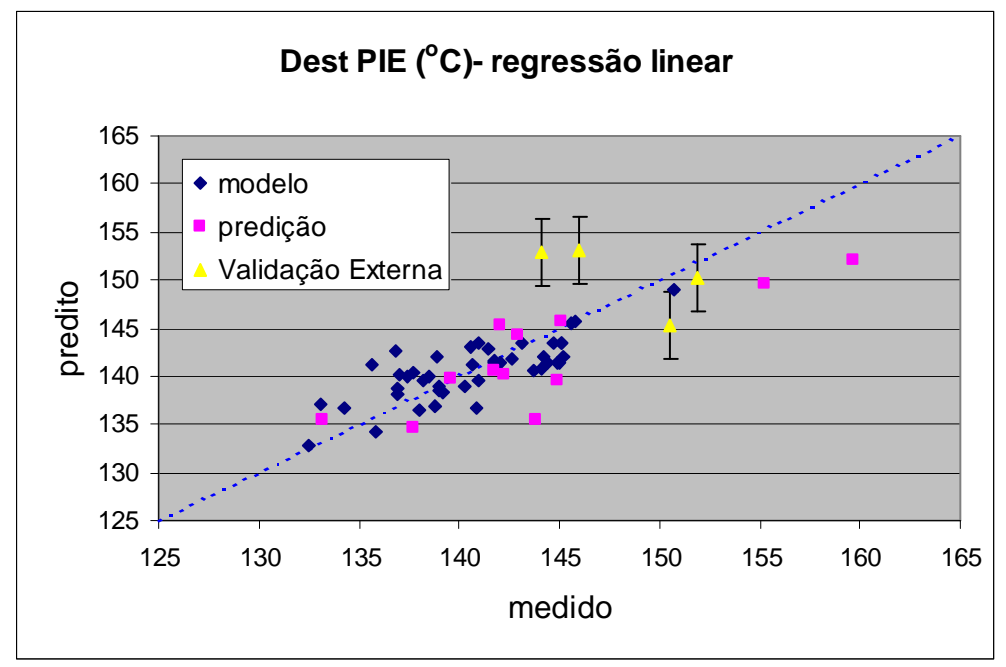

Figura 5.36 - Resultados da regressão linear para o PIE da Destilação

RMSE da calibração $=2,41^{\circ} \mathrm{C}$

RMSEP da predição $=4,30{ }^{\circ} \mathrm{C}$

RMSEP da validação externa $=6,30{ }^{\circ} \mathrm{C}$

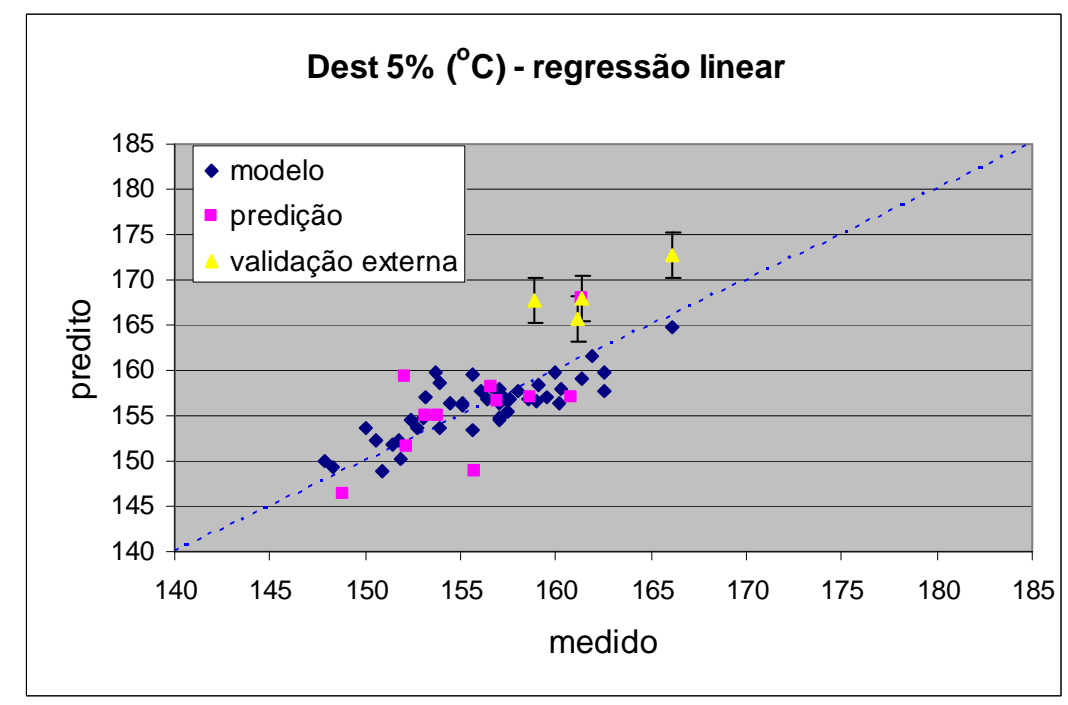

Figura 5.37 - Resultados da regressão linear para os $5 \%$ recuperados

RMSE da calibração $=2,31^{\circ} \mathrm{C}$

RMSEP da predição $=3,97^{\circ} \mathrm{C}$

RMSEP da validação externa $=6,85^{\circ} \mathrm{C}$ 


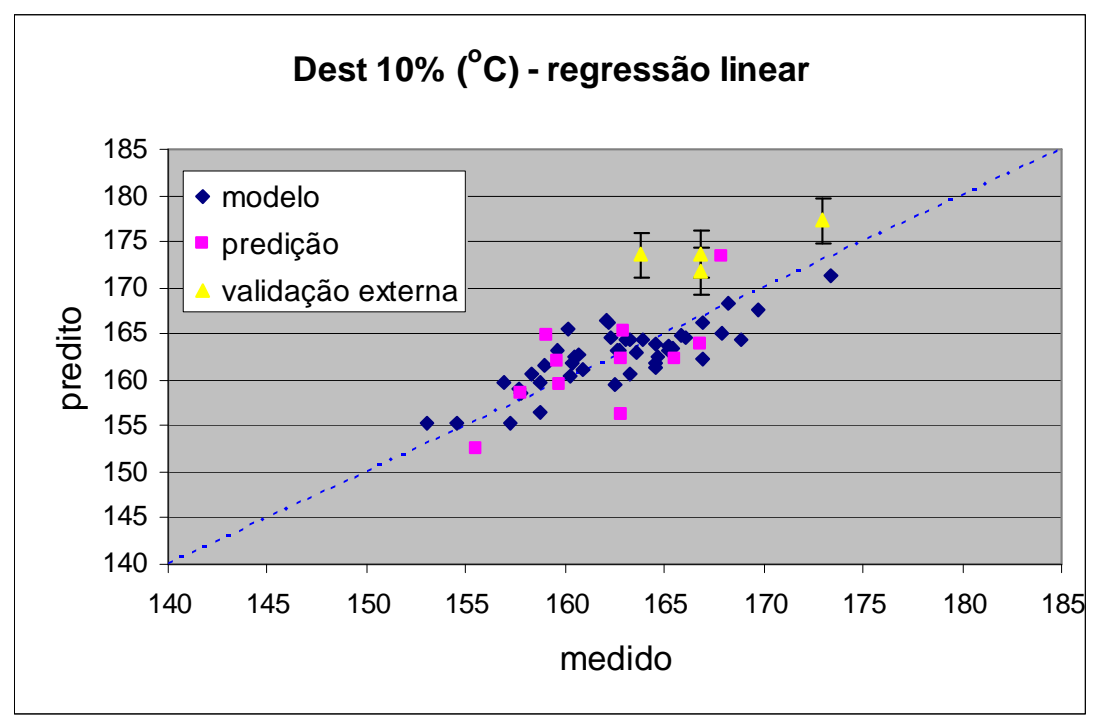

Figura 5.38 - Resultados da regressão linear para os $10 \%$ recuperados

RMSE da calibração $=2,35 \stackrel{\circ}{\circ}$

RMSEP da predição $=3,64 \stackrel{\circ}{\circ}$

RMSEP da validação externa $=6,81^{\circ} \mathrm{C}$

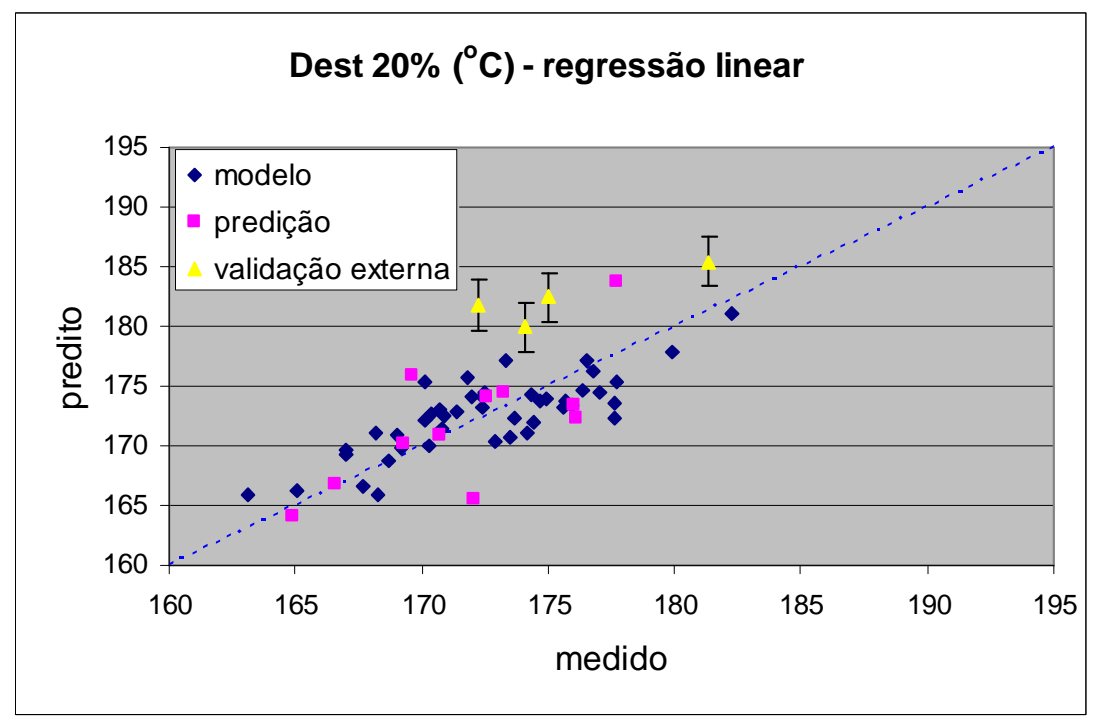

Figura 5.39 - Resultados da regressão linear para os $20 \%$ recuperados

RMSE da calibração $=2,36 \stackrel{\circ}{\circ}$

RMSEP da predição $=3,64{ }^{\circ} \mathrm{C}$

RMSEP da validação externa $=7,04 \stackrel{\circ}{\circ}$ 


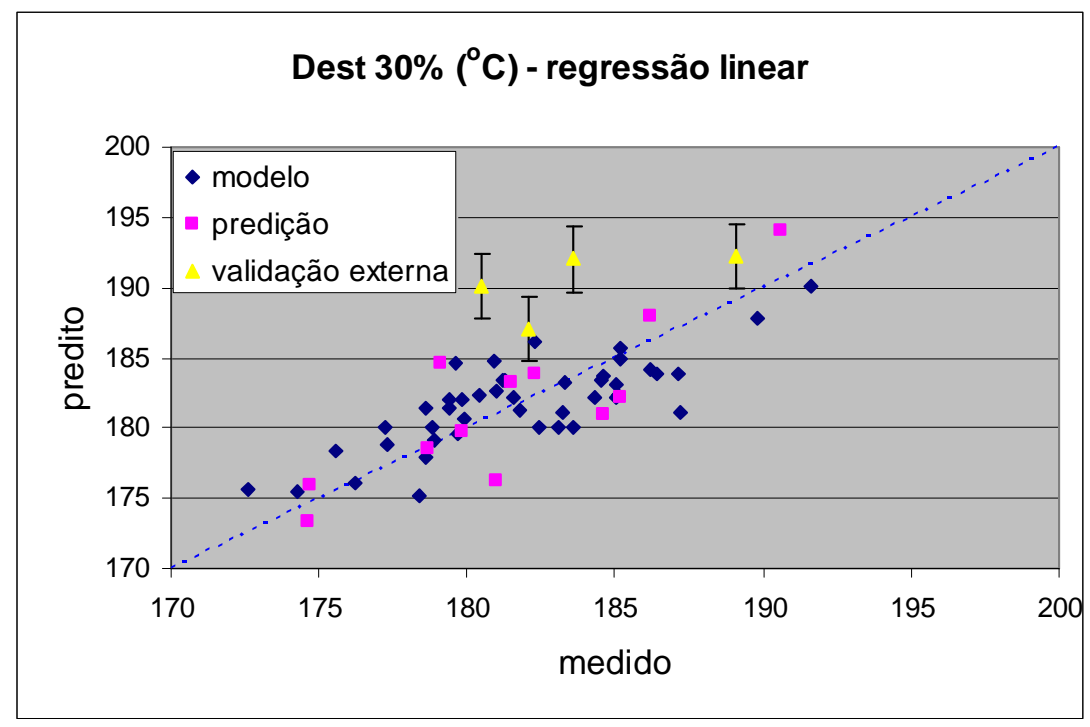

Figura 5.40 - Resultados da regressão linear para os $30 \%$ recuperados

RMSE da calibração $=2,43 \stackrel{\circ}{\circ} \mathrm{C}$

RMSEP da predição $=2,87^{\circ} \mathrm{C}$

RMSEP da validação externa $=7,04 \stackrel{\circ}{\circ}$

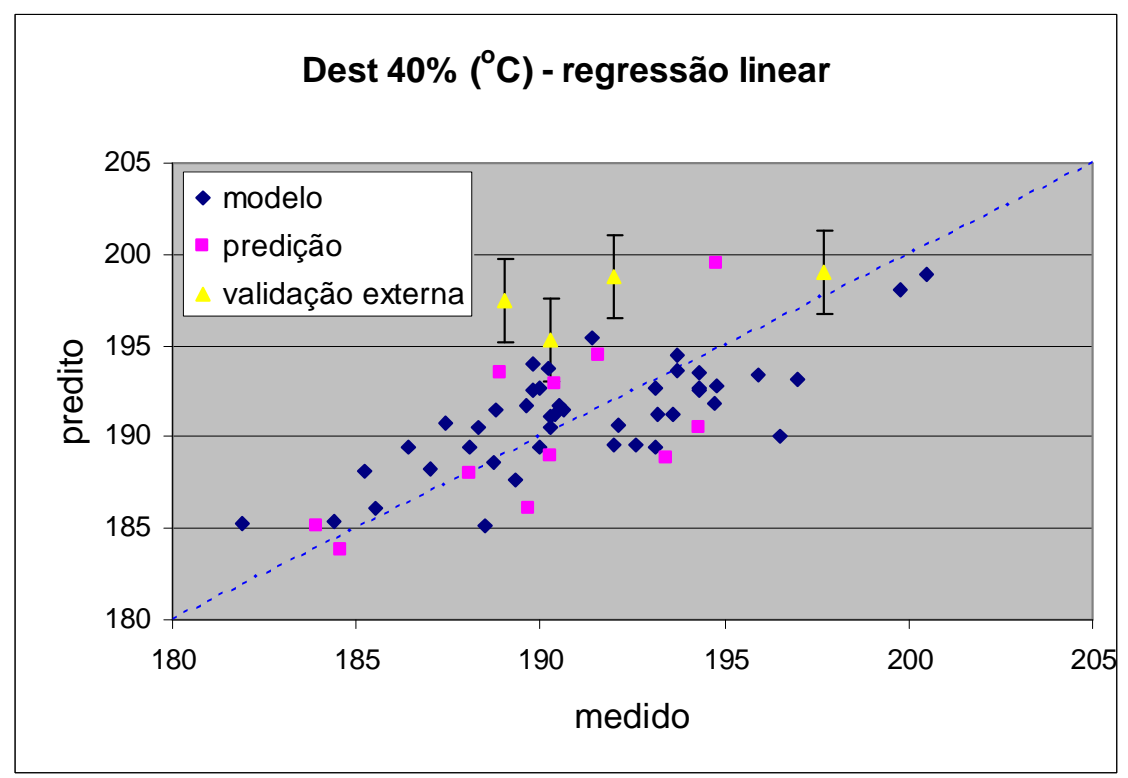

Figura 5.41 - Resultados da regressão linear para os $40 \%$ recuperados

RMSE da calibração $=2,47 \stackrel{\circ}{\mathrm{C}}$

RMSEP da predição $=3,15 \stackrel{\circ}{\circ}$ 
RMSEP da validação externa $=6,02 \stackrel{\circ}{\circ}$

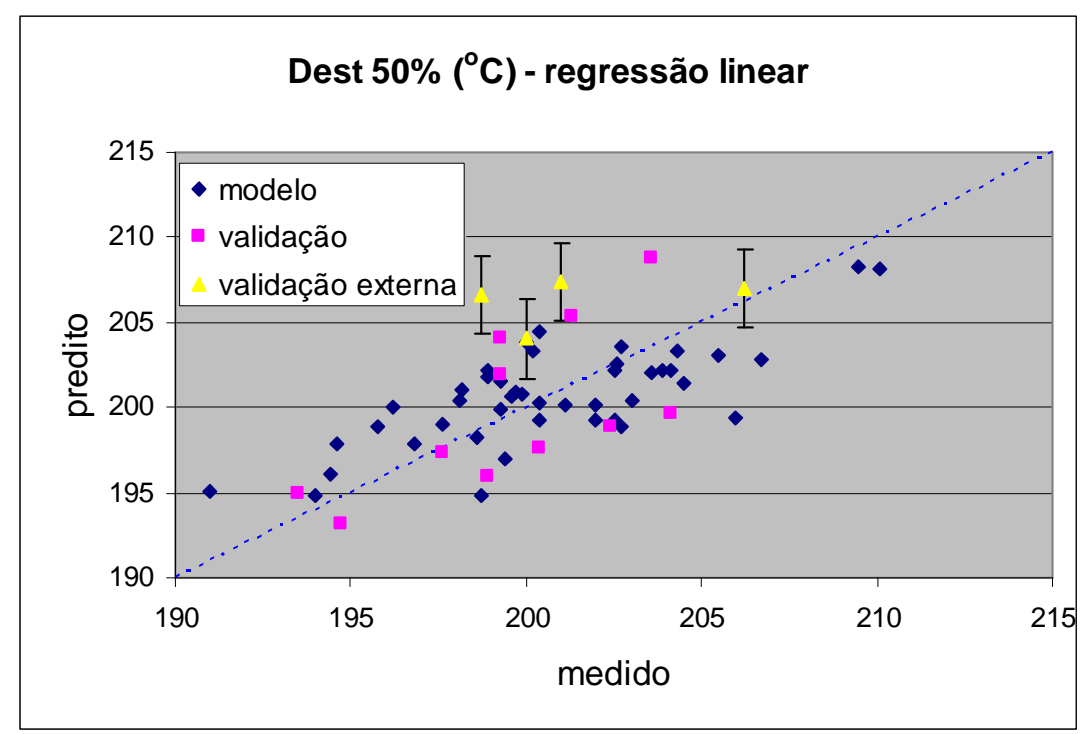

Figura 5.42 - Resultados da regressão linear para os $50 \%$ recuperados

RMSE da calibração $=2,59{ }^{\circ} \mathrm{C}$

RMSEP da predição $=3,38 \stackrel{\circ}{\circ}$

RMSEP da validação externa $=5,49 \stackrel{\circ}{ } \mathrm{C}$

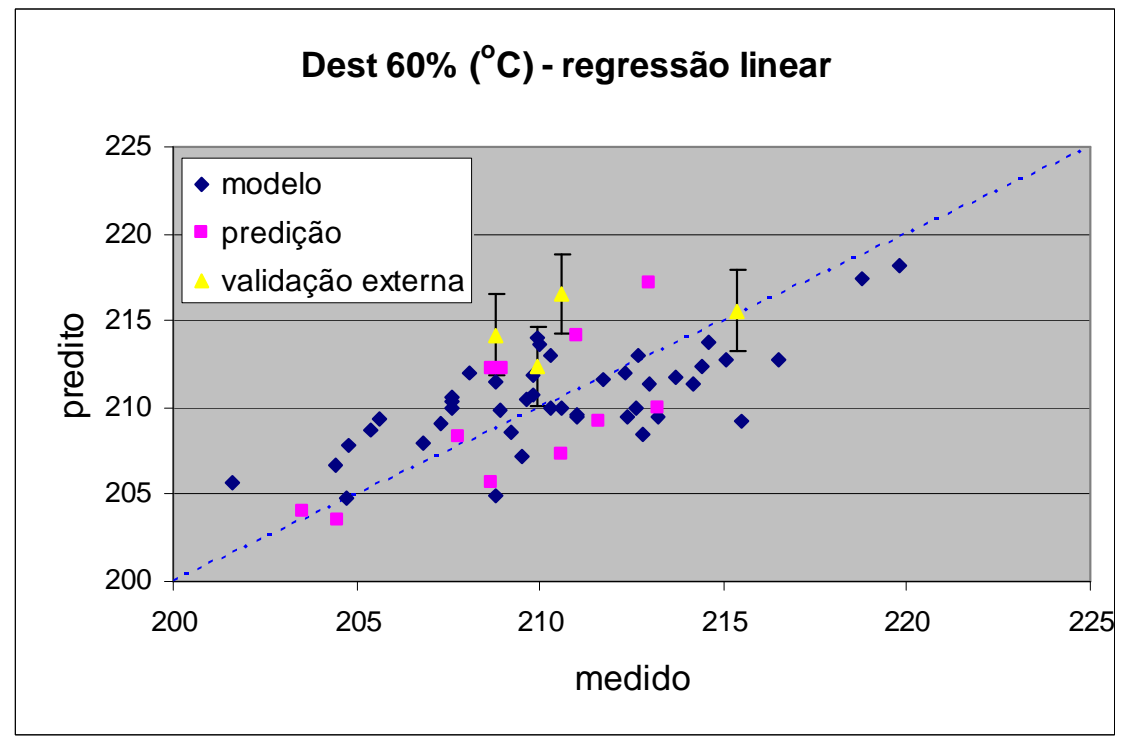

Figura 5.43 - Resultados da regressão linear para os $60 \%$ recuperados

RMSE da calibração $=2,64 \stackrel{\circ}{ } \mathrm{C}$ 
RMSEP da predição $=2,82^{\circ} \mathrm{C}$

RMSEP da validação externa $=4,20 \stackrel{\circ}{C}$

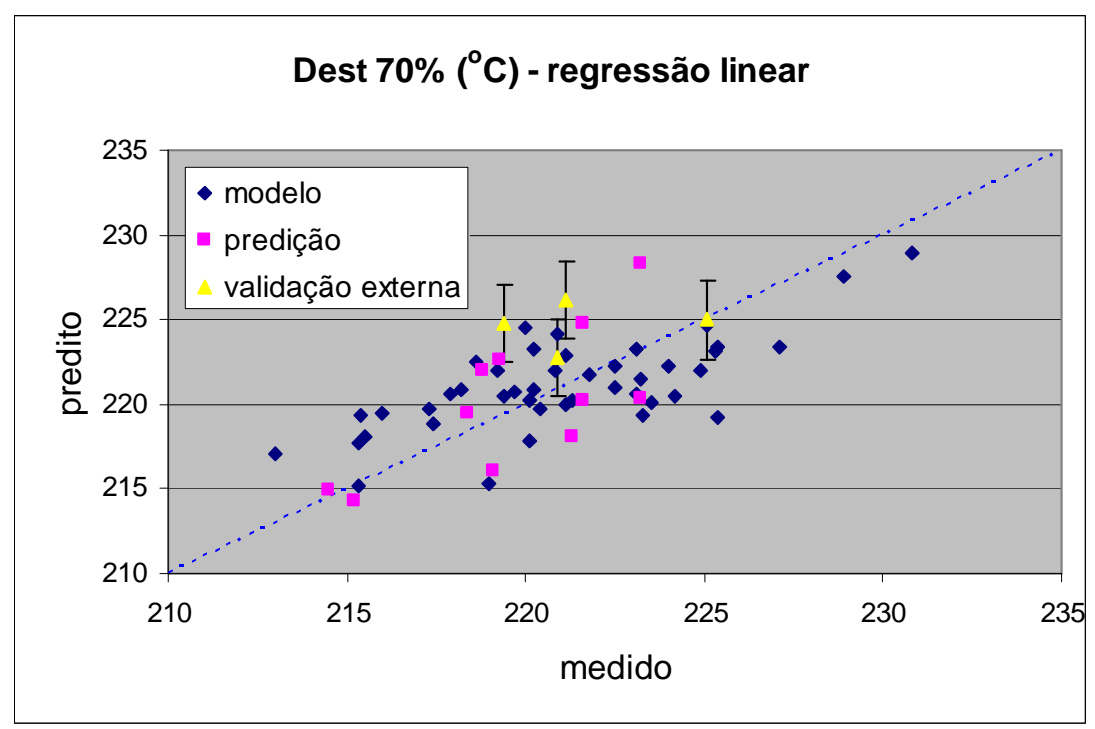

Figura 5.44 - Resultados da regressão linear para os $70 \%$ recuperados

RMSE da calibração $=2,62{ }^{\circ} \mathrm{C}$

RMSEP da predição $=2,85^{\circ} \mathrm{C}$

RMSEP da validação externa $=3,81 \stackrel{\circ}{ } \mathrm{C}$

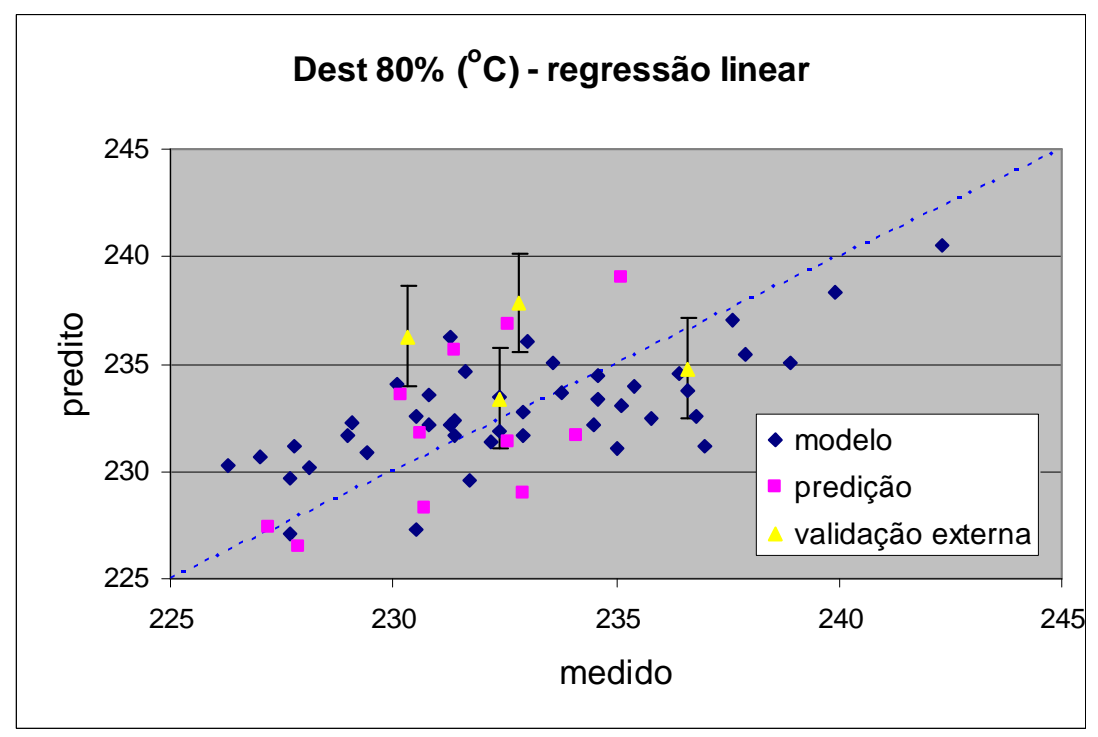

Figura 5.45 - Resultados da regressão linear para os $80 \%$ recuperados

RMSE da calibração $=2,58 \stackrel{\circ}{ } \mathrm{C}$ 
RMSEP da predição $=2,94 \stackrel{\circ}{ } \mathrm{C}$

RMSEP da validação externa $=4,06{ }^{\circ} \mathrm{C}$

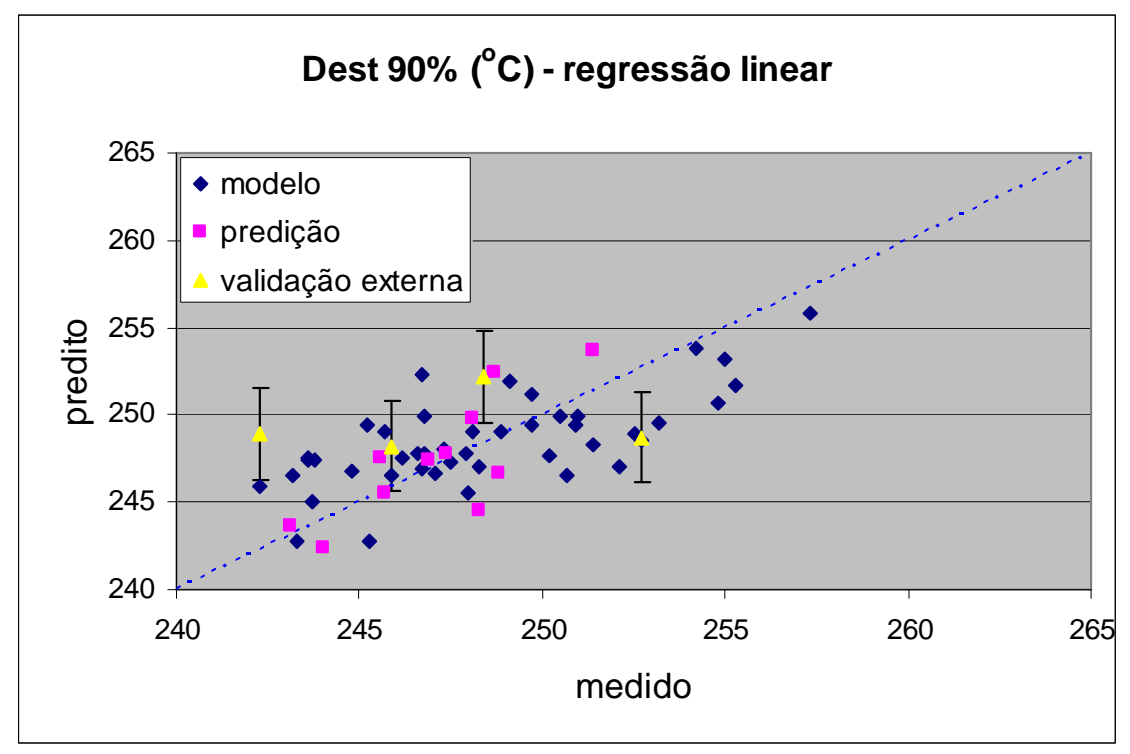

Figura 5.46 - Resultados da regressão linear para os $90 \%$ recuperados

RMSE da calibração $=2,67^{\circ} \mathrm{C}$

RMSEP da predição $=2,09 \stackrel{\circ}{ } \mathrm{C}$

RMSEP da validação externa $=4,47^{\circ} \mathrm{C}$

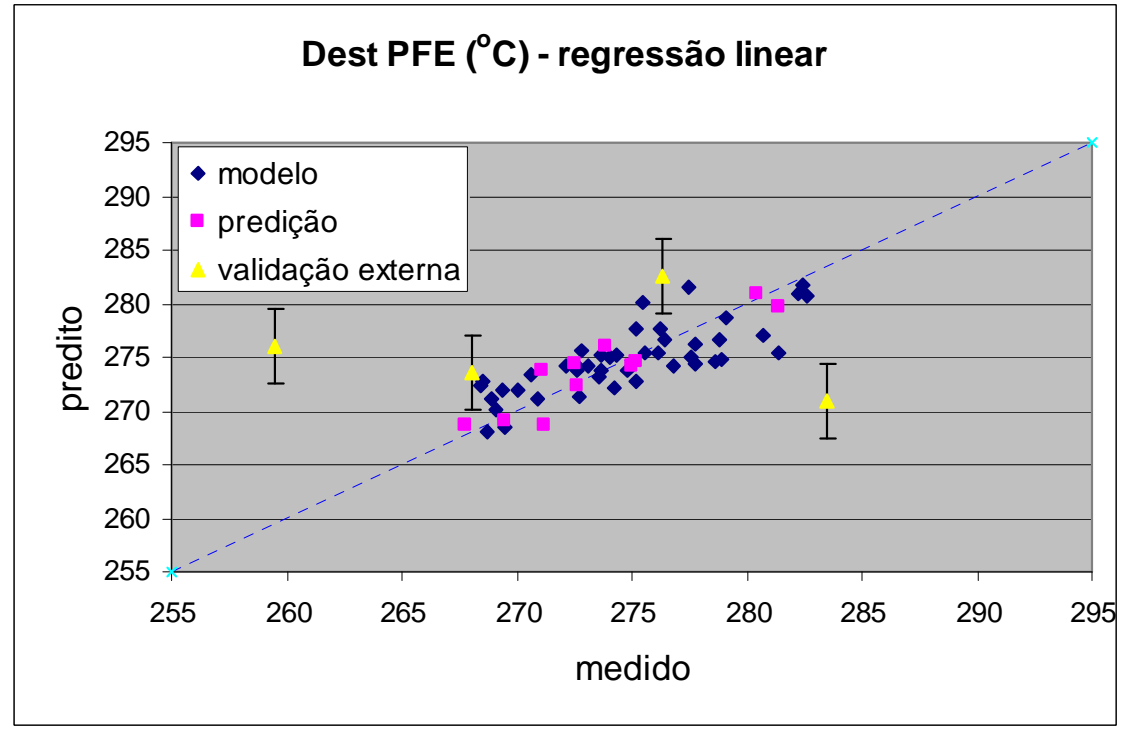

Figura 5.47 - Resultados da regressão linear para PFE da Destilação 
RMSE da calibração $=2,43{ }^{\circ} \mathrm{C}$

RMSEP da predição $=1,56 \stackrel{\circ}{\circ}$

RMSEP da validação externa $=11,22{ }^{\circ} \mathrm{C}$

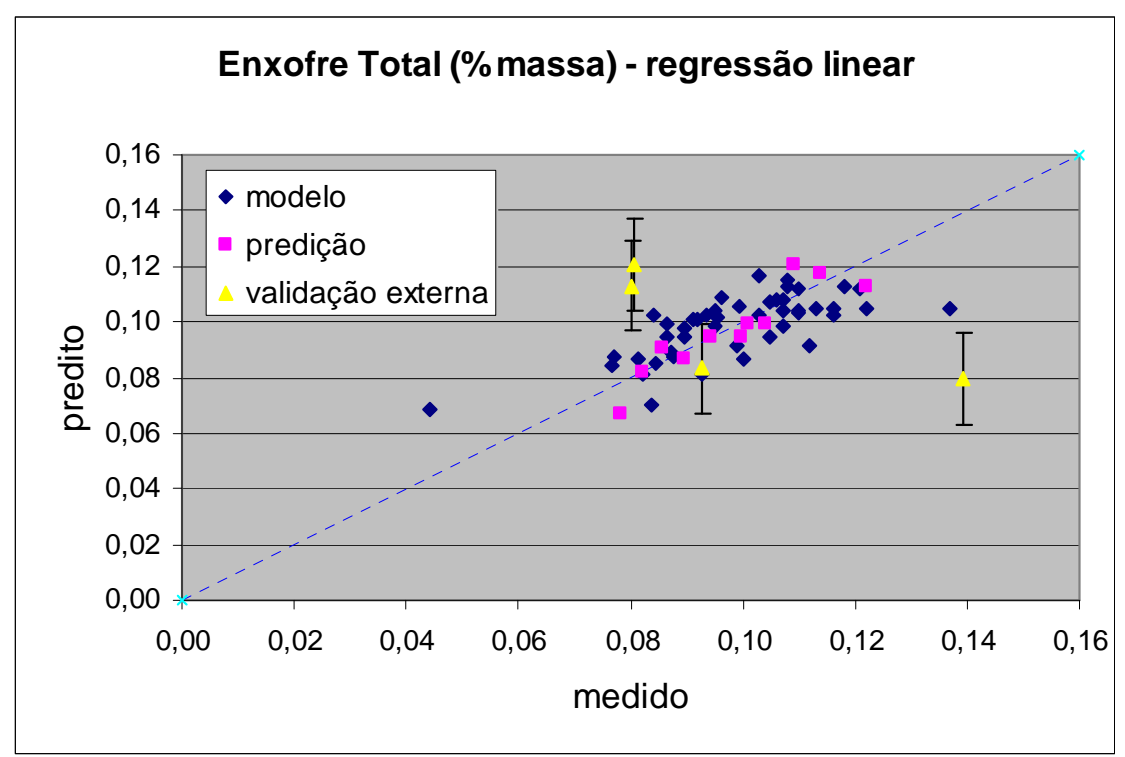

Figura 5.48 - Resultados da regressão linear para o enxofre total

RMSE da calibração $=0,0108 \% \mathrm{~m}$

RMSEP da predição $=0,0063 \% \mathrm{~m}$

RMSEP da validação externa $=0,0399 \% \mathrm{~m}$

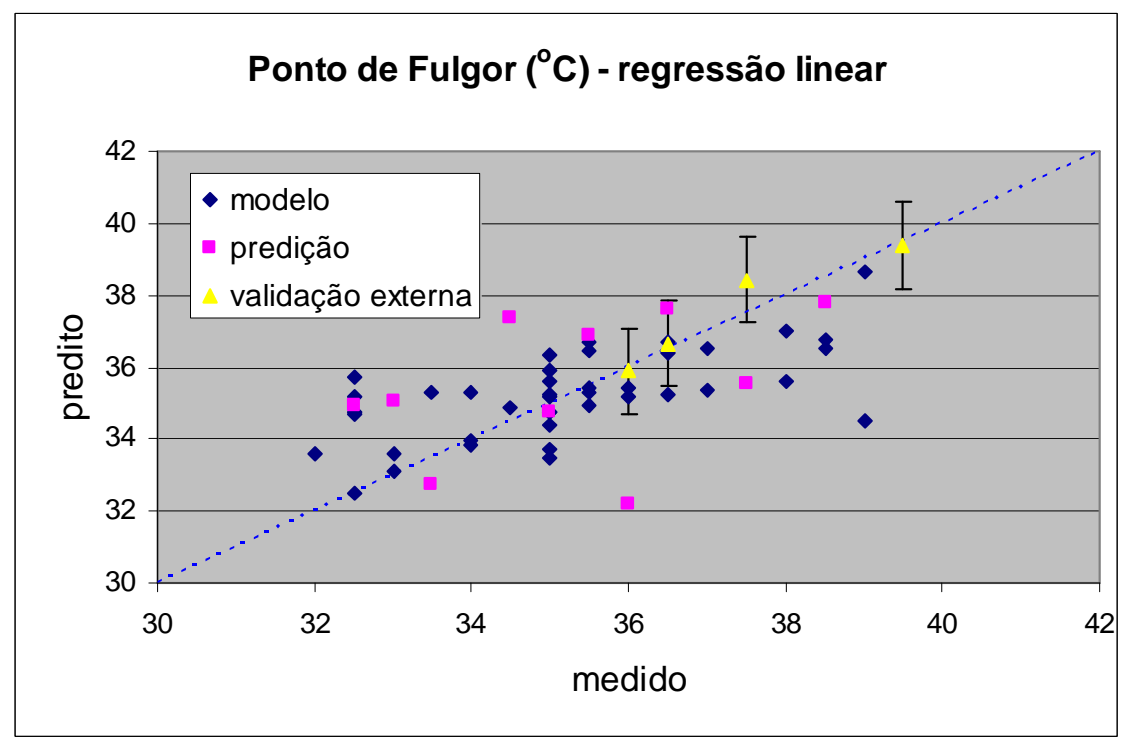

Figura 5.49 - Resultados da regressão linear para o ponto de fulgor 
RMSE da calibração $=1,44{ }^{\circ} \mathrm{C}$

RMSEP da predição $=2,03^{\circ} \mathrm{C}$

RMSEP da validação externa $=0,48 \stackrel{\circ}{\circ}$

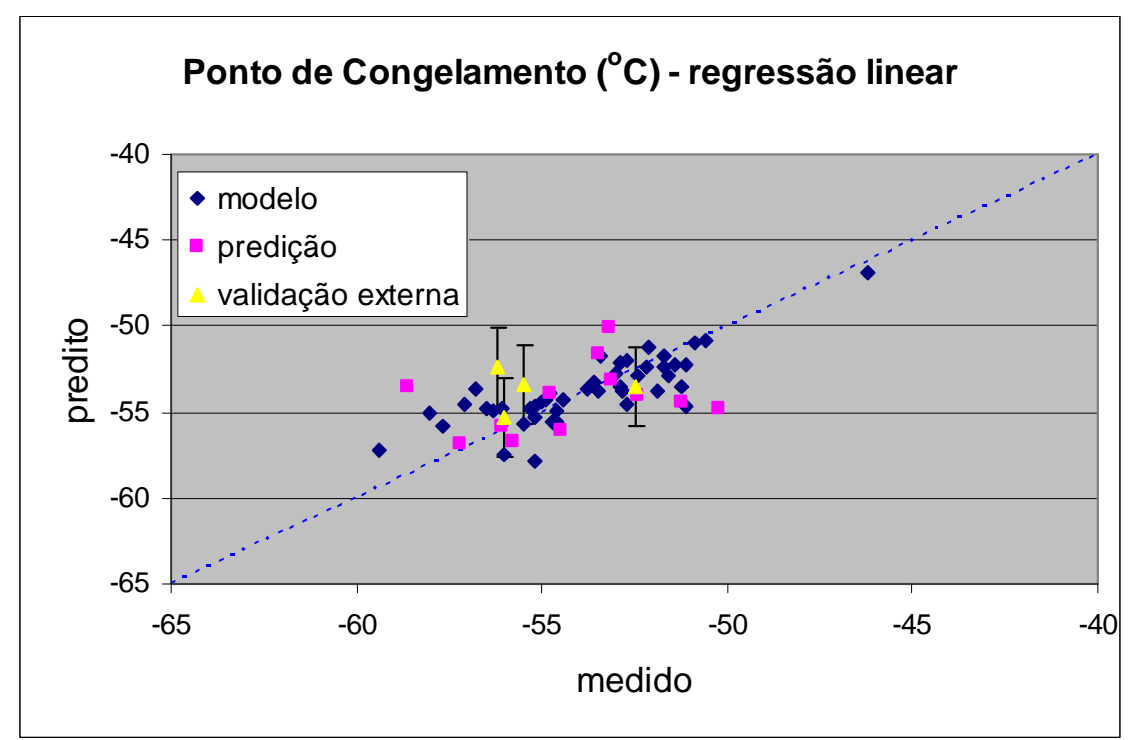

Figura 5.50 - Resultados da regressão linear para o ponto de congelamento

RMSE da calibração $=1,40{ }^{\circ} \mathrm{C}$

RMSEP da predição $=2,55^{\circ} \mathrm{C}$

RMSEP da validação externa $=2,27^{\circ} \mathrm{C}$

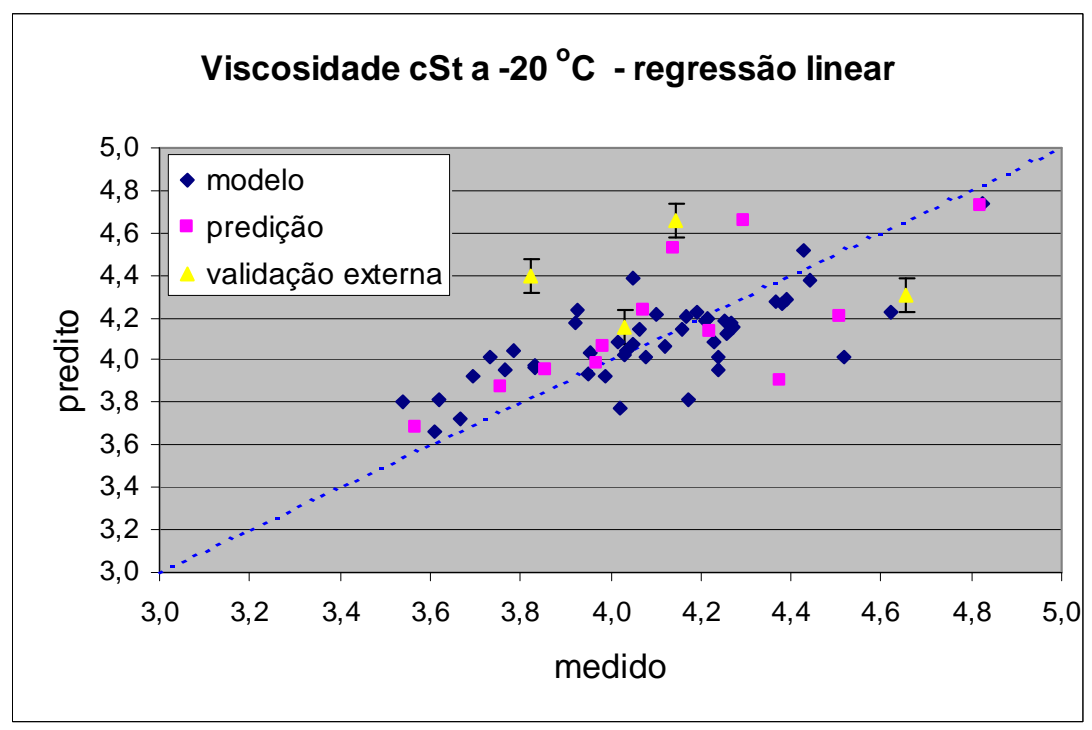

Figura 5.51 - Resultados da regressão linear para a viscosidade a $-20^{\circ} \mathrm{C}$ 
RMSE da calibração $=0,185 \mathrm{cSt}$

RMSEP da predição $=0,239 \mathrm{cSt}$

RMSEP da validação externa $=0,431 \mathrm{cSt}$

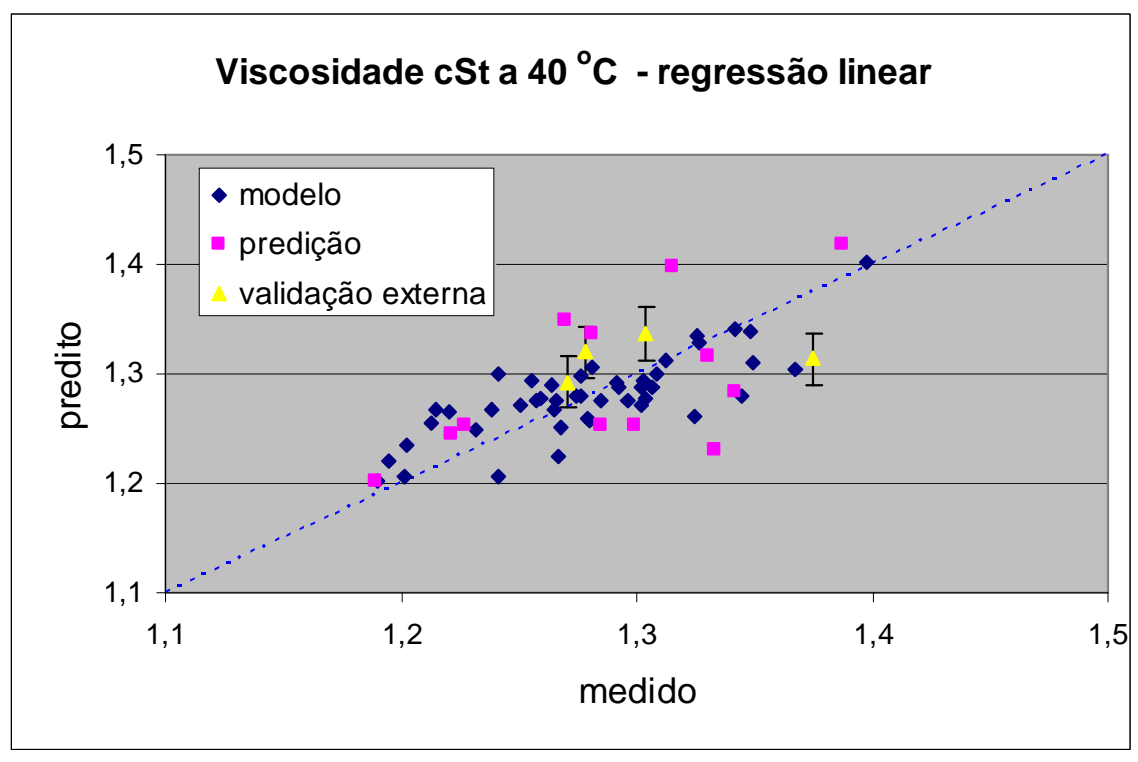

Figura 5.52 - Resultados da regressão linear para a viscosidade a $-40{ }^{\circ} \mathrm{C}$

RMSE da calibração $=0,029 \mathrm{cSt}$

RMSEP da predição $=0,055 \mathrm{cSt}$

RMSEP da validação externa $=0,042 \mathrm{cSt}$

Os resultados aplicando a regressão multilinear para as propriedades físicas do querosene em função das variáveis de processo apresentam maiores erros que os obtidos através de espectroscopia NIR. Todos os dados obtidos na avaliação de inferência através de variáveis de processo foram coletados em situações que o processo de destilação estava em estado estacionário.

Os resultados obtidos tanto de calibração quanto de validação externa utilizando dados espectrais na região NIR modelados através de PLS para as propriedades de Densidade, Viscosidades e Ponto de Congelamento apresentaram bons resultados. Os obtidos através de modelos de redes neurais para as propriedades de Destilação, Enxofre Total e Ponto de Fulgor apresentaram resultados razoáveis, porém melhores que aqueles obtidos da regressão linear multivariada baseada nas 
variáveis operacionais. Para melhor visualização, na tabela 5.5 são apresentados os erros dos modelos obtidos via NIR e via regressão linear multivariável.

Tabela 5.5 - Comparação entre erros dos modelos obtidos via NIR e via regressão linear multivariável

\begin{tabular}{|c|c|c|c|c|c|c|}
\hline & \multicolumn{3}{|c|}{ NIR } & \multicolumn{3}{|c|}{ Regressão linear multivariável } \\
\hline & $\begin{array}{l}\text { RMSE do } \\
\text { conjunto } \\
\text { de } \\
\text { calibração }\end{array}$ & $\begin{array}{l}\text { RMSE do } \\
\text { conjunto } \\
\text { de teste }\end{array}$ & $\begin{array}{l}\text { RMSEP } \\
\text { do } \\
\text { conjunto } \\
\text { de } \\
\text { validação } \\
\text { externa }\end{array}$ & $\begin{array}{l}\text { RMSE do } \\
\text { conjunto de } \\
\text { calibração }\end{array}$ & $\begin{array}{l}\text { RMSE do } \\
\text { conjunto } \\
\text { de teste }\end{array}$ & $\begin{array}{l}\text { RMSEP } \\
\text { do } \\
\text { conjunto } \\
\text { de } \\
\text { validação } \\
\text { externa }\end{array}$ \\
\hline $\operatorname{PIE}\left({ }^{\circ} \mathrm{C}\right)$ & 2,01 & 4,59 & 6,15 & 2,41 & 4,30 & 6,30 \\
\hline $5 \%\left({ }^{\circ} \mathrm{C}\right)$ & 2,19 & 3,06 & 4,73 & 2,31 & 3,97 & 6,85 \\
\hline $10 \%\left({ }^{\circ} \mathrm{C}\right)$ & 2,20 & 3,91 & 3,73 & 2,35 & 3,64 & 6,81 \\
\hline $20 \%\left({ }^{\circ} \mathrm{C}\right)$ & 1,28 & 3,45 & 3,84 & 2,36 & 3,64 & 7,04 \\
\hline $30 \%\left({ }^{\circ} \mathrm{C}\right)$ & 1,37 & 3,38 & 3,95 & 2,43 & 2,87 & 7,04 \\
\hline $40 \%\left({ }^{\circ} \mathrm{C}\right)$ & 2,63 & 3,24 & 3,63 & 2,47 & 3,15 & 6,02 \\
\hline $50 \%\left({ }^{\circ} \mathrm{C}\right)$ & 1,23 & 2,64 & 3,84 & 2,59 & 3,38 & 5,49 \\
\hline $60 \%\left({ }^{\circ} \mathrm{C}\right)$ & 1,54 & 3,14 & 2,90 & 2,64 & 2,82 & 4,20 \\
\hline $70 \%\left({ }^{\circ} \mathrm{C}\right)$ & 1,25 & 3,30 & 1,79 & 2,62 & 2,85 & 3,81 \\
\hline $80 \%\left({ }^{\circ} \mathrm{C}\right)$ & 1,51 & 2,63 & 2,18 & 2,58 & 2,94 & 4,06 \\
\hline $90 \%\left({ }^{\circ} \mathrm{C}\right)$ & 1,67 & 4,85 & 2,13 & 2,67 & 2,09 & 4,47 \\
\hline $\operatorname{PFE}\left({ }^{\circ} \mathrm{C}\right)$ & 1,02 & 1,82 & 5,45 & 2,43 & 1,56 & 11,22 \\
\hline $\begin{array}{c}\text { Enxofre Total } \\
\text { (\%massa) }\end{array}$ & 0,0082 & 0,0096 & 0,0272 & 0,0108 & 0,0063 & 0,0399 \\
\hline $\begin{array}{l}\text { Ponto de Fulgor } \\
\left({ }^{\circ} \mathrm{C}\right)\end{array}$ & 0,77 & 0,94 & 1,91 & 1,44 & 2,03 & 0,48 \\
\hline Densidade & 0,0007 & - & 0,0012 & 0,0017 & 0,0021 & 0,0069 \\
\hline $\begin{array}{c}\text { Ponto de } \\
\text { Congelamento } \\
\left({ }^{\circ} \mathrm{C}\right)\end{array}$ & 1,13 & - & 0,71 & 1,40 & 2,55 & 2,27 \\
\hline $\begin{array}{c}\text { Viscosidade a - } \\
20{ }^{\circ} \mathrm{C} \text { (cSt) }\end{array}$ & 0,091 & - & 0,152 & 0,185 & 0,239 & 0,431 \\
\hline $\begin{array}{c}\text { Viscosidade a } \\
40{ }^{\circ} \mathrm{C}(\mathrm{cSt})\end{array}$ & 0,020 & - & 0,005 & 0,029 & 0,055 & 0,042 \\
\hline
\end{tabular}


Como ilustração apresenta-se na figura 5.53 a curva de destilação da amostra Q61 com os dados de laboratório, o simulado por redes neurais e o simulado por regressão linear.

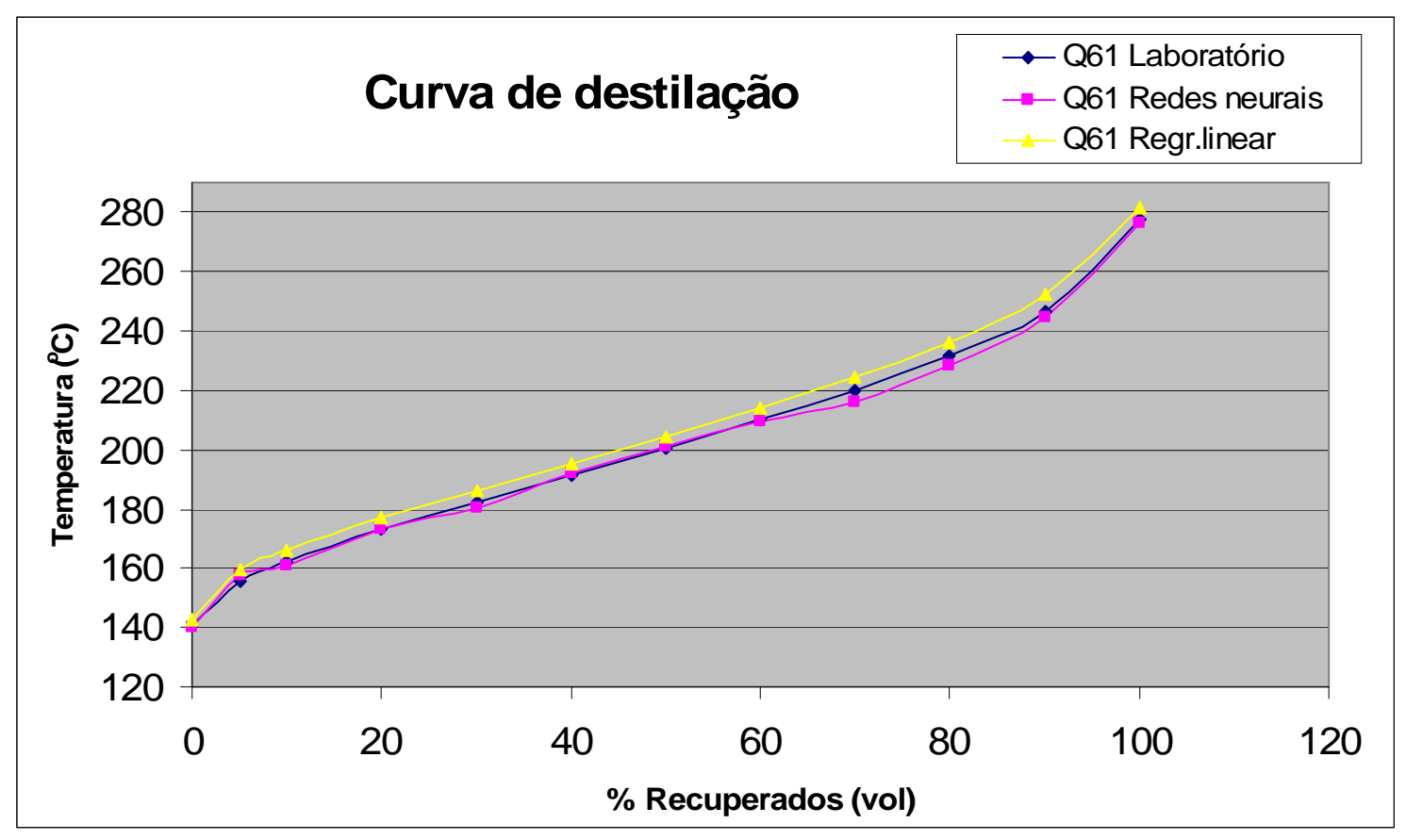

Figura 5.53 - Curva de destilação da amostra Q61 


\section{CONCLUSÕES E RECOMENDAÇÕES}

Pretende-se utilizar os resultados obtidos neste trabalho em uma planta industrial e para tanto foram verificados num "loop" os efeitos das variações de temperatura e de velocidade de escoamento nos espectros obtidos. Constatado que não há influência nem da temperatura e nem da velocidade sobre os espectros NIR.

A caracterização do Querosene a partir da espectroscopia NIR se mostra eficaz para balizar sua produção com uso de otimizadores on-line ou mesmo para controle pelos operadores da unidade de destilação.

Neste trabalho não possível coletar amostras durante um período instável da Unidade de Destilação ou durante um transiente de mudança de qualidade de carga da Unidade. Recomenda-se que nessas situações sejam coletas amostras para análise espectroscópica, pois se acredita que mesmo num transiente as informações obtidas pela espectroscopia fornecerão as propriedades com exatidão. Inferências baseadas nas variáveis operacionais não conseguem refletir as propriedades num transiente, pois as mesmas são obtidas considerando a estabilidade de Unidade.

Foi possível a partir das informações espectrais relacionar as propriedades físicas densidade D20 $/ 4^{\circ} \mathrm{C}$, destilação (PIE, 5\%, 10\%, 20\%, 30\%, 40\%, 50\%, 60\%, 70\%, $80 \%, 90 \%$ e PFE), enxofre total, ponto de fulgor, ponto de congelamento e viscosidade a $-20^{\circ} \mathrm{C}$ e a $40^{\circ} \mathrm{C}$ com resultados satisfatórios. As previsões de validação externa (informações coletadas em campanha após parada programada de manutenção) mostraram que estão dentro da magnitude dos erros das medidas e que não prejudicam a especificação do produto. Todas as previsões da validação externa atendem a especificação do produto.

Atualmente as inferências baseiam-se em variáveis de processo. Quando o sistema não está em estado estacionário normalmente essas inferências apresentam grandes desvios. A utilização de inferências construídas a partir da espectroscopia NIR não tem este problema uma vez que as informações são obtidas da saída do 
produto. Esta é uma contribuição muito importante na construção de inferências independentes das condições operacionais.

As inferências obtidas com os dados operacionais da planta industrial foram comparadas com as obtidas por espectroscopia. As inferências, via espectroscopia $\mathrm{NIR}$, mostraram-se superiores e como dito anteriormente, são independentes das variáveis do processo. 


\section{REFERÊNCIAS}

- ANDRADE, JOSÉ M.; MUNIATEGUI, SOLEDAD; LÓPEZ-MAHIA, PURIFICACIÓN AND PRADA, DARIO, Use of multivariate techniques in quality control of kerosene production, Fuel, Vol. 76, №1,pp. 51-59, 1997. .

- BARAK, P., Smoothing and Differentiation by an adaptive-degree polynomial filter, Anal. Chem., Vol. 67, p. 2758 - 2762, 1995

- BUENO, A. F.; Fundamentos de espectroscopia no infravermelho próximo, Petrobras-Revap, 2006

- CHAMINADE, P.; BAILLET, A.; FERRIER, D., Data treatment in near infrared spectroscopy, Analusis, 26 (4), M33 - M38, 1998

- CHUNG, H.; KU, M-S., Comparison of near-infrared, infrared, and Raman spectroscopy for the analysis of heavy petroleum products, App. Spectrosc., 54 (2), p. $239-245,2000$

- CHUNG, H.; KU, M-S.; LEE, J-S., Comparison of near-infrared and midinfrared spectroscopy for the determination of distillation property of kerosene, Vib. Spectrosc., 20, p. $155-163,1999$

- CYBENKO, G, Math Control Signal Syst., 2, 303,1989

- DIVYA, O.; MISHRA, A.K., Multivariate methods on the excitation emission matrix fluorescence spectroscopic data of diesel-kerosene mixtures: a comparative study., Analytica Chimica Acta, vol 592, p. 82 - 90, 2007.

- FerReira, M. M. C, ANTUNes A. M., MELGo M. S. E VOlPe P. L. O., Quím. Nova vol.22 n.5 São Paulo Sept./Oct. 1999

- GÓMEZ - CARRACEDO, M.P.; ANDRADE, J. M.; CALVIÑO, M.; FERNÁNDEZ, E.; PRADA, D. ; MUNIATEGUI, S., Multivariate prediction of eight kerosene properties employing vapour-phase mid-infrared spectroscopy, Fuel, 82 (2003) $1211-1218$

- GORRY, P.A., General least-squares smoothing and differentiation by the convolution (Savitzky-Golay) method, Anal. Chem., 62, p. 570 - 573, 1990

- HECHT-NIELSEN, ROBERT-Neurocomputing. HNC, Inc. and University of California, San Diego, 1991 
- HIDAJAT, K.; CHONG S.M., Quality characterisation of crude oils by partial least squares calibration of NIR spectral profiles, J. Near Infrared Spectrosc., 8 , p. $53-59,2000$

- HONIGS, D.E.; HIRSCHFELD, T.B.; HIEFTJE, G.M., Near-infrared determination of several physical properties of hydrocarbons, Anal. Chem., 57, p. $443-445,1985 b$

- HOPFIELD, J. Neural Networks and Physical Systems with Emergent Collectives Computational Abilities. Proceedings of the National Academy of Sciences 79,1982

- KHATTREE, RAVINDRA AND DAYANAND N. NAIK, Multivariate Data Reduction and Discrimination with SAS Software, Cary, NC: SAS Institute Inc., 2000

- KELLY, J.J.; CALLIS, J.B., Nondestructive analytical procedure for simultaneous estimation of the major classes of hydrocarbon constituents of finished gasolines, Anal. Chem., 62, p. 1444 - 1451, 1990

- KIM, M.; LEE, Y-H.; HAN, C., Real-time classification of petroleum products using near-infrared spectra, Comput. Chem. Engng., 24, p. 513 - 517, 2000

- KOWALSKI, B. R.; SEASHOLTZ, M. B., J. Chemometrics,., 5, 129, 1991

- LITANI-BARZILAI, I.; SELA, I.; BULATOV, V.; ZILBERMAN, I.; SCHECHTER, I., On-line remote prediction of gasoline properties by combined optical methods, Anal. Chim. Acta, 339, p. $193-199,1997$

- MALINOWSKI, E. R.; "Factor Analysis in Chemistry"; John Wiley \& Sons, New York 1991.

- MARTENS, H.; NAES, T., Multivariate Calibration, John Wiley \& Sons, 1989

- NAES, T.; ISAKSSON, T., Different strategies for handling non-linearity problems in NIR calibration, NIR news, Vol. 5 (1), p. 4-5, 11, 1994a

- NAES, T.; ISAKSSON, T., Some aspects of scatter-correction in calibration. Part I, NIR news, Vol. 5 (2), p. 4-5, 15, 1994b

- NASCIMENTO C.A.O.; GUARDANI, R. Programa para preparação de dados, Ajuste e Simulação de Redes Neurais. LSCP/DEQ-EPUSP, São Paulo, 1998. 
- O'HAVER, T., An Introduction to Signal Processing in Chemical Analysis (Department of Chemistry and Biochemistry, University of Maryland). Disponível em: <http://www.wam.umd.edu/ toh/spectrum/Differentiation.html>, 2001

- RUMELHART, D.E. \& MCCLELLAND, J. L.; Parallel Distributed Processing:explorations in the microestructure of cognition, MIT Press, Cambridge, MA., 1986.

- SAVITZKY, A.; GOLAY, M.J.E., Smoothing and differentiation of data by simplified least squares procedures, Anal. Chem., 36 (8), p. 1627 - 1638, 1964

- SIESLER, H. W.; OZAKI, Y.; KAWATA, S.; HEISE, H.M., Near-Infrared Spectroscopy. Principles, Instruments, Applications, Wiley-VCH, 2002

- TAFNER, MALCON ANDERSON, Revista "cérebro \& mente", 2(5), março/maio 1998

- TATIBANA C. Y. E KAETSU, D. Y. http://www.din.uem.br/ia/neurais, 2008

- The electromagnetic spectrum. http://www.Ibl.gov/MicroWorlds/ALSTool/EMSpec/EMSpec2.html, 2008

- WORKMAN, JERRY JR AND WEYER, LOIS; Practical guide to interpretive near-infrared spectroscopy; Taylor \& Francis Group, LLC; 2008

- XING, Z.; WANG, J.; YE, Y.; SHEN, G., Rapid quantification of kinematical viscosity in aviation kerosene by near-infrared spectroscopy., Energy \& Fuels, vol. 20, p. $2486-2488,2006$ 


\section{APÊNDICE A}

\section{Especificação do Querosene de Aviação}

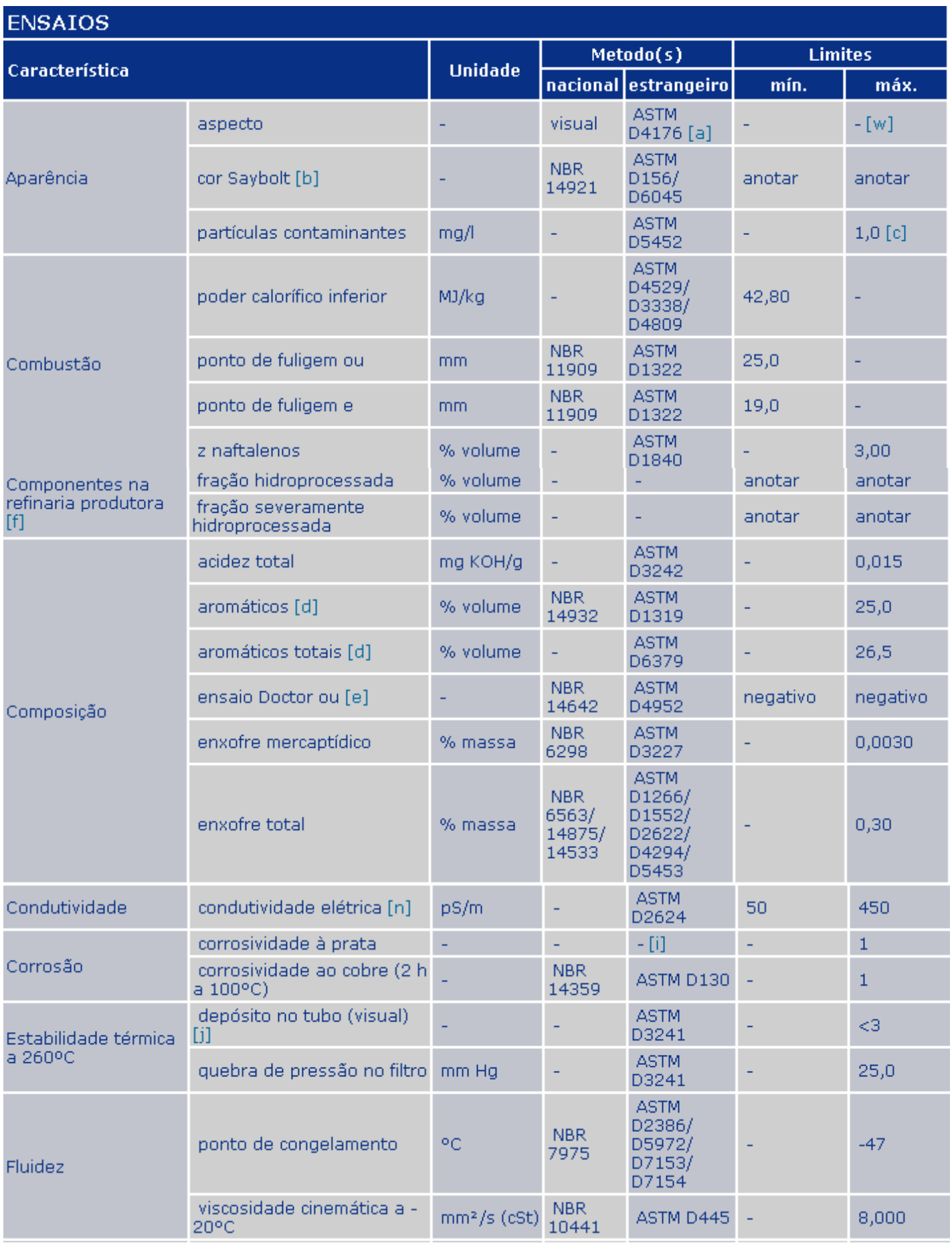




\begin{tabular}{|c|c|c|c|c|c|c|}
\hline \multicolumn{7}{|l|}{ ENSAIOS } \\
\hline \multirow{2}{*}{\multicolumn{2}{|c|}{ Característica }} & \multirow{3}{*}{$\begin{array}{c}\text { Unidade } \\
\mathrm{mg} / 100 \mathrm{~mL}\end{array}$} & \multicolumn{2}{|c|}{ Metodo(s) } & \multicolumn{2}{|c|}{ Limites } \\
\hline & & & \multirow{2}{*}{\begin{tabular}{|l} 
nacional \\
NBR \\
14525
\end{tabular}} & \multirow{2}{*}{\begin{tabular}{|l|} 
estrangeiro \\
ASTM D381
\end{tabular}} & \multirow{2}{*}{ mín. } & \multirow{2}{*}{$\begin{array}{l}\text { máx. } \\
7\end{array}$} \\
\hline Goma atual [k] & - & & & & & \\
\hline \multirow{2}{*}{$\begin{array}{l}\text { Indice de separaçãa } \\
\text { de água, MSEP [m] }\end{array}$} & $\begin{array}{l}\text { com dissipador de cargas } \\
\text { estáticas }\end{array}$ & - & - & $\begin{array}{l}\text { ASTM } \\
\text { D3948 }\end{array}$ & 70 & - \\
\hline & $\begin{array}{l}\text { sem dissipador de cargas } \\
\text { estáticas }\end{array}$ & - & - & $\begin{array}{l}\text { ASTM } \\
\text { D3948 }\end{array}$ & 85 & - \\
\hline Lubricidade [0] & lubricidade, BOCLE & $\mathrm{mm}$ & - & $\begin{array}{l}\text { ASTM } \\
\text { D5001 }\end{array}$ & - & 0,85 \\
\hline Tolerância à água [I] & Condições Interfaciais & - & $\begin{array}{l}\text { NBR- } \\
6577\end{array}$ & $\begin{array}{l}\text { ASTM } \\
\text { D1094 }\end{array}$ & - & $1 b$ \\
\hline \multirow{3}{*}{ Volatilidade } & $\begin{array}{l}\text { massa específica a } 20^{\circ} \mathrm{C} \\
\text { [h] }\end{array}$ & $\mathrm{kg} / \mathrm{m}^{3}$ & $\begin{array}{l}\text { NBR } \\
7148 / \\
14065\end{array}$ & $\begin{array}{l}\text { ASTM } \\
\text { D1298/ } \\
\text { D4052 }\end{array}$ & 771,3 & 836,6 \\
\hline & ponto de fulgor & ${ }^{\circ} \mathrm{C}$ & $\begin{array}{l}\text { NBR } \\
7974\end{array}$ & ASTM D56 & 40,0 ou & - \\
\hline & ponto de fulgor & ${ }^{\circ} \mathrm{C}$ & - & $\begin{array}{l}\text { ASTM } \\
\text { D3828 }\end{array}$ & 38,0 & - \\
\hline \multirow{7}{*}{$\begin{array}{l}\text { Volatilidade - } \\
\text { Destilação [g] }\end{array}$} & $10 \%$ vol. recuperado & ${ }^{\circ} \mathrm{C}$ & $\begin{array}{l}\text { NBR } \\
9619\end{array}$ & ASTM D86 & - & 205,0 \\
\hline & $50 \%$ vol. recuperado & ${ }^{\circ} \mathrm{C}$ & $\begin{array}{l}\text { NBR } \\
9619\end{array}$ & ASTM D86 & anotar & anotar \\
\hline & $90 \%$ vol. recuperado & ${ }^{\circ} \mathrm{C}$ & $\begin{array}{l}\text { NBR } \\
9619\end{array}$ & ASTM D86 & anotar & anotar \\
\hline & $\begin{array}{l}\text { P.F.E (ponto final de } \\
\text { ebulição) }\end{array}$ & ${ }^{\circ} \mathrm{C}$ & $\begin{array}{l}\text { NBR } \\
9619\end{array}$ & ASTM D86 & - & 300,0 \\
\hline & $\begin{array}{l}\text { P.I.E. (ponto inicial de } \\
\text { ebuliçãa) }\end{array}$ & ${ }^{\circ} \mathrm{C}$ & $\begin{array}{l}\text { NBR } \\
9619\end{array}$ & ASTM D86 & anotar & anotar \\
\hline & perda & $\%$ volume & $\begin{array}{l}\text { NBR } \\
9619 \\
\end{array}$ & ASTM D86 & - & 1,5 \\
\hline & resíduo & $\%$ volume & $\begin{array}{l}\text { NBR } \\
9619\end{array}$ & ASTM D86 & - & 1,5 \\
\hline \multirow{6}{*}{ z Aditivos [p] } & antioxidante [q] & $\mathrm{mg} / \mathrm{l}$ & - & - & 17,0 & 24,0 \\
\hline & desativador de metal $[r]$ & $\mathrm{mg} / \mathrm{l}$ & - & - & - & 5,7 \\
\hline & detetor de vazamentos [u] & $\mathrm{mg} / \mathrm{kg}$ & - & - & - & 1,0 \\
\hline & $\begin{array}{l}\text { dissipador de cargas } \\
\text { estáticas [s] }\end{array}$ & $\mathrm{mg} / \mathrm{l}$ & - & - & - & 5,0 \\
\hline & $\begin{array}{l}\text { inibidor de formação de } \\
\text { gelo [t] }\end{array}$ & $\%$ volume & - & - & 0,10 & 0,15 \\
\hline & $\begin{array}{l}\text { melhorador de lubricidade } \\
\text { [v] }\end{array}$ & - & - & - & - & - \\
\hline
\end{tabular}




\section{APÊNDICE B}

Repetibilidade e reprodutibilidade das análises do querosene para a faixa típica das amostras coletadas

\begin{tabular}{|lllrr|}
\hline proprie dade & método referência & unidade & repetibilidade & reprodutibilidade \\
\hline Densidade 20/4 ${ }^{\circ} \mathrm{C}$ & ASTM D 4052 & $\mathrm{Adm}$ & 0,0001 & 0,0005 \\
Destilação PIE & ASTM D 86 & ${ }^{\circ} \mathrm{C}$ & 3,5 & 8,5 \\
Destilação 10\% recup & ASTM D 86 & ${ }^{\circ} \mathrm{C}$ & 2,5 & 5,4 \\
Destilação 20\% recup & ASTM D 86 & ${ }^{\circ} \mathrm{C}$ & 2,1 & 5,3 \\
Destilação 50\% recup & ASTM D 86 & ${ }^{\circ} \mathrm{C}$ & 2,3 & 5,9 \\
Destilação 90\% recup & ASTM D 86 & ${ }^{\circ} \mathrm{C}$ & 2,6 & 5,4 \\
Destilação PFE & ASTM D 86 & ${ }^{\circ} \mathrm{C}$ & 3,5 & 10,5 \\
Viscosidade & ASTM D 445 & $\mathrm{CSt} \mathrm{a} \mathrm{-20C}$ & - & 0,08 \\
Viscosidade & ASTM D 445 & ${ }^{\mathrm{CSt} \mathrm{a} \mathrm{40C}}$ & - & 0,024 \\
Ponto de Cong elamento & ASTM D 2386 & ${ }^{\circ} \mathrm{C}$ & 0,8 & 2,3 \\
Ponto de Fulgor & ASTM D 56 & ${ }^{\circ} \mathrm{C}$ & 1,2 & 4,3 \\
Enxofre Total & ASTM D 4294 & $\mathrm{mg} / \mathrm{Kg}$ & 35 & 155 \\
& & & & \\
\hline
\end{tabular}

